The effects of an early intervention on outcomes in mothers, fathers and moderately and late preterm infants during the infants' first year of life -

\title{
A randomized controlled trial
}

Effects of the Mother-Infant Transaction Program on maternal depression, parenting stress, breastfeeding, mothers' perception of infant temperament, infants' communication skills and social interaction between mothers and preterm infants.

Ingrid Helen Ravn

Neonatal Intensive Care Unit, Woman \& Children’s Division,

Oslo University Hospital, Ullevål

Institute of Health and Society

Faculty of Medicine

University of Oslo

Norway

2011

UiO : Universitetet i Oslo

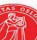


(C) Ingrid Helen Ravn, 2012

Series of dissertations submitted to the Faculty of Medicine, University of Oslo No. 1326

ISBN 978-82-8264-283-5

All rights reserved. No part of this publication may be reproduced or transmitted, in any form or by any means, without permission.

Cover: Inger Sandved Anfinsen.

Printed in Norway: AIT Oslo AS.

Produced in co-operation with Unipub.

The thesis is produced by Unipub merely in connection with the thesis defence. Kindly direct all inquiries regarding the thesis to the copyright holder or the unit which grants the doctorate. 


\section{Table of contents}

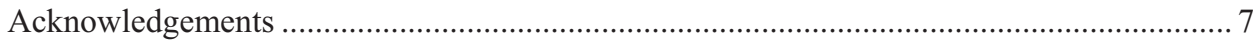

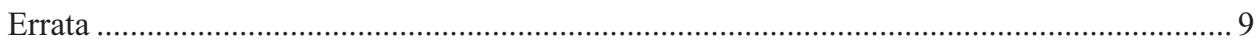

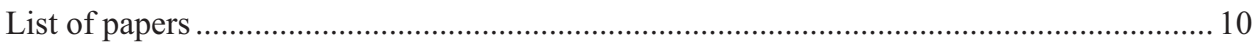

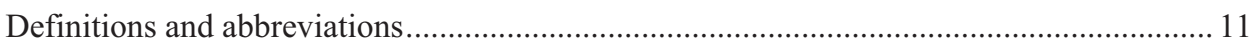

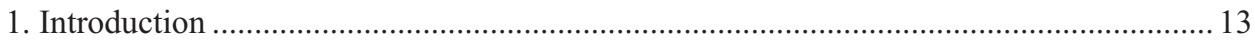

2. The rationale of the study ....................................................................................... 13

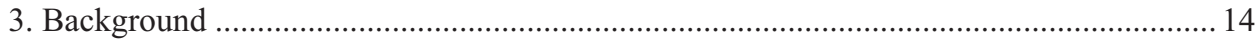

3. 1. Transactional model of social interaction............................................................... 14

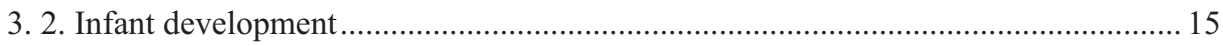

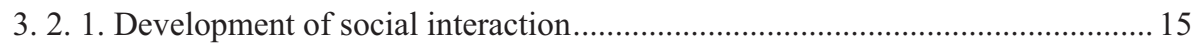

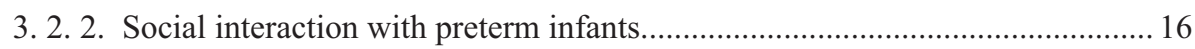

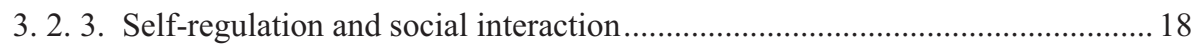

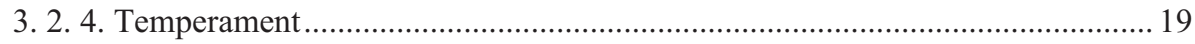

3. 2. 5. Moderate and late preterm infants ................................................................ 21

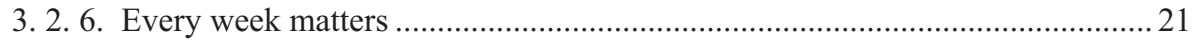

3. 2. 7. Developmental outcomes in moderate and late preterm infants ..................... 21

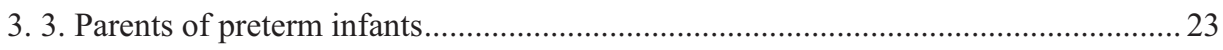

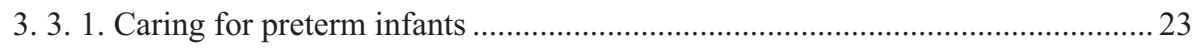

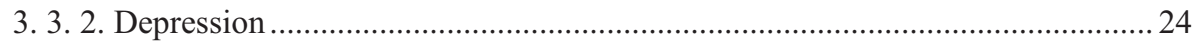

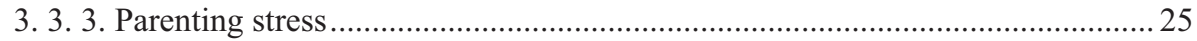

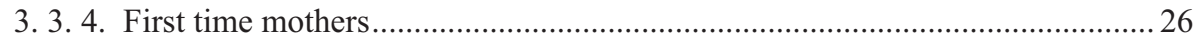

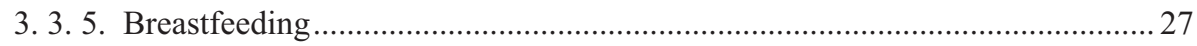

3. 4. The mother-infant transaction program......................................................... 28

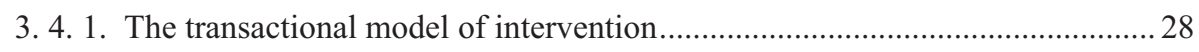

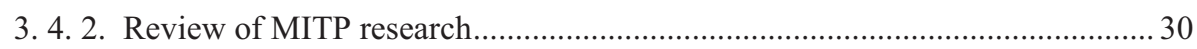

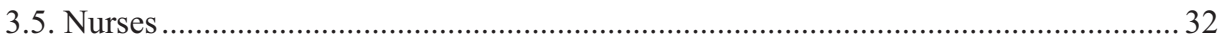

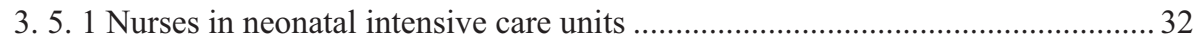

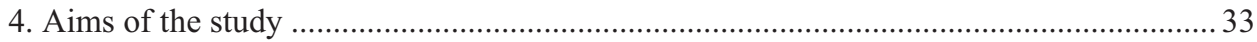

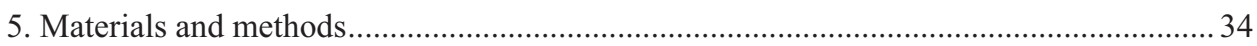

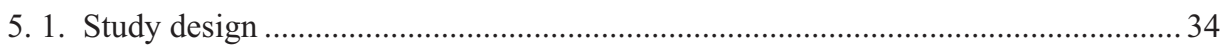

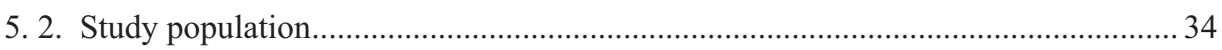

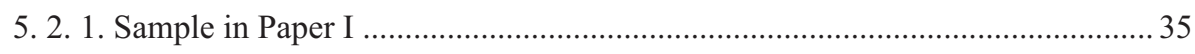

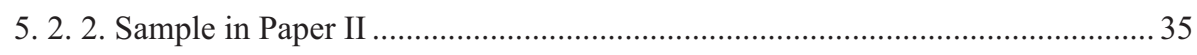




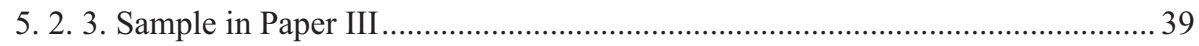

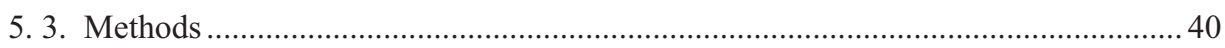

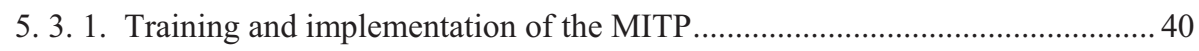

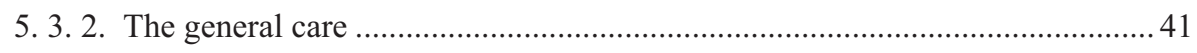

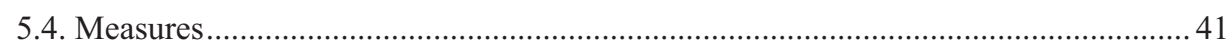

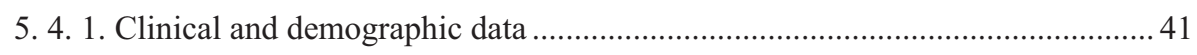

5. 4. 2. The Center for Epidemiological Studies Depression Scale................................ 41

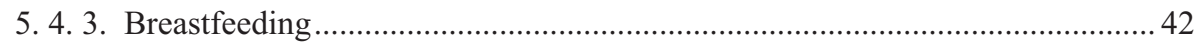

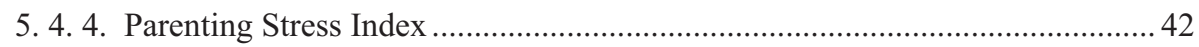

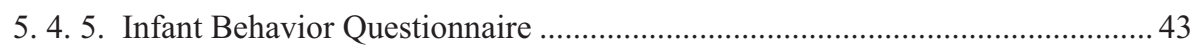

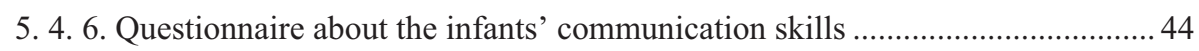

5. 4. 7. Video observation of mother-infant interactions at 12 months ........................ 44

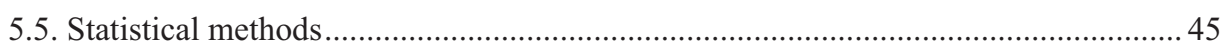

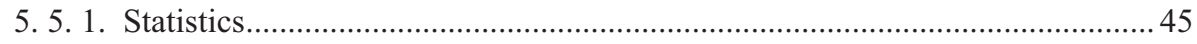

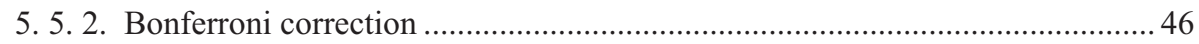

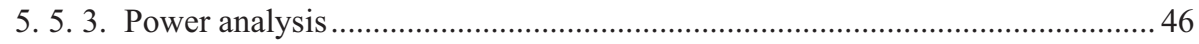

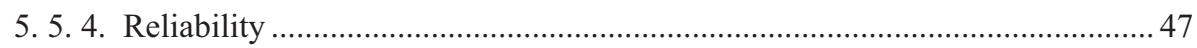

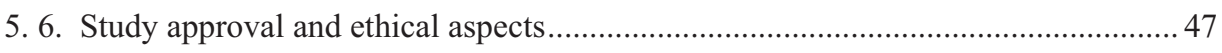

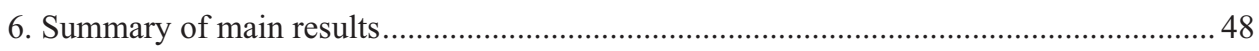

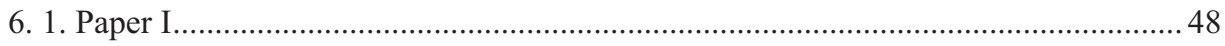

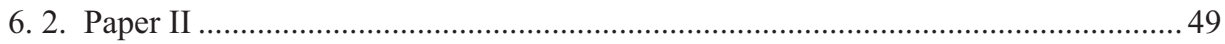

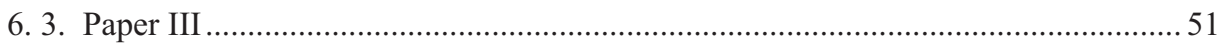

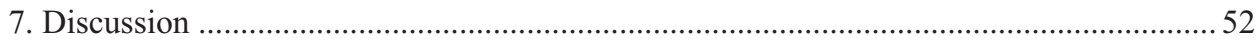

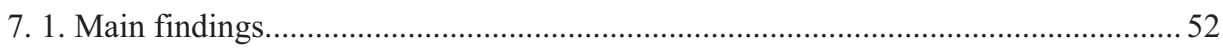

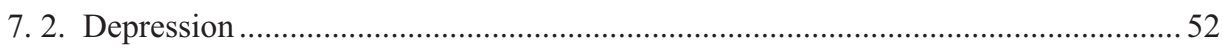

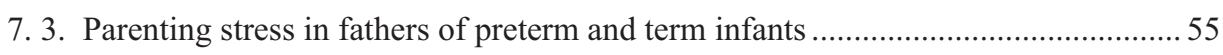

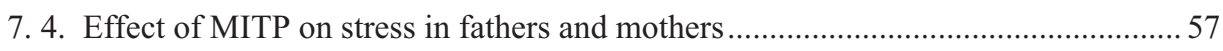

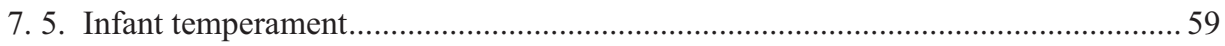

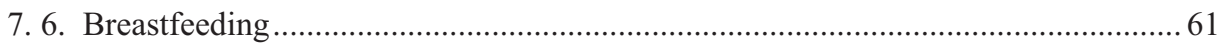

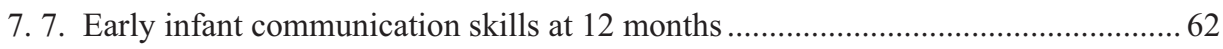

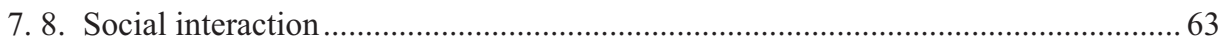

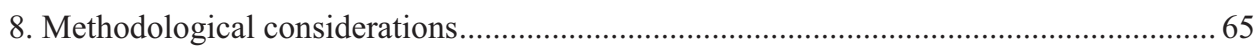

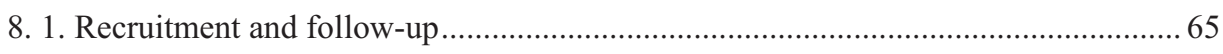

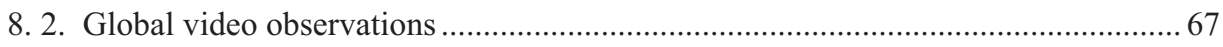




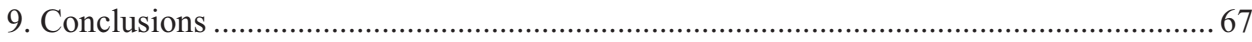

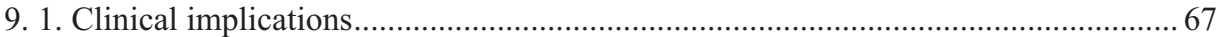

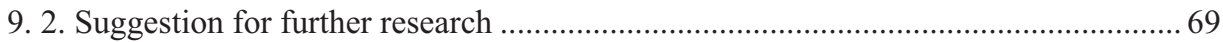

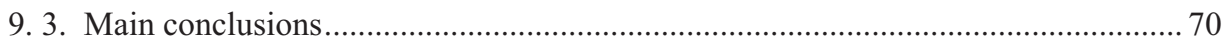

Papers

Appendix 


\section{Acknowledgements}

This research has been supported by grants from the South-Eastern Norway Regional Health Authority; The Royal Norwegian Ministry of Health; the Centre for Child and Adolescent Mental Health, East and Southern Norway; the Women \& Children's Division, Oslo University Hospital, Ullevål; the Department of Nursing Research, Oslo University Hospital, Ullevål and the Norwegian Nurses Association.

My interest and fascination for early infant development started during my psychology studies in the seventies, and was essential for deciding to work with newborn and preterm infants as a graduate nurse in 1982. The most obvious and interesting place to start working was on the Neonatal Intensive care Unit on Ullevål hospital. The present work has been carried out at the Neonatal Intensive Care Unit, Woman \& Children's Division, Oslo University Hospital, Ullevål.

Special thanks go to Pub.H. RN and resarch assistent Kari S. Halle for good advices and useful discussions at the start of prosject; and for recruiting families to the project. I also want to thank all the nurses delivering the intervention: Signe Bandlien, Cecilie Braaten, Lars Erik Engen, Lene Grønvold, Anne Marie Krokedal, Gunn Inger Hoffart Onstad, Tonje Rød, Vigdis Skaug, Elin Storvik and Inger Johanne Tølløfsrud, and all the infants, mothers and fathers making this study possible.

I would like to express my sincere gratitude to all my excellent supervisors. Thanks to my main supervisor Lars Smith, professor in psychology, for sharing your knowledge in infant development, constructive feedback and instructive discussions, and for guiding me through this dissertation. I want to thank my co-supervisor Rolf Lindemann, professor in Neonatology, for intellectual support and encouragement, and for sharing your expertise in neonatology, and for always having an "open door". A special thank to my co- supervisor Dr Nina Aarhus Smeby, for analytic skills, encouragement and for always being optimistic, and to my co-supervisor Eli Haugen Bunch, professor in nursing, for support and advice and engagement in the work.

And finally, a special thank to research assistant and $\mathrm{PhD}$ student Nina M. Kynø, for recruiting families to the project, for daily discussions and endless days with SPSS, word and Reference Manager, and lots of fun.

I also want to express my sincere gratitude to Dr. Glenys Hamilton for statistical supervision and encouragement and Dr. Margaret Tresch Owen for training and guidance with the NICHD-scales. A special thank goes to PhD students Monica Sarfi and Schale Azak for inspiring and enjoyable discussions and interesting videoobservations. 
A special thank to Leiv Sandvik, professor in biostatistics in the Section of Epidemiology and Biostatistics in Oslo University hospital, for valuable statistical advices and inspiring discussions.

I also owe special thanks to my wonderful research fellows Kirsti Tøien, Karen Bjøro, Inger Schou-Bredal, Irene Lie, Sidsel Børmark, Laila Skogstad, Stig Tore Bogstrand at former Departement of Nursing Research, whose daily professional and social support made everyday life a little better.

Last, but not least, I want to thank my dear husband Einar, who has continuously supported me, encouraged me and believed in me though this prosject; and my wonderful children Linn Karen, Sindre and Sophie. Thank you for your patience, I love you all. Finally, my thanks go to my mother Inger Johanne and my sister Siri, as well as my friends. I look forward to spend more time with all of you.

Ullevål, november 2011. 


\section{Errata}

Paper I. Page 3: The numbers and percentage of lost to follow-up was not correctly reported. The correct numbers for the intervention group are: 9 (17.3\%) and for the control group 6 $(12.0 \%)$.

Paper II. In the abstract: As reported in the flow diagram, baseline 82 fathers of infants with gestational age $\geq 30.0$ and $<36$ weeks, were randomized to a preterm intervention group $(\mathrm{n}=43)$ and a preterm control group $(\mathrm{n}=39)$, and forty-five fatheres were recruited to a term reference group. The number of fathers listed in the abstract refers to fathers participating at six months. Page 3: The percentage of lost for follow-up was not correctly reported. The correct percentage for the intervention group is 10 (25.6\%) and for the term reference group $5(11.4 \%$ ). Page 5: $\mathrm{N}=38$ (mean) for the Term reference group in Table 1 should be replaced with $\mathrm{n}=39$.

Paper III. Page 219: The text "Random assignment of Families (infants, mothers, fathers) $N$ $=118$ " on page 219 in Fig.1 (Flow diagram), should be replaced by the text "Random assignment of Families (infants, mothers) as $\mathrm{n}=118$ applies to mothers-infants, not fathers. 


\section{List of papers}

This dissertation builds on the following papers

PAPER I

Infant Behavior \& Development (Accepted for publication 27 september 2011)

Effects of early mother-infant intervention on outcomes in mothers and moderately and late preterm infants at age 1 year: a randomized controlled trial.

Ingrid H. Ravn, Lars Smith, Nina Aarhus Smeby, Nina Margrethe Kynø, Leiv Sandvik, Eli Haugen Bunch, Rolf Lindemann

\section{PAPER II}

Early Child Development and Care. 2011, 1-16, iFirst Article

Stress in fathers of moderately and late preterm infants: a randomised controlled trial Ingrid Helen Ravn, Rolf Lindemann, Nina Aarhus Smeby, Eli Haugen Bunch, Leiv Sandvik, Lars Smith

PAPER III

Infant Behavior \& Development 34 (2011) 215-225

Effect of early intervention on social interaction between mothers and preterm infants at 12 months of age: A randomized controlled trial

Ingrid Helen Ravn, Lars Smith, Rolf Lindemann, Nina Aarhus Smeby, Nina Margrethe Kynø, Eli Haugen Bunch, Leiv Sandvik 


\section{Definitions and abbreviations}

Apgar score

BW

CES-D

Corrected age

CPAP

GA

IBQ

IBR

$\mathrm{ICC}$

EPDS

Intersubjectivity

Joint attention
Apgar score is a measure of the physical condition of a newborn infant. It is obtained by adding points $(2,1$, or 0$)$ for heart rate, respiratory effort, muscle tone, response to stimulation, and skin coloration; a score of ten represents the best possible condition. Birthweight The Centre for Epidemiological Studies Depression Scale Age calculated from expected day of delivery Continuous positive airway pressure Gestational age Infant Behavior Questionnaire Initiating behavior regulation/request Intraclass correlations coefficient Edinburgh Postnatal Depression Scale A basic differentiation between the self and others Joint attention skills refer to the capacity to coordinate attention to objects and events with attention to another person during social interactions, and are considered to be critical for language and cognitive development

IBR Initiating behavior regulation/request

IJA Initiating joint attention

RJA Responding to joint attention

$\mathrm{KMC}$

Kangaroo mother care is early, prolonged and continuous skin-to-skin care between stable preterm infant and mother or father

Late preterm infant

LBW

Infant born between 34 0/7 and 36 6/7 weeks of pregnancy

LOS

Birthweight $<2500 \mathrm{~g}$

MDI

Length of stay

MITP

Mental developmental index scores

Mother-Infant Transaction Program

Moderate preterm

LS

MLPI

Infant born between 32 0/7 and 33 6/7

Life stress

NBAS

Infants in the present study born between 30 0/7 and 35 6/7

NICU
Brazelton Neonatal Behavioral Assessment Scale

Neontal intensive care unit 
NICHD

NIDCAP

PPD

PBIP

PICS

PSI

$\mathrm{PSI} / \mathrm{SF}$

$\mathrm{RCT}$

$\mathrm{RN}$

SES

Self-regulation

SGA

Sensitivity

Stress

Turn-taking
Temperament

National Institute of Child Health and Human Development in US. Newborn Individualized Developmental Care and Assessment Program

Based on DSM -IV-TR and ICD-10 criteria, postpartum depression or mental and behavioral disorders associated with the puerperium, refers to the intense, sustained and sometimes disabling depression experienced by woman after giving birth. The DSM-IV mandates that, in order to qualify as postpartum depression, onset occur within one month of delivery. It has been said that postpartum depression can last as long as three months

The Parent Baby Interaction Programme

The Pictoral Infant Communication Scales

Parenting Stress Index (long version)

Parenting Stress Index (short version)

Randomized controlled trials

Registered nurse

Socioeconomic status

Regulation is at the core of all physiological and behavioral systems. Self-regulation develops gradually over time within the relationship with primary caregivers

Small for gestational age

The parent's ability to perceive and interpret the child's signals and intentions and to respond quickly and appropriately

Three main domains of stressors are associated with dysfunctional parenting: Child characteristics, parent characteristics, and situational or demographic life stress

Individual differences in emotional, motor, and attentional reactivity measured by latency, intensy, and recovery response, and selfregulation processes susch as effortful control that modulate reactivity The understanding that during a communicative exchange each participant takes turns to communicate in an alternating fashion

Very preterm infant Gestational age $<32$ weeks

VLBW 


\section{Introduction}

This dissertation assesses the effect of the Mother-Infant Transaction program (MITP) $(1 ; 2)$ on outcomes in parents as well as in moderate and late preterm infants (MLPI) during the infants' first year of life. The MITP is influenced by transactional approaches/stages of infant organization (3), and it was hypothesized that the MITP would have a positive effect on social interaction between mothers and infants at 12 months. It was also hypothesized that the MITP would have a positive effect on mothers' perception of infant temperament and preterm infant communication skills; and on breastfeeding, self-reported depression in mothers and self-reported stress in parents.

\section{The rationale of the study}

Early social interaction refers to the infants' patterns of interactions with others. It depends on the characteristics of the infants and the parents' sensitivity to the infants' signals (4). According to the transactional model, infant development takes place in the context of interacting with caregivers and in the social context in which the infant is reared (5). Early social interaction is thought to have significant consequences for the infants' development and for the parents' mental health and wellbeing. Maternal sensitivity to infant cues and the quality of early social interactions are important for the acquisition of language (6-8) and the development of attachment (9). Furthermore, social interaction in early years seems to influence cognitive, social and emotional competences, and may be related to later child development (10-12). The mothers' ability to be sensitive to infant cues is essential for interaction quality, however depressed parents $(13 ; 14)$ and mothers with high stress $(15 ; 16)$ are reported to be less sensitive during interactions with their preterm infants.

Newborn infants communicate with their caregivers through social signals and vocalization, but social interaction with preterm infants is challenging because they are less attentive and responsive compared with term infants, and often evince atypical behavior making it more difficult for parents to read their cues and respond appropriately $(17 ; 18)$. Social interaction also depends on the infants' developmental advances and is related to maturation and development of the infants' central nervous system (19). Since a substantial part of brain maturation takes place during the last trimester of the pregnancy, preterm infants are usually less neurologically mature and evidence less organization in their behaviors as compared with full-term infants (20). This may contribute to communication problems (17), and make social interaction between preterm infants and parents more difficult. 
The incidence of preterm births in Norway is about 6-7\% (21) as compared with about 10\% in the Unites States (22;23). Infants with gestational age (GA) between 30-36 weeks account for about $50 \%$ of all preterm deliveries in Norway (24). The prevalence of moderate and late preterm infants (MLPI) accounts for more than 70\% of preterm birth in the US (25), and is associated with considerable treatment cost (26).

There is mounting evidence that MLPI are at greater risk for morbidity, poorer neurodevelopmental outcomes and increased rates of aberrant psychological development as compared with term infants (27-34). MLPI experience significant morbidity, still these infants have been studied less than very low birth weight infants (VLBW) (35). There is a dearth of contemporary studies with data on the effects of early interaction-based interventions on MLPI's development and parenting during the infants' first year of life. In general, research, resources and focus of attention by nurses and physicians in neonatal intensive care units (NICU) have mainly been on somatic issues in low birth weight infants (LBWI) as they are played out in the NICU emergency rooms at "the start" (36). This dissertation focuses on psychological issues in MLPI and their parents at discharge from the NICU, at "the end", and on follow-up during the infants' first year of life. Parent-child interactions are increasingly recognized as an important focus of early intervention programs (18), and the main objective of the present one-year longitudinal randomized controlled trial (RCT) was to assess the possible effect of an intervention program on outcomes in MLPI and their parents during the infants' first year of life. This research may contribute to more knowledge and better follow-up of MLPI and their parents after the neonatal period.

\section{Background}

\section{1. Transactional model of social interaction}

The conceptual framework for this study is the transactional model of development. This model suggests that the relationship between infants and parents may be conceived as a bidirectional and dynamically interacting system $(5 ; 37 ; 38)$. One of the important aspects of the transactional model is the emphasis placed on the effect of the child on the environment, not only the effect of the family/parents on the child. This means that the infant influences the care he receives from his caregivers by the ways he behaves $(3 ; 39)$. However, this care 
is also influenced by the parents' skills in being sensitive and by their ability to respond in an appropriate and timely way to the infant's cues, needs, moods and interest in the context of daily interactions (18). The transactional model is posited on the assumption that early development is an outcome of the ongoing interplay of conditions of the infants and conditions of the parents/environment (Figure 1) (40). This way of looking at infant development was the background for choosing The Mother Infant Transaction Program as a method for early intervention during neonatal hospitalization $(1 ; 2 ; 41)$.

Figure 1 Transactional process by A. J. Sameroff (40) ${ }^{1}$

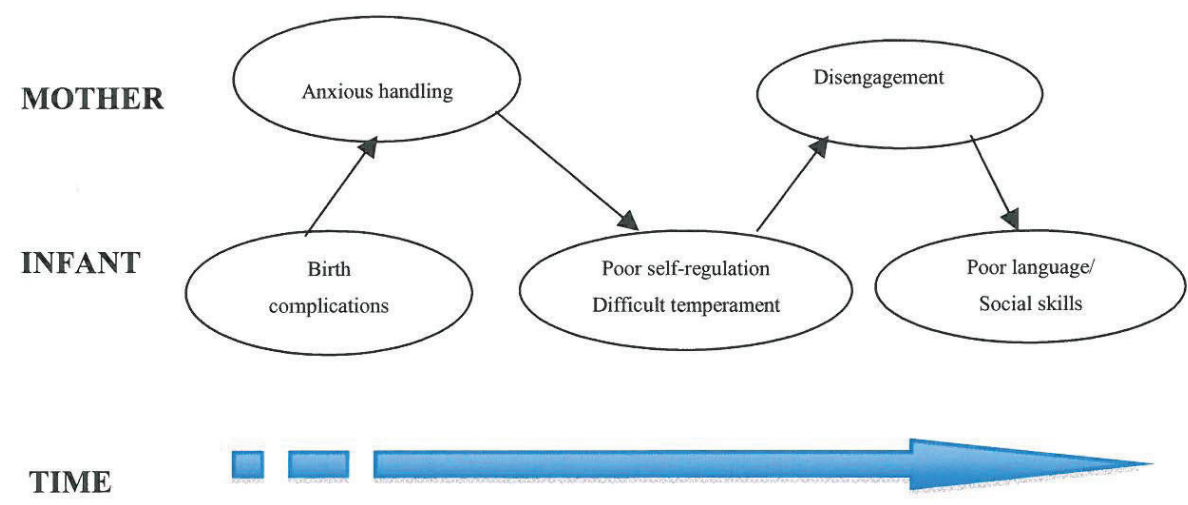

\section{2. Infant development}

\section{2. 1. Development of social interaction}

Early social interaction seems to have four important functions: To promote social understanding, to bolster the development of attachment, to provide a context for the acquisition of language and to facilitate emotional regulation (42).

Rochat describes three developmental periods during the infants' first year of life; the newborn phase, the two-month revolution and the nine-month revolution (43). In the earliest

\footnotetext{
${ }^{1}$ Printed with permission of A. J. Sameroff
} 
weeks of life, infants' interactions with others are mainly concerned with regulation of basic biological processes, such as feeding and waking-sleeping states (4). From birth and during the first 6 weeks (the newborn phase) the infants seem to have "an essentially innate sensitivity to social stimuli", and their stance towards people seems to be attentional "with no signs of intersubjectivity" (43). At about two months of age there is changes in the way infants interact with caregivers; at this time they display the first signs of shared experience with caregivers (primary intersubjectivity) (43). A complex communication system is slowly developing in which parents and infants respond in an appropriate way to the others' cues (44). The infants gradually become more aware of and interested in their external environment, and regulate their mutual attention and responsiveness in face-to-face situations with caregivers (4). Infants gradually switch their main preoccupation from faces to objects, and eventually, in contact with others, they demonstrate a more active participation in the interaction process (turn-taking). At 8 months infants are increasingly initiating attention to others (4). The second transition occurs around 9 months, when infants become observant about intentionality in others, an ability that helps them to cross the threshold to symbolic communication (43). By the end of the first year, infants become increasingly skilled in joint attention (45), which refers to the ability to coordinate visual attention in relation to objects in the environment (46), and the capacity of coordinating attention to a social partner and an object of mutual interest $(47 ; 48)$. Joint attention is regarded to be an important developmental milestone (49). By means of this type of attention skill infants develop new strategies for learning about the environment (50). Responding to and initiating joint attention are associated with later language development and better intellectual functioning at pre-school age and at 8 years $(47 ; 48)$.

\section{2. 2. Social interaction with preterm infants}

Prematurity seems to have an impact on the dyadic quality of mother-infant interaction $(51 ; 52)$. The behavioral cues and responses of preterm infants tend to be small and weak, they are often less attentive and responsive compared with term infants in mother-infant interactions $(53 ; 54)$, and their behavior is reported to be disorganized and unpredictable with an enhanced risk for poor behavioral regulation $(55 ; 56)$. Preterm infants' attentiveness and positive affect seem to be easily disturbed in early interactions, thus making reciprocal and harmonious interactions between infants and caregivers difficult $(57 ; 58)$. 
Preterm infants' threshold to stimulation, and their ability to modulate arousal and process information during social interaction are reported to be different from term born infants (17). In the "Optimal Activation band model" (Figure 2) Field suggests that optimal stimulation to produce attentiveness and positive affect has a narrower range for high-risk preterm infants, since the lower threshold for attentive or orienting responses may be higher and the upper threshold for aversive/defensive reactions may be lower $(17 ; 59)$. When the thresholds are exceeded because of too low or too high stimulation, preterm infants tend to be less attentive and show more gaze averting and fewer positive affective responses such as smiling and laughing in early face-to-face interactions compared with term infants $(57 ; 58)$.

Figure 2 Field's (1981) proposed "optimal activation band"(17) 2

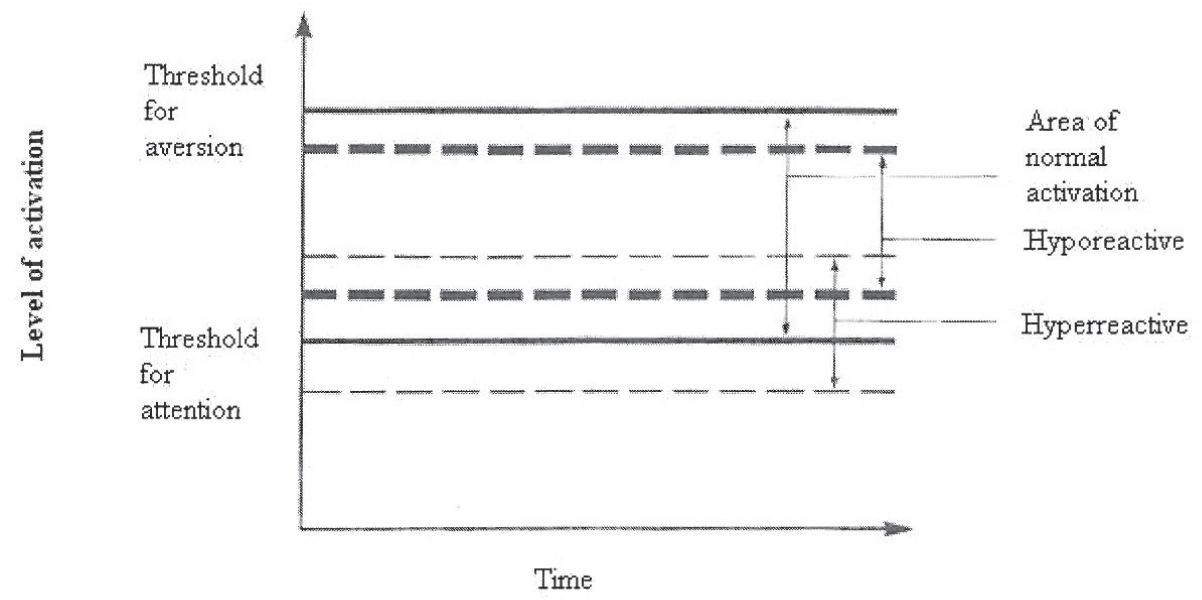

Early social interaction between preterm infants and their parents depends on the characteristics and behavior of both infants and caregivers, and differs from that of full-term infants in different ways (4). Social interaction starts at an earlier age in their development when the infants are generally more immature and vulnerable and the medical conditions are different (60). The interaction takes place under the physical constraints of the NICU environment, often in the context of parental affects with shock, stress, grief and depression combined with guilt for the preterm birth and anxiety about infant's survival (55), and the

\footnotetext{
${ }^{2}$ Printed with permission of T. Field
} 
parents have to relate to many health care providers of different professional background. These conditions may affect the infants' ability to adapt to the social experiences and respond to social stimuli, and affect the parents' capacity to be sensitive and responsive to the infants' cues (55).

Several studies report differences in social interaction skills between preterm and term infant during the first 12 months of life. Between 3 and 4 months preterm infants have been reported to be significantly less responsive than term infants when interacting with their mothers (61). Preterm infants tend to show more negative affect and withdrawn behavior during interactions (62), and vocalize less in response to their mothers utterances (63). At 6 months preterm infants are reported to be less active and relate more poorly with their mothers as compared to the fullterm dyads (64). Coordinating attention with another person depends upon the caregiver's sensitivity and responses to the infant's social gestures, expressions, and signals, and preterm infants seem to have more difficulties in initiating and responding to joint attention interactions. They also differ from full-term infants in having deficits in exploratory and communicative responses (65), and seem to have an elevated risk for delayed preverbal and verbal development. They make less positive responses during still-face procedures and followed gaze less at 9 months (66). Mothers of preterms seem to differ in their timing of child-directed speech (63). MLPI are also reported to show significantly more disorganized behavior than term infants, and are probably more demanding social partners than term infants (67). Still we know little about social interaction between MLPI and their mothers.

\section{2. 3. Self-regulation and social interaction}

One of the first requirements of early infant development is the acquisition of capacities to self-regulate behavior. Early self-regulation includes physiological regulation, selfregulation means controlling emotions, ability to sustain attention and gradually to gain control of patterns of satisfying social interactions with parents and peers (5). Newborn preterm infants with GA $<34$ weeks have little capacity to regulate the experiences of events in their environment and seem to have deficits in early self-regulation (68). Different models all suggest that self-regulation develops in the context of parent-infant interactions (69). Optimal social interaction depends on caregivers who are able to read and understand the infants' signals and give contingent responses, and parents seem to be important coregulators. The infants' capacity for self-regulation of emotions, attention and behavior 
increases, whereas other-regulation decreases over time and age through reciprocal transactions. These processes rely on consistent social interaction and caregivers responses (Figure 3).

Figure 3 Sameroff's Transactional Regulation Model $^{3}$

\section{Transactional Regulation Model}

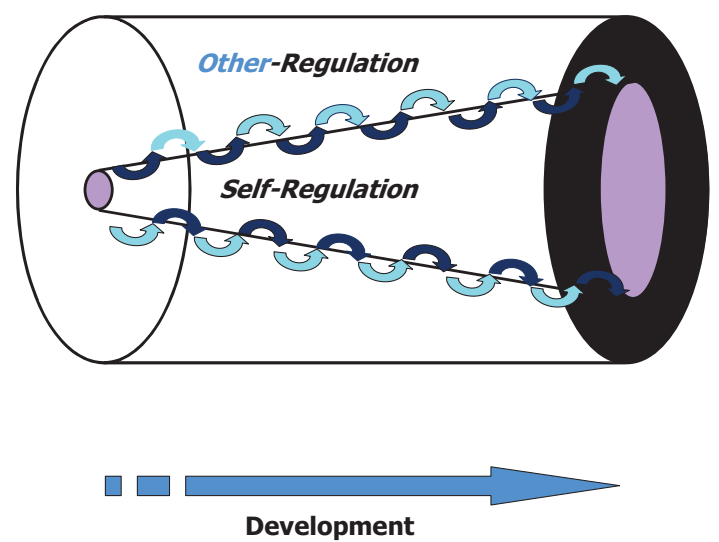

\section{2. 4. Temperament}

The infant's temperament is considered to have a separate contribution to the emergence and development of self-regulation $(69 ; 70)$, and temperament seems to be implicated in adaptive behavior (71). Belsky's susceptibility hypothesis suggests that infants vary in their plasticity and susceptibility to adverse and beneficial effects of environmental influences (72-74); infants with difficult temperament seem to be more susceptible to rearing influences than infants with easy temperament (75).

The individuality of an infant is expressed in temperament and behavioral style, and parents are important co-regulators of early self-regulation and development of infant temperament (5). Mothers' intrusiveness and infants' poor interactive behavior in early mother-infant interaction, as well as parental distress, significantly increase the infants' risk of being perceived as difficult (76). At 4 months the temperament of preterm infants with GA $\leq 30$

\footnotetext{
${ }^{3}$ Printed with permission of A.J. Sameroff
} 
weeks was reported to be similar to that of term infants, and in both groups infant temperament served as an independent risk factors for high levels of parenting stress (77). Infant temperament and maternal sensitivity may interact and impact the dyadic system, and influence the mothers' perception of infant temperament. Mothers of preterm infants with GA 24-32 weeks rated their infants' behavior at 6 weeks as significantly less rhythmic, more distractible, less approaching, and less intense when compared with standardized norms for full-term infant (78). Hughes et al. reported that infant temperament became more typical over time, but still remained lower in persistence at 12 months (78). Similarly, mothers at 4 months rated their infants with $\mathrm{GA} \leq 34$ weeks as having more difficult temperament than term infants (more negative mood, less adaptable, more difficult overall) (79). In another study, after controlling for infant age, late-preterm status predicted higher ratings of infant negativity by mothers (80). These differences were not revealed by global observers or by microanalytic coding. These mothers also reported more elevated and chronic co-morbid symptoms of depression and anxiety (80). Other researchers report no differences in temperament between preterm with GA $<36$ weeks and term infants aged 4 to 8 months (81) or in infants with BW $<1701$ gram at 12 months (82). Larroque et al. (83) suggested that prematurity (GA $<29$ weeks) did not affect mothers' temperament ratings at 9 months, however, very preterm infants with neurological insults were rated higher by their mothers on some of the temperament scales (the Dull, Unadaptable, and Unpredictable scales). The research findings are conflincting, and little is known about temperament in MLPI.

Although temperament theories presume a biological basis and genetic influences on individual differences in early self-regulation and other temperamental qualities $(84 ; 85)$, temperament is also assumed to be influenced by the quality of the infants' experiences (84) and related to maternal sensitivity (86). Difficult infant temperament may contribute to strained interactions between mothers and infants (5), but Jaffee et al. demonstrated that sensitive and stimulating parenting practices modify difficult temperament and may lead to better development of vulnerable infants (87). One of the aims of the MITP was to help mothers to be more sensitive and responsive to infants cues and to enable them to appreciate the infants' temperament and thereby rate their infants as temperamentally easier (2). In an earlier study, mothers who had received the MITP reported a more favorable perception of infant temperament than mothers in the control group (41). However, earlier research has not asked if the MITP had any positive effects on maternal temperament ratings of moderate and late preterm infants. 


\section{2. 5. Moderate and late preterm infants}

Moderately preterm infants commonly refer to infants born between 32.0 and 33.6 weeks of pregnancy, and late preterm births include infants born between 34.0 and 36.6 weeks (88). These infants account for a large proportion of all preterm births $(24 ; 28)$, and are typically healthier than very preterm infants. Though, being born even a few weeks too early is pathological and not healthy for the infants (36). In this dissertation we initially wanted to include preterm infants with GA from 28.0-35.6 weeks. Due to another ongoing study the inclusion criteria were adjusted to 30.0-35.6 weeks. It was decided to use the term "moderately and late preterm infants" (MLPI) for this sample, although $25 \%$ of the present sample were very preterm infants between 30.0 and 31.6 weeks.

\section{2. 6. Every week matters}

The last trimester of pregnancy is a period of rapid growth, development and maturation (89), and this is a critical period for the organization of the cortex and maturation of the central nervous system. More than one-third of the infant's brain size increase takes place during the last 6-8 weeks of gestation, and by 34 weeks the brain volume is approximately $65 \%$ of the term brain (20). A five-fold increase in white matter volume occurs between 35 and 41 weeks of gestation (20) with a significant development of gray matter and cerebellum (90), structural maturation and increasing synaptic junctions (20). Infants undergo a critical period of brain growth during the last trimester. Consequently the brain of MLPI at birth is immature and vulnerable for adverse conditions. These facts emphasize the need for research on short-term and longer-term developmental outcomes in this group of preterm infants. Furthermore infants who are endowed with normal brains may also encounter a variety of negative experiences in their caregiving environment that exert a deleterious effect on neurobiological structure, function, and organization, which may contribute to distortions in the way in these children interpret and react to the world (91).

\section{2. 7. Developmental outcomes in moderate and late preterm infants}

Preterm births are associated with a variety of social and cognitive delays and risk factors for adverse medical, psychosocial and behavioral outcomes $(92 ; 93)$, but less attention has been given to behavioral outcomes and development in MLPI by health providers. The number of hospital admissions is increasing with degree of preterm birth (94-96), but due to 
their high numbers MLPI infants occupy a large proportion of all beds in neonatal units (97). The number of hospital readmission is more likely to be high in late preterm infants, both in the immediate postnatnal period and later in infancy $(94 ; 98 ; 99)$, with a higher rate of readmission (especially among males) in the three first months after discharge compared with term infants (35). Being first-time mothers and infants with $\mathrm{GA}<37$ weeks are reported to be risk factors for readmissions for jaundice, dehydration and feeding difficulties (99). Moderately preterm infants experience significant morbidity during their hospital stay after birth, morbidity increases with decreasing GA (100) and is reported to be higher than in term infants $(34 ; 35 ; 58 ; 98 ; 101-107)$. Twin pregnancies born moderately and late preterm are also susceptible to higher rates of neonatal morbidity compared with twins born at term (88).

Late preterm infants of adolescent mothers were reported to have more immature neurobehavioral performance at 24-72 hours of life compared to term neonates (108), and increased risk of adverse neurological development with mental or physical development delay (109). The risk of medical and social disabilities in adulthood (30), and the increase in psychiatric hospital admissions seem to increase with decreasing gestational age at birth $(96 ; 110)$. Thus moderately preterm birth seems to carry a considerable risk for long-term impairment.

About one third of infants born at GA 32 -35 weeks may have school problems at age 7 (111). Compared with healthy term infants late preterm infants seem to face a greater risk for developmental delays and school-related problems up through the first 7 years of life $(25 ; 31)$. Late pretrem births is associated with subtle deficits in cognitive functioning (33), and infants born at GA 32-36 weeks seem to have an increased risk for poor school outcome (112). Romeo et al. however, reported that late preterm infant at 12 and 18 months had similar mental developmental index scores (MDI) as those obtained by term-born infants (113).

The balance between normalizing the behavior and development in "low-risk preterm infants" and the risk for ignoring problems in follow-up is difficult, but recent research indicates that there is a risk associated with the birth of MLPI (36). Both short-and longterm outcomes indicate that the gestational week matter for later developmental outcomes. MLPI infants seem to be more vulnerable than term infants in their development $(25 ; 114)$, and outcomes are associated with a variety of social and cognitive delays and risk factors for adverse medical, psychosocial and behavioral outcomes (92;93). However, MLPI seem to have been largely ignored in follow-ups by health providers (106), and this emphasizes the 
need for more research on developmental outcomes in this group of preterm infants and their parents during the first year of life.

\section{3. Parents of preterm infants}

\section{3. 1. Caring for preterm infants}

Maternal sensitivity refers to responding promptly, consistently and appropriately to the infants cues in daily social interactions $(115 ; 116)$. A sensitive interaction is child-centered, and sensitive parents are tuned to the infants' cues, needs, moods and capabilities, and provide stimulation that is appropriate to the situation and the characteristics of the individual infant (65). Sensitivity training for parents in the NICU is associated with improved cerebral white matter development in preterm infants (117). Increased maternal responsiveness may facilitate greater growth in the area of social, emotional, communication and cognitive competence across 6-13 months of age in VLBW preterm infants (118). Greater parent-child synchrony is associated with greater social-emotional competence and early neurobehavioral development in very preterm infants (119). Early mother-infant interactions have an impact on developmental outcomes in preterm infants, however infants' characteristics also affect parental sensitivity and care. Preterm infants' atypical and less organized behavior, which entails limited cues to others about their needs and focus of attention, makes it difficult for parents to read their cues and respond appropriately (18) and this may also elicit anxiety in parents (3).

Two specific patterns of interaction, either a protective (cooperative pattern) or a risk precipitating (controlling pattern) were discovered among mother-preterm infant dyads (11). The controlling pattern was more prevalent among preterm than term dyads, and was related to less favorable infant outcome. It may be difficult for mothers to adjust their stimulation to the infants' cues and time their actions to their needs when interacting with preterm infants with disorganized and unpredictable behavior. Mothers might hence be intrusive and controlling and impose their own agenda on the infant, not allowing the baby to influence the pace of interaction $(52 ; 120 ; 121)$. Difficult infant temperament may contribute to strained interactions between mothers and infants $(5 ; 122)$. The mother's reduced ability to recognize, read and interpret behavioral cues of a less organized preterm infant makes it diffucult for her to understand the meaning of the infants' behavior, and preview what the infant is developmentally ready for. This makes sensitive and responsive caregiving difficult when parents are discharged from the hospital with a preterm infant. Early parent-infant 
interactions seem to be predictive of later infant development, which underscore the clinical importance of health providers promoting and supporting a healthy parent-infant relationship in the NICU before discharge from the hospital.

\section{3. 2. Depression}

Parents in general report the highest risk for depression in the first year after birth of their child (123), and depression in mothers and fathers has been found to be moderately correlated (124). A population based longitudinal cohort-study reported a substantial continuity in maternal anxiety/depression from pregnancy to 18 months after birth, which suggests that the incidence of depression in mothers is constant (125). Thus maternal anxiety/depression represents a risk for infants' development that extends across the preand postnatal period (125). In two meta-analyses Beck et al. concluded that postpartum depression had a moderate to large effect on maternal-infant interaction; it was considered a risk factor for social interaction between parents and infants (126) and a risk factor for infant development (127). Depressed mothers have been reported to be less emotionally available to their infants (128), and the effects of maternal depression are propably more evident when the infants are young and more dependent on nurturing and sensitive caregivers. Several caregiving activities seem to be compromised by postpartum depression, including breastfeeding and sleep routines (14). Videotapes of social interaction between depressed mothers and their infants suggest that depressed mothers spend less time looking, touching and talking with their infants, and their infants show lower activity and vocalization, more negative faces and tend to look away more frequently (128). Depressed mothers are reported to be less sensitive, with less contingent responses during interactions with their infants. They may show more intrusive and controlling behavior with an overstimulating style, or alternatively withdrawn with flat affect and a passive and understimulation style $(13 ; 14)$. Higher maternal depressive symptoms seem to be associated with lower levels of maternal sensitivity and a decrease in sensitivity from 6-36 months (129).

Mothers of preterm infants are more likely to have a higher risk for depression than mothers of term infants throughout the first postpartum period (130;131), also after controlling for depression in pregnancy (132). Maternal depression is reported to be a risk factor in the development of mother-infant relationship in preterm infants with $\mathrm{GA}<32$ weeks og $\mathrm{BW}<$ 1500 gram (133). Depressive symtoms in mothers of preterm infants have been reported to 
decline during the first year of life (134;135), but at the end of the infants' first year of age, $20 \%$ of the mothers still had clinical symtoms of anxiety and depression, and $25 \%$ of the infants displayed cognitive problems and $40 \%$ motor problems (135).

Giving birth and becoming mothers and fathers of a preterm infant produces changes in the parents' life. It has an impact on parents' psychosocial wellbeing and how parenting is done with consequences for the developing infant (136;137). Most important, maternal depression seems to make mothers less sensitive and responsive to infant cues.

\section{3. 3. Parenting stress}

The birth of a preterm infant can be intensely stressful. Its subsequent hospitalization in the NICU and being parents during the infants' first year of life is associated with long term stress on families (138), and is a source of considerable stress for both mothers and fathers (137;139-145). Two months after discharge from the NICU parents of preterm infants still show higher levels of parental stress and lower perception of parental competence than did parents of term infants (145). Compared to mothers of term infants, mothers of VLBW infants had significant higher incidence of psychological distress during the neonatal period; at 3 years, however, the stress among mothers did not differ (140). Other researchers failed to find significant differences in parenting stress reported by mothers of VLBWI and term infants in the second half of the first year of life (146). Null differences have also been reported between parents of very preterm infants and less preterm infants at infant age 18 months, and between parents of very preterm and term children at 2 years (147). However high stress in parents may also reflect realistic concerns about their infants' development (148).

Some research suggest that stress experienced by mothers of preterm infants following hospital discharge is largely attributable to the particular characteristics of infants with low GA, such as the infants' biological risk status, age or developemental outcome $(139 ; 140 ; 149 ; 150)$. Parenting stress may also be related to behavioral characteristics of their infants and their own child-rearing attitudes (146). Other studies found no relation between medical risk in infant and maternal distress (151;152). However, Robson et al. (153) reported that the developmental status of VLBW infants and the quality of the infant-parent relationship contributed to parenting stress beyond the effects of neonatal medical risk. A cross-sectional questionnaire study reported that difficult temperament in term infants related directly to more parenting stress (154). Moreover, stress in mothers of term infants 
increased the infants' risk of being perceived as having a difficult temperament (76).

Parenting stress and difficult infant temperament seem to be associated, and parental stress related to preterm and term infants' distractibility during infancy is reported to predict childhood behavior problems at age 7 years (155). This suggests that parental stress in critical phases of infancy carry long-term consequences for later infant developement. Preterm infants, who initially have little capacity to self-regulate the experiences in their environment (68), depend upon their caregivers who are able to read and understand the infants' signals and give contingent responses. However, preterm infants may be challenging social partners $(57 ; 58)$ and may trigger stress in mothers; and mothers with greater stress are reported to be less sensitive to their infants' signals (15;16). At 6 months, mothers with high posttraumatic stress symptoms were more likely to follow a controlling pattern of dyadic interaction, when interacting with their preterm infants with $\mathrm{GA}<34$ weeks (52). Muller-Nix et al. reported that highly stressed mothers of preterm infants with GA under 34 weeks were less sensitive and more controlling than full-term mothers in a dyadic play (121). The quality of the infant-parent relationship may contribute to parenting stress (153), and the impact of parental stress on the quality of social interactions between infants and parents in infancy may lead to negative parent-infant transactions. This is therefore an important area for early intervention.

\section{3. 4. First time mothers}

Nullparity is associated with a significant increased risk for LBW/SGA birth (156), which indicates that a significant proportion of mothers of preterm infants are first-time mothers. Adjusting to the birth of a first child is reported to be different and more difficult than the adjustment taking place for multiparous mother (157). First-time mothers report lack of preparedness to care for their infant, with all the demands of learning new skills related to infant care. Mothers also seem to struggle to adapt to new role expectations (158). Being both a first-time mother and the mother of a preterm infant can be a major challenge in the infants' first year. Mothers of preterm infants seem to experience more stress and lower parental competence than mothers of fullterm infants (145), and they are more often facing infants with difficult temperament (78) and disorganized behavior (67). Stolk et al. (159) suggested that parity is a moderator of intervention effectiveness and reported a more positive impact of intervention on parenting in mothers of first-born children as compared with multiparas. First-time mothers probably have less competence and ability to recognize 
and respond to infant cues during social interaction, and might benefit from an early intervention that aims to promote sensitive mother-infant interactions.

\section{3. 5. Breastfeeding}

Breastfeeding is associated with close contact between mother and infant, and mothers' sensitivity to the infants' needs and the quality of the dyadic interactions between mothers and infants seem to influence the initiation and duration of breastfeeding. Britton et al. reported that mothers who initiated breastfeeding of term newborn had higher sensitivity scores at 3 months postnatally than those who did not, and mothers who continued breastfeeding and still were breastfeeding at 12 months received higher sensitivity scores (after controlling for demographic and social variables) (160). This suggests that maternal sensitivity is a significant predictor of the duration of breastfeeding during the first year, and maternal sensitivity seem to be related to the initiation and the likelihood of continuing breastfeeding (160). Mothers who choose breastfeeding over bottle feeding seem more likely to be sensitive in responding to infants cues in dyadic interactions (161). Other researchers have reported links between early breastfeeding and maternal brain responses (implicated in maternal-infant bonding and empathy) to own infant stimuli (infant-crying) (162). Breastfeeding mothers showed greater activations in the superior frontal gyrus, insula, precuneus, striatum, and amygdala when listening to their own baby-cry as compared to formula-feeding mothers. The researchers reported signficant correlations between brain activations and maternal sensitivty in videotaped dyadic interactions observed 3 to 4 months postpartum (for all mothers). These findings suggest that greater maternal brain response to infant cues at 1 month postpartum may facilitate greater maternal sensitivty, suggesting an early link between greater maternal response to infant cues, breastfeeding and later maternal sensitivity (162).

Both depressed and non-depressed mothers and their infants seem to benefit by breastfeeding. Breastfeeding mothers of term infants had better performance on an Interaction Rating Scale at 3 months (mothers spent more time stroking their infants, less instrusive behavior) as compared with bootlefeeding mothers (161). Similarly, Pearson et al. (163) suggested that the act of breastfeeding may influence the mothers' attentional sensitivity towards the infants, and that breastfeeding and/or infant interaction may contribute to maternal sensitivity. These findings suggest that the act of breastfeeding influences maternal sensitivity, through positive reciprocal transactions between infants and mothers. 
Postpartum depression seems to impact breastfeeding (164), since mothers with higher postpartum depression scores were significantly more likely to discontinue breastfeeding at 4 to 16 weeks $(165 ; 166)$. Moreover, the level of exclusive breastfeeding was significant lower in mothers of elevated postpartum symtoms 2-4 weeks after birth. The severity of depression was not significantly related to breastfeeding; however, higher matermal age, living with a partner and higher income were positively related to breastfeeding (167). Mothers who breastfed, were more likely to have a bachelor or higher degree, to be older, to have not smoked in pregnancy and have a first-born child $(168 ; 169)$.

\section{Summary}

Being first-time mothers and caring for preterm infants with disorganized behavior are challenging tasks. Social interaction between infants and parents is influenced by characteristics of the infants (immature behaviour, difficult temperament, atypical early social communication) and characteristics of the parents (reduced sensitivity, high levels of stress or depression). Both parents and preterm infants seem to be at risk for being less optimal as a social partner (60), and low quality of parent-infant interactions is unfavourable for later infant development (170). Early social interaction of high quality can promote and support early infant development, and this dissertation was carried out to investigate if MITP may have a positiv effect on mothers' perception of the moderate and late preterm infants behavioral' cues and signals and thereby promote social interaction.

\section{4. The mother-infant transaction program}

\section{4. 1. The transactional model of intervention}

The purpose of prevention and early intervention is to "increase probability of normal development trajectories in childhood and to decrease potential later disorders" (171). The strategy for the transactional model of intervention is aimed at improving mother-infant interaction and to implement the intervention before adverse interactions are established, either by changing the way the infants behave toward the parents (remediation), changing the parents' perception of the infants' behavior (redefinition) or improving the parents' ability to take care of the infants and thereby changing the way parent behaves toward the child (reeducation) (5). The third of these ways to intervene, and to prevent difficult interactions between preterm infants and parents, is to change the interactions by reeducating parents and give them new knowledge about preterm infants and thereby changing their repertoire of responses and the way they behave toward the infant (5). 
The MITP is an early intervention method designed to improve developmental and mental health outcomes in preterm infants and their parents (2). The MITP is targeting preterm infants and their parents, and was designed to enhance the quality of interaction between mothers and infants, and the mothers' enjoyment of their preterm infants $(1 ; 2)$. The program consists of an 11-session one-hour standardized intervention method, and was carried out by particularily well trained nurses in the NICU (Table 1). The aim was to help parents appreciate their infant's unique characteristics, temperament and developmental potential, acquaint the parents with the infants' functioning and help them to be more sensitive and responsive to their infants' physiological and social cues, particularly those that signal stimulus overload. The MITP focuses on teaching the parents to understand the individuality of an atypical infant, to establish a good pattern of interaction and encourage the parents to enjoy their infants and facilitate adjustment to the care of low-birthweight infants. The MITP was primarily developed for mothers; it was influenced by Bromwich's concept of stepwise progression of parental skills built on research on parent-child interactions, and was aimed at altering the interactive behaviors of both partners in the relationship $(2 ; 172 ; 173)$. The intervention was also influenced by transactional approaches/stages of infant organization (3). The MITP is presented in Table 1. A more detailed description of the program has been given by Rauh et al. (2) and is presented in Appendix A. It was hyphotized that the MITP would sensitize the parents to infant cues and enables them to better adjust to poorly regulated preterm infants, with a positive effect on social interaction and early social communication. It was also hyphotized that mothers and fathers consequently would be less stressed, and that the mothers would be less depressed in relation to their parenting. This was asssumed since the MITP presumable teaches the parents to better understand their infants' behavior and encouraged them to enjoy their infants and thereby facilitated parenting $(1 ; 2)$. 
Table 1 Outline of The Mother Infant Transaction Program

\begin{tabular}{|c|c|}
\hline \multicolumn{2}{|c|}{ The Mother Infant Transaction Program $(1 ; 2)^{4}$} \\
\hline In the Hospital & At home \\
\hline $\begin{array}{l}\text { Day 1. Introduction: Getting acquainted with the baby. } \\
\text { Demonstration of Brazelton Neonatal Behavioral Assessment Scale } \\
\text { (demonstrate the infant's uniqueness and potential for self-regulation and } \\
\text { interaction). }\end{array}$ & $\begin{array}{l}\text { Home visit } 1 \text { (three days after discharge): } \\
\text { Consolidation } \\
\text { Consolidation and adjustment. }\end{array}$ \\
\hline $\begin{array}{l}\text { Day } 2 \text {. Homeostasis: how the baby feels. } \\
\text { Respiration, skin circulation, autonomically mediated movement, facial } \\
\text { movement and visceral activity. }\end{array}$ & $\begin{array}{l}\text { Home visit } 2 \text { (two weeks after discharge): } \\
\text { Mutual enjoyment through play }\end{array}$ \\
\hline $\begin{array}{l}\text { Day 3. The motor system: How the baby moves. } \\
\text { Posture, tone and movement. }\end{array}$ & $\begin{array}{l}\text { Home visit } 3 \text { (one month after discharge) } \\
\text { Temperamental patterns }\end{array}$ \\
\hline $\begin{array}{l}\text { Day 4. State regulation: enhancing the baby's organization } \\
\text { Predominant states, changes and consolability } \\
\text { How parent can help infant with better organization. }\end{array}$ & $\begin{array}{l}\text { Home visit } 4 \text { (three months after discharge) } \\
\text { Review and termination }\end{array}$ \\
\hline $\begin{array}{l}\text { Day 5. Social interaction: Engaging the baby and sustaining an } \\
\text { interaction } \\
\text { Attention, alertness and responsivity. How parents can engage the infant to } \\
\text { sustain in social interaction. }\end{array}$ & \\
\hline $\begin{array}{l}\text { Day 6. Recognizing and responding to cues: Facilitating daily care } \\
\text { Waking, changing, feeding and bathing) } \\
\text { Learn to cooperate in daily activities with the infant- sensitivity and } \\
\text { responsiveness in daily care giving. }\end{array}$ & \\
\hline $\begin{array}{l}\text { Day 7. Preparing for home } \\
\text { Alerting, timing and methods. }\end{array}$ & \\
\hline
\end{tabular}

\section{4. 2. Review of MITP research}

Review of literature published before the present study was done is based on follow-up studies of low-birthweight infants with $\mathrm{BW}<2500$ gram and $\mathrm{GA}<37$ weeks carried out

4 The following sessions were carried out by RN especially trained in the MITP 
between 1980 and $1981(1 ; 2 ; 41 ; 174 ; 175)$. Significant intervention effects of the MITP were found at 6 months on maternal role satisfaction and self-confidence, and maternal perception of infant temperament (1). Interevention mothers perceived their infants as more adaptable, happy and approachable, and less eaily distressed. These findings suggest that the MITP modified the mothers' perception of infants' temperament (1). No significant effects were reported on infants' early cognitive development at 6 and 12 months (1), but a longerterm positive effect on cognitive development was found at 36 and 48 months (2), and again at 7 years (174) and 9 years (175). Furthermore, at 9 years the intervention group was rated as better by parents and teachers on school functioning (175). However the follow-ups from the 1980 study are old, the sample was small, the researchers did not test the effect of MITP on social interactions between mothers and infants, and fathers were not included.

Furthermore these studies showed mixed outcomes on mothers and infants, and did not provide a coherent picture of the effects of interactional guidance on infant development and parenting during the infants' first year of life and nine years follow-up.

Review of research published after the present study was started is based on a modified version of the MITP. In the "Project Early Intervention 2000" follow-up, the modification included an initial intervention session in which parents could vent experiences from the hospital stay, secondly they adopted a more active participation from parents in evaluating and handling the infants and their cues (176-183). The MITP was reported to reduce parenting stress during the first year (176) and at 2 years (180). The MITP was also reported to benefit certain aspects of joint attention performance in preterm infants (177). However, no group differences were found at 6 and 12 months in infant temperament (179). Olafsen et al. reported strong negative correlations between stress and regulatory competence at 6 months, and suggest that the intervention sensitized the mothers to the temperamental regulatory competence of their preterm infants and changed the relation between stress and temperament (179). Kaaresen et al. found no positive effects of the MITP on cognitive, motor or behavioral outcomes at 2 years (180), but the MITP seemed to lead to better nurturant child-rearing attitudes at 12 and 24 months (181), Nordhov et al. reported improved cognitive outcomes at 5 years (182) and the parents reported less behavioral problems (183).

The Australian MITP study aimed to reproduce the core aspects of the MITP (184) but extended the seven sessions of the intervention over two weeks during the infants' hospitalization, reduced the home visits to two visits (personal communication with 
Newnham), and included some information about kangaroo care and massage. The research group reported that the MITP enhanced the mother-infant interactions, and infants in the intervention group were temperamentally easier, had fewer regulatory problems and more developed communication skills, and the mothers were less stressed by their infant at 3 months (184).The findings reported by the Norwegian and Australian MITP research teams show mixed outcomes, and the results are mainly based on very preterm infants. There is still a dearth of firm knowledge about the effects of the MITP on moderate and late preterm infants or their fathers.

\subsection{Nurses}

\section{5. 1 Nurses in neonatal intensive care units}

The professional responsibility of registered nurses $(\mathrm{RN})$ working with preterm infants includes meeting the special needs of infants and supporting fragile parents. The national guidelines for follow-up of preterm infants and their parents recommend that parents receive guidance and training in social interaction with their preterm infants (185). Nurses in NICUs stay in contact with the preterm infants twenty-four hours, day and night, and they are well positioned to assist families during difficult times, and to educate parents about caring for themselves and their newborn infants during the NICU stay and in the early postpartum period.

Preterm infants in neonatal care units are facing the dual challenge of sustaining a period of illness while at the same time meeting appropriate developmental milestones. The parents are often facing high levels of stress and depression, and lack of competence and confidence after birth of a preterm infant (186). Special caregiving skills are needed for parents to care for and communicate with atypical preterm infant, and to meet the special needs of developmentally immature infants. Follow-ups of moderate and late preterm infants require attention by neonatal and public health nurses and include individualizing the care for infants and parents. Through reeducation (5) nurses can give parents new skills, making parents of preterm more confident in caregiving and social interaction with their infants, and thereby enhancing the infants' growth and neurodevelopmental potential $(187 ; 188)$. They can also prepare good infant development, as well as wellbeing in both infants and parents after discharge from hospital. 


\section{Aims of the study}

The overall aim of this dissertation was to investigate the effects of The Mother-Infant Transaction program on outcomes in moderate and late preterm infants and parents during the infants' first year of life (corrected age). The specific research questions are stated as follows.

Paper I: Effects of early mother-infant intervention on outcomes in mothers and moderately and late preterm infants at age 1 year: a randomized controlled trial.

- Assess if MITP reduced maternal depression and stress during the infants' first year of life

- Assess if the MITP had a positive effect on duration of breastfeeding

- Assess if the MITP had a positive effect on mothers' perception of infant temperament at 6 and 12 months and preterm infant communication skills at 12 months.

Paper II: Stress in fathers of moderately and late preterm infants - A randomised controlled trial.

- Assess the level of stress among fathers of infants born moderate and late preterm compared to fathers of infants born at term

- Test if the MITP was effective to reduce stress in fathers of moderate and late preterm infants at 6 and 12 months

- Assess if high or low exposure of the intervention had differential effects on stress scores

Paper III: Effect of early intervention on social interaction between mothers and preterm infants at 12 months of age: A randomized controlled trial.

- Test if the MITP would have a positive effect on social interaction between moderately and late preterm infants and their mothers at 12 months (corrected age)

- $\quad$ Test if the MITP would be more appropriate for first-time mothers as compared with experienced mothers 


\section{Materials and methods}

\section{1. Study design}

This study is a single-center randomized controlled trial conducted at Oslo University Hospital, Ullevål, an academic and urban Level 3 hospital in Norway. Mothers and fathers of preterm infants with ultrasound $\mathrm{GA} \geq 30.0$ and $<36$ weeks were consecutively recruited from the NICU between January 2005 and December 2006. Parents were eligible if they could speak, read and write Norwegian, had no known history of drug or alcohol abuse or severe psychiatric disorders, and if a hospital stay of minimum eight days was anticipated. Infants with congenital anomalies, neurological sequelae, hearing loss or chromosomal disorders were excluded. After the parents had signed the informed consent they were allocated to groups through a simple randomization, using computer generated random numbers and sealed envelopes, consecutively numbered. Twins were randomized to the same group. An especially well trained research nurse was responsible for recruitment, randomization, and assignment of intervention nurse, and the intervention nurse should not be the family's assigned nurse while in the hopital. Before the families were discharged from the hospital, the research nurse collected baseline clinical and sociodemographic data on the parents and perinatale data from the medical charts of the infants. The author (IHR), but not the families, was totally blinded to the group allocation. A term reference group was recruited from the hospital's maternity ward if the infants had uncomplicated birth and Apgar score $>7$ at 5 minutes, GA $\geq 37.0$ weeks and birth weight $\geq 2500$ grams. Term infants were matched to the same gender and mothers' education level as the last infant assigned to the preterm intervention group. No records were allowed to be kept of the parents from the ordinary maternity ward who said no to participate in the study. All infants were tested for hearing loss with an Algo®3i Newborn Hearing Screener before enrollment to the study to rule out hearing loss, which could bias the outcome measures.

\section{2. Study population}

Baseline 162 mothers of a total of 190 preterm infants were invited to participate in the study, and 106 mothers accepted (65.4\%). A total of 118 preterm infants were randomized to the preterm groups; twins were randomized to the same group. One hundred and fiftyeight fathers of 186 preterm infants were invited to partipate, and 82 fathers accepted (51.9\%). Baseline, 56 mothers, 43 fathers and 61 preterm infants (including 5 twin pairs) 
were randomized to the intervention group, and 50 mothers, 39 fathers and 57 infants (including 7 twin pairs) were randomized to the pretem control group. Finally, 52 mothers, 45 fathers and 52 infants were recruited by the research nurse to the term reference group. No differences were found between non-consenting and consenting preterm groups in mean BW (1941g vs. 1930g), GA (33.3 vs. 33.0 weeks) and gender (50\% versus 54.7\% males), all with $\mathrm{p}>0.05$. The dissertation has three samples. The papers included in the dissertation are presented in Table 2

\section{2. 1. Sample in Paper $I$}

Title: Effects of early mother-infant intervention on outcomes in mothers and moderately and late preterm infants at age 1 year: a randomized controlled trial.

The sample in Paper I included the mothers and infants participating in data collection during the infants first year of life. As twin observations may be influenced by the observation of the other twin, one infant from each twin pair was randomly selected and included in the statistical analysis, and mothers' participation in the study was registered only once. The lost to follow-up from baseline to 12 months for mothers was 9 (17.3\%) in the intervention group and $6(12.0 \%)$ in the preterm control group. The figures for lost to follow-up are corrected because the first calculation incorrectly included mothers that had been excluded from the study. A flowchart of the total participating mothers, fathers and infants is presented in Figure 4.

\section{2. 2. Sample in Paper II}

Title: Stress in fathers of moderately and late preterm infants - A randomised controlled trial.

The sample in Paper II included the fathers and infants participating at 6 and 12 months, and data were analysed when both parents had consented to participate. One infant from each twin pair was randomly selected and included in the statistical analysis, and fathers' participation in the study was registered only once. Twins had been recruited to the preterm groups only, and one twin in the intervention group was already excluded from the analysis due to sequela. At 12 months, 10 (25.6\%) fathers were lost to follow-up in the intervention group, $7(17.9 \%)$ in the preterm control group, and $5(11.4 \%)$ in the term group. The figures for lost to follow-up are corrected for the intervention group and the term reference group because the first calculation incorrectly included fathers that had been excluded from the study. A flowchart of the total participating fathers and infants is presented in Figure 5. 
Figure 4 Flow diagram of participants in Paper I

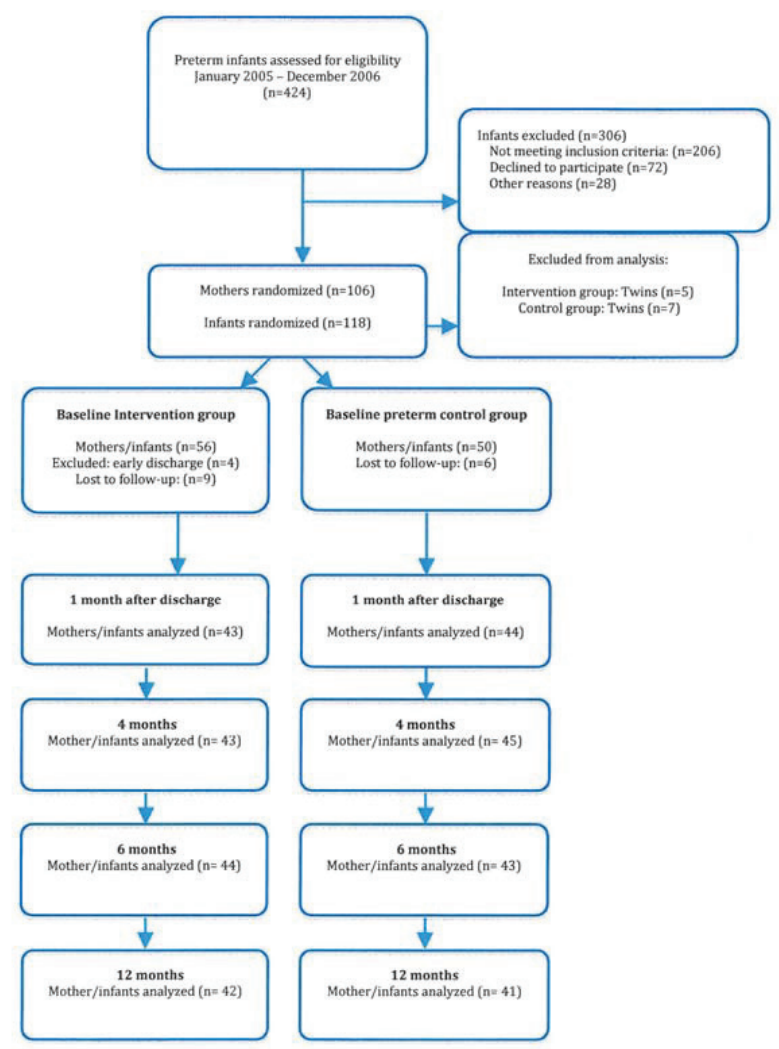


Figure 5 Flow diagram of participants in Paper II

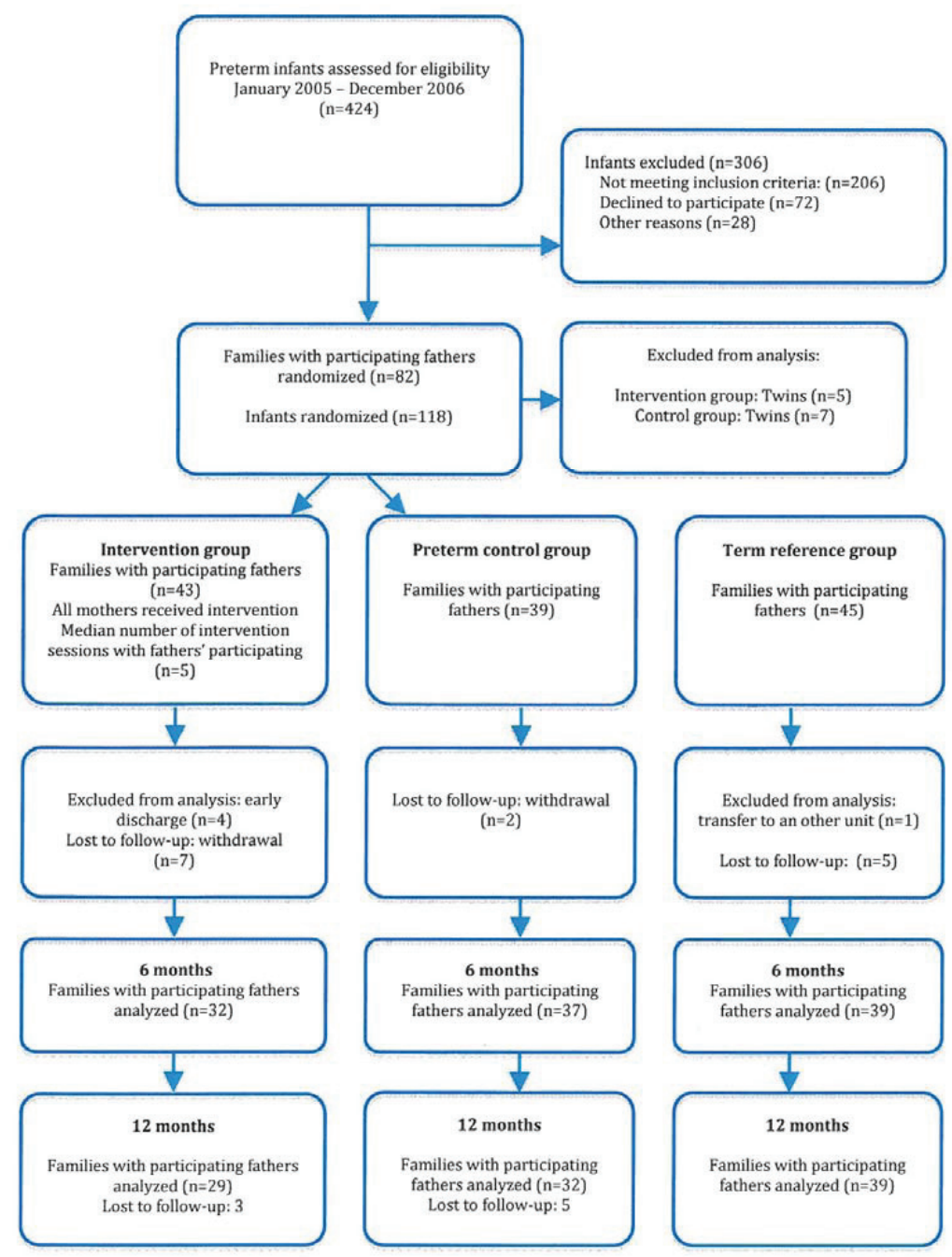


Figure 6 Flow diagram of participants in Paper III

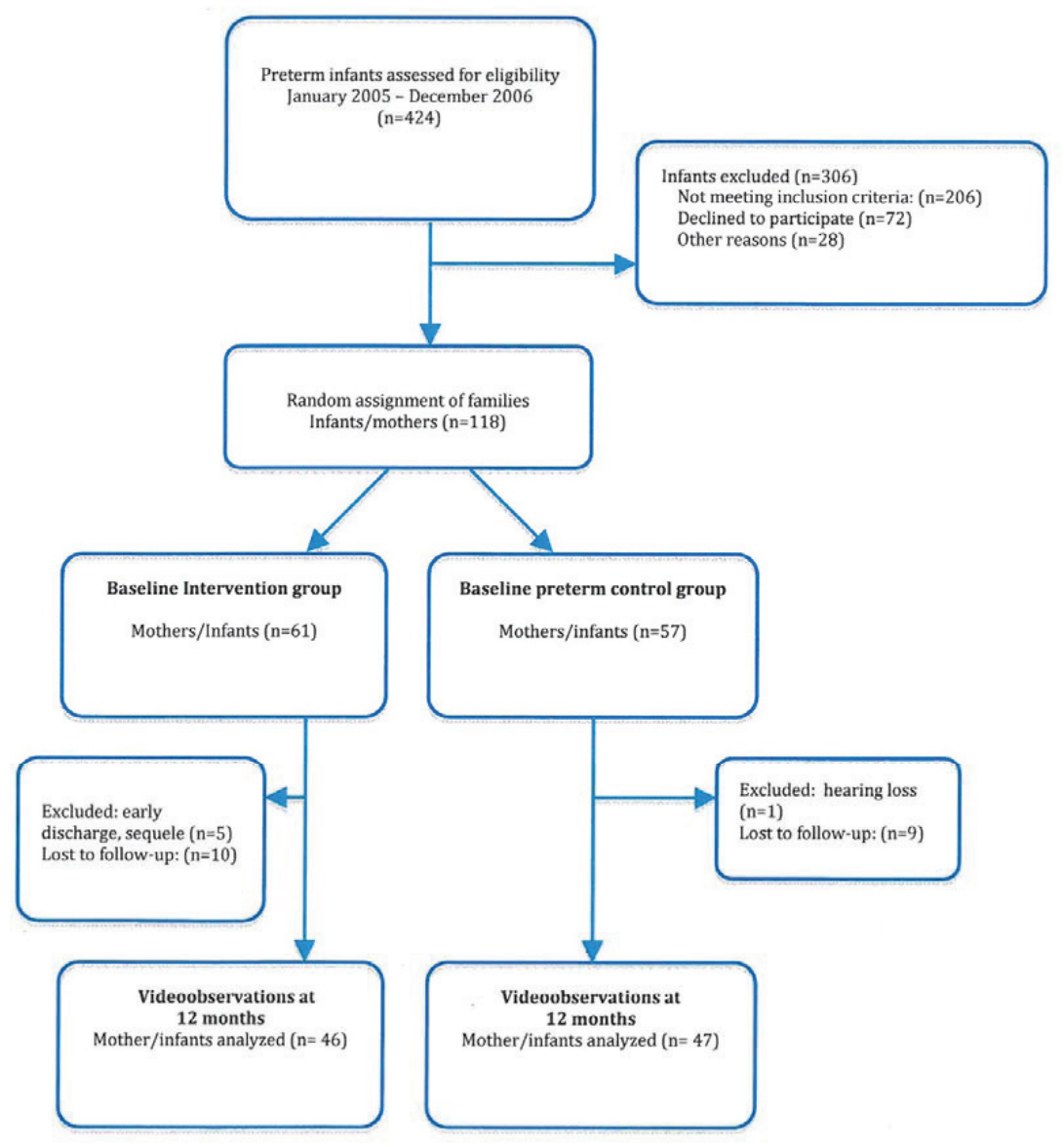




\section{2. 3. Sample in Paper III}

Title: Effect of early intervention on social interaction between mothers and preterm infants at 12 months of age: A randomized controlled trial.

The sample in Paper III included all the mothers and preterm infants participating in video observations at 12 months. Twin observations may partly be influenced by the observation of the other twin. However it was assumed that mother-infants dyads in twins constitute mainly independent observations with different scores depending on both infant and maternal behavior. Consequently it was decided to include both twins in the statistical analysis, and mothers of twins were counted twice. However, one twin in the intervention group was excluded from the analysis because of sequela. Among the participating mothers $10(16.4 \%)$ were lost to follow-up in the preterm intervention group and $9(15.8 \%)$ in the preterm control group. A flow diagram of the total participating mothers, fathers and infants is presented in Figure 6.

\section{Table 2 Overview of the papers included in the thesis}

\begin{tabular}{|c|c|c|c|}
\hline Title & Sample & Instruments & Statistical analyses \\
\hline $\begin{array}{l}\text { PAPER I } \\
\text { Effects of early } \\
\text { mother-infant } \\
\text { intervention on } \\
\text { outcomes in } \\
\text { mothers and } \\
\text { moderately and late } \\
\text { preterm infants at } \\
\text { age } 1 \text { year: a } \\
\text { randomized } \\
\text { controlled trial }\end{array}$ & $\begin{array}{l}\text { Mothers and infants } \\
\text { during the infants' first } \\
\text { year of life } \\
\text { Comparing } \\
\text { preterm intervention } \\
\text { with preterm control } \\
\text { group }\end{array}$ & $\begin{array}{l}\text { CES-D: } \\
\text { 1, } 6 \text { and } 12 \text { months } \\
\text { Breastfeeding: } \\
6,9 \text { and } 12 \text { months } \\
\text { PSI/SF: } 6 \text { months } \\
\text { PSI: } 12 \text { months } \\
\text { IBQ: } 6 \text { and } 12 \text { months } \\
\text { PICS: } 12 \text { months }\end{array}$ & $\begin{array}{l}\text { Baseline data of demographic and clinical } \\
\text { variables summarized by descriptive } \\
\text { statistics. } \\
\text { Independent samples t-tests and Chi- } \\
\text { square tests to compare between-group } \\
\text { differences. } \\
\text { Paired t-tests (and Wilcoxon signed ranks) } \\
\text { employed to make comparisons within } \\
\text { groups }\end{array}$ \\
\hline $\begin{array}{l}\text { PAPER II } \\
\text { Stress in fathers of } \\
\text { moderately and late } \\
\text { preterm infants - A } \\
\text { randomised } \\
\text { controlled trial }\end{array}$ & $\begin{array}{l}\text { Fathers and infants } \\
\text { participating at } 6 \text { and } 12 \\
\text { months } \\
\text { Comparing preterm } \\
\text { control group with term } \\
\text { reference group } \\
\text { Comparing preterm } \\
\text { intervention group with } \\
\text { preterm control group } \\
\text { Comparing stress scores } \\
\text { in fathers with low vs. } \\
\text { high "intervention dose" }\end{array}$ & $\begin{array}{l}\text { PSI/SF: } 6 \text { months } \\
\text { PSI: } 12 \text { months }\end{array}$ & $\begin{array}{l}\text { Baseline data of demographic and clinical } \\
\text { variables summarized by descriptive } \\
\text { statistics } \\
\text { Independent samples t- tests were used to } \\
\text { compare between-group differences } \\
\text { Chi-square tests to compare between - } \\
\text { group differences for categorical variables }\end{array}$ \\
\hline
\end{tabular}




\begin{tabular}{|c|c|c|c|}
\hline $\begin{array}{l}\text { PAPER III } \\
\text { Effect of early } \\
\text { intervention on } \\
\text { social interaction } \\
\text { between mothers } \\
\text { and preterm infants } \\
\text { at } 12 \text { months of age: } \\
\text { A randomized } \\
\text { controlled trial }\end{array}$ & $\begin{array}{l}\text { Mothers and infants } \\
\text { participating at } 12 \text { months } \\
\text { Comparing preterm } \\
\text { intervention with } \\
\text { preterm control group }\end{array}$ & $\begin{array}{l}\text { Qualitative Ratings } \\
\text { for Parent-Child Interaction at } \\
\text { 3-15 months months of age: } \\
\text { Video-observations at } 12 \text { months }\end{array}$ & $\begin{array}{l}\text { Baseline data of demographic and clinical } \\
\text { variables summarized by descriptive } \\
\text { statistics } \\
\text { Independent samples t-tests and Chi- } \\
\text { square tests were used to compare } \\
\text { between-group differences } \\
\text { Chi-square tests to compare between - } \\
\text { group differences for categorical variables } \\
\text { Relation between categorical variables was } \\
\text { analyzed using a Linear-by-Linear } \\
\text { Association Chi-square test. } \\
\text { A two-ways analysis of variance (Anova) } \\
\text { was used to control for imbalance in infant } \\
\text { gender in first-time mothers }\end{array}$ \\
\hline
\end{tabular}

\section{3. Methods}

\section{3. 1. Training and implementation of the MITP}

Ten neonatal RN received formal MITP training by a specialist psychologist in infant development to secure adequate training and regular clinical supervision of the intervention nurses. Measures were undertaken to secure fidelity to the protocol and the intervention (189). The nurses wrote logs from the intervention sessions, and the author (IHR) and the research assistant reviewed the logs to secure that the protocol was followed and intervention was implemented according to the guidelines. Updated implementation guidelines were published in the "Vermont Journal"- a paper circulated (with a total of 16 issues). Seven sessions were carried out in the NICU 7-10 days before discharge, as it was impossible to fit all 7 sessions into the last week of the infants' hospitalization. Four sessions were given by the same nurse at home during the first three months with infant and mother present, and whenever possible also the father. Due to holidays, sick leaves and working conditions it was not always possible for the same nurse to implement all 11 sessions, and this may have weakened the intervention fidelity and added extraneous variation to the intervention sessions. Furthermore, it cannot be ruled out that parents in the 
preterm control group gained some knowledge of the MITP via other parents, though both parents and intervention nurses were requested not to share the MITP with other families in the NICU.

\section{3. 2. The general care}

Both preterm groups received the routine care practiced at the NICU at the time of the study. The parents participated in daily caregiving, and mothers were encouraged to breastfeed their infants. The general perinatal care and follow-up for the preterm infants in the NICU included general clinical examination and a discharge consultation with a physician, a nurse and eventually a physiotherapist. The general perinatal care for term infants included a physician examination on the 2nd day, and a discharge consultation with primary midwife.

\subsection{Measures}

Outcome assessments for parents and infants were done repeatedly to get a follow-up evaluation of developmental progress in infants and parents, and in order to compare the results with findings from similar studies.

\section{4. 1. Clinical and demographic data}

Clinical and demographic/social data of the infants, mothers and fathers were collected from the medical records and by parents' self-reports. GA was based on ultrasound examination at 16-18 weeks of gestation. Parents' educational status and nationality of origin (Norwegian or Non-norwegian) were based on parents' self-reporting. Mothers reported retrospectively on infants' possible admissions to hospital after discharge at videoobservation at 6, 9 and 12 months. Information about first-time mothers was based on the variables Parity (dichotomized into no earlier pregnancy or earlier pregnancy) and Firstborn (dichotomized into yes or no).

\section{4. 2. The Center for Epidemiological Studies Depression Scale}

The Center for Epidemiological Studies Depression Scale (CES-D) is designed to assess clinical depressive symptoms in the general population. A Norwegian translation was used to assess mothers' self-reported levels of depressive symptoms one month after discharge, 
and again at 6 and 12 months (190). CES-D has 20 items and four subscales: depressive affect, somatic symptoms, positive affect and inter-personal relations. Total possible scores range from 0 to 60 ; higher scores indicate more depression symptoms. The cutoff-point for depressive symptoms is 16 , and is commonly used to identify mothers considered to be at high risk for depression. In the present study Cronbach's alphas ranged from .71 to .82 on the subscales; total alpha was .85. The scale has been shown to be a valid and reliable instrument for measuring depression $(134 ; 190)$, but has not been validated in a Norwegian sample.

\section{4. 3. Breastfeeding}

Mothers reported on breastfeeding at videoobservations 6, 9 and 12 months, based on the WHO breast-feeding categories: exclusive breastfeeding (breast milk only, but allows vitamins and medicines), predominant breast feeding (breast milk as predominant source of nourishment, but allows water, juice, vitamins and medicines) and partial breastfeeding (breast milk combined solid or semi-solid foods, formula or non-human milk) $(191 ; 192)$. Mothers were also asked to report on not breastfeeding.

\section{4. 4. Parenting Stress Index}

Parental stress was assessed by a Norwegian translation of the Parenting Stress Index (PSI) translated and back-translated by Abidin and psychologist J.A. Rønning (139;176). PSI identifies potentially stressful/dysfunctional areas in parent-infant interactions. The instrument was developed on the assumptions that stressors are additive and multidimensional, and it allows identification of three major sources of stressors: Child characteristics, parent characteristics and situational/demographic life stress.

The PSI short version (PSI/SF), administered at 6 months, has 36 items; each rated on a 5point Likert scale with three subscales consisting of 12 items each: The Parental Distress subscale, The Parent-child Dysfunctional Interaction subscale and The Difficult Child subscale. The PSI short version is composed of 36 items taken from the full-length PSI. The short version has been found to be highly correlated with the PSI long version (139). Total stress scores in PSI/SF range from 36 to 180, high scores indicate poor function. The Cronbach's alpha levels for mothers were $>.77$ on the subscales, and .82 for Total stress; fathers alpha levels were $>.80$ on all subscales, and .92 for Total stress. 
The PSI long version (PSI), administered at 12 months, comprises 123 questions and distinguishes three major sources of stressors: child characteristics (6 subscales), parental characteristics (7 subscales), and 22 Life stress items (LS) that indicates stress outside the parent-infant relationship. Three Life stress items are added in the Norwegian version of the PSI. A defensive Responding score of 24 or less indicates defensive responding or cheating. Total stress scores may range from 101 to 505; computed by summing the scores on the Child and the Parent domains (139). The Child domain reflects stress associated with parental perception of infant characteristics. The Parent domain reflects stress associated with parental functioning. The long version had satisfactory Cronbach's alpha levels in all domains. Alpha levels for mothers were .83 and .85 for the Child and Parents domain, respectively, and .94 for Total stress. Fathers' alpha levels in all domains were $>.75$ and for Total stress (.93).

\section{4. 5. Infant Behavior Questionnaire}

Infant Behavior Questionnaire (IBQ) is a parent-report instrument used for assessing infant temperament observed during the preceding week (193-195), administered at 6 and 12 months. Items were rated on a 7-point Likert scale (never to always) and yielded the following dimensions/subscales of temperament: Activity Level, Distress to Limitations, Approach, Duration of Attention, Smile and Laughter and Soothability. IBQ consists of 94 items. Higher scores indicate more evidence on the dimension being measured regardless of whether this dimension is considered optimal or not. Activity Level subscale consists of 17 items that characterize the infant's gross motor activity, including movements of arms and legs, squirming and locomotor activity. Distress to Limitations subscale consists of 20 items that characterize the infant's fussiness, crying and showing of distress in different situations. Distress and latency to Approach Sudden or Novel Stimuli subscale consist of 16 items that characterize the infant's distress to sudden changes in stimulation and the infant's distress and latency of movement toward a novel, social or physical object. Duration of Attention subscale consists of 11 items that characterize the infant's vocalization, looking at, and/or interaction with a single object for extended periods of time when there has been no sudden change in stimulation. Smile and Laughter subscale consist of 15 items that characterize the infant's smiling or laughter in general caretaking and play situations. The Soothability subscale consists of 11 items that estimates the infant's recovery from fussing, crying, or distress when the infant's caregiver uses soothing techniques. Cronbach's alphas for the 
subscales reported by mothers at 6 months ranged from .59 to .70. Activity Level (.70), Distress to Limitations (.79), Approach (.59), Duration of Attention (.77), Smile and Laughter (.79) and Soothability (.79).

\section{4. 6. Questionnaire about the infants' communication skills}

A Norwegian translation of The Pictoral Infant Communication Scales (PICS), derived from the Early Social Communication Scales (196), was administered at 12 months. The instrument employs photographs to aid parents' understanding of the behaviors of interest, and is reported to have good validity and reliability (197). PICS is a parent report measure of early infant communication development with 16 items, each consists of a four-point Likert scale with three subscales: Initiating joint attention (IJA), Initiating behavior regulation/request (IBR) and Responding to joint attention (RJA). Joint attention skills refer to the capacity to coordinate attention to objects and events with attention to another person during social interactions. Such skills are considered to be critical for language and cognitive development $(47 ; 48)$. Total PICS scores may range from 0 to 48; high scores indicate more optimal communication skills. The Cronbach's alphas for the subscales in the present study ranged from .75 to .85 ; total alpha was .87 . To our knowledge, this is the first study to report results obtained by using PICS.

\section{4. 7. Video observation of mother-infant interactions at 12 months}

Mothers and infants were invited to participate in video observations at 6,9 and 12 months. This dissertation presents data from video observations of mothers and preterm infants playing in a hospital laboratory at corrected age 12 months, approximately 9 months after the intervention had been completed. The rationale for including the videoobservations at 12 months in the analyses was dual. Due to time and resources it was impossible in this study to analyze the videoobservations at 6 and 9 months. Furthermore we expected the social interaction between mothers and infants at 12 months to be more consolidated, partly because of the establishement of attachment (198).

The play sessions were videotaped using two Panasonic cameras on the adjacent wall in two opposite corners of a hospital laboratory to keep both mother and child in focus; a microphone was attached to the wall. The mothers were instructed not to expose their group affiliation to the tester (the author). The observation of mothers' and infants' behavior was 
scored according the guidelines of Cox Complete P-C Coding Manual Final $(199 ; 200)$ on a 5-point Likert scale (Not at all characteristic to Highly characteristic). The NICHD guidelines (201) instructed the tester to act in an uninvolved manner and not make herself available to the mother or infant throughout the videotaping. The observation started with a sensitizing informal chat to acclimate the mother to the presence of the tester and the camera, and to reduce the effect of participant reactivity (202). Then the infants' weight, length and head circumference were measured and the mothers' breastfeeding status was documented. The mothers were then given a standardized instruction of the video observation, and asked to show her infant three age-appropriate toys (a story book, a toddler kitchen and a farmhouse) in a set order in a semi-structured 15-minute free play situation, according to the "three bag method" of The NICHD Study of Early Child Care (201). The play interactions were videotaped and coded by raters, blinded to group affiliation of the infants. The coding was carried out according to the "Qualitative Ratings for ParentChild Interaction at 3-15 months of age" (199;200), which is a slight modification of the coding system used by the National Institute of Child Health and Human Development (NICHD) Study of Early Child Care (NICHD early Child Care Network 1997) (203). Global ratings of seven subscales of maternal behavior and five subscales of infant behavior were coded according to a predetermined scale from 1 to 5 , indicating the degree to which behaviors specified in the manual characterized the interaction, based on both quality and quantity of the observed behaviors. Higher scores indicate more evidence of the dimension being coded regardless of whether this dimension is considered good or bad for the interaction. Description of the subscales of maternal and infant behavior is presented in Table 1 in Paper III.

\subsection{Statistical methods}

\section{5. 1. Statistics}

SPSS 15.0 for Windows was used for the statistical analyses. A significance level was set at $\mathrm{p} \leq 0.05$. The statistics in the papers are presented in Table 2. Descriptive statistics was conducted on baseline data to summarize demographic and clinical variables. Independent samples t-tests were used to compare between-group differences in all the papers, and paired t-tests were employed to make comparisons within groups in Paper 1. Chi-square tests were used to compare between-group differences on categorical variables in Paper 1 and 2. In Paper 3 the relation between categorical variables was analyzed using a Linear-by- 
Linear Association chi-square test. Subgroup analysis was planned for first-time mothers, and a two-ways analysis of variance (Anova) was used to control for imbalance in infant gender among first-time mothers. Missing values in different instruments were handled according to the manual of the different instruments.

\section{5. 2. Bonferroni correction}

Bonferroni corrections control the probability of false positives and are sometimes used to reduce Type I error when multiple tests are conducted (204). It was decided not to use Bonferroni, as this procedure could further reduce the power and may increase the probability of producing false negative (Type II error) (205).

\section{5. 3. Power analysis}

\section{Paper I.}

Maternal sensitivity to infant cues and behavior was central to this dissertation, and this measure was chosen for power calculation, although not reported in Paper 1.

\section{Paper II.}

Stress in fathers was not a prime objective of the study, and a post hoc power calculation was performed. The standard deviation (SD) of total stress scores of fathers at 6 months (S6) was 12.7 in the intervention group $(n=29)$ and 16.3 in the preterm control group $(\mathrm{n}=34)$. When comparing mean S6 in these two groups, a two-tailed independent sample ttest was used, with a 5\% significance level. We assume that the true SD in the two groups is equal to the observed standard deviations. With the present sample sizes and $80 \%$ test power, the true mean S6 difference between the groups must then be at least 10.4. Thus, the least detectable S6 difference in the present study is about 10.

\section{Paper III.}

Maternal sensitivity to infants' cues and behavior was central to this project and chosen for power calculation. The standard deviation of maternal sensitivity at 12 months (S12) was 0.93 in the premature control group $(n=46)$ and 0.92 in the intervention group $(n=47)$. When comparing mean S12 in these two groups, a two-tailed independent sample t-test was used, with a 5\% significance level. It was assumed that the true standard deviation in the two groups was 0.93 . With the present sample sizes and $80 \%$ test power, the true mean S12 
difference between the groups should be at least 0.54 . Thus, the least detectable S12 difference in the present study is about 0.54 .

\section{5. 4. Reliability}

Dr. Margaret Tresch Owen, affiliated with the NICHD study, trained coders for reliability in an advanced training course, before the actual coding started. Reliability training included scoring of NICHD training films and regular training and consensus scoring in the research group. Intraclass correlation coefficient (ICC) statistics was used to examine level of agreement between scorers of videoobservations (206). The global scoring included notes of qualitative and quantitative behavior of mothers and infants to increase the reliability of the observations. Approximately $20 \%$ of all the interactions were randomly selected and double coded by three trained coders, including the author, all blinded to group affiliation and clinical and demographic information about the participants. The reliability coefficients for maternal and infant behaviors at 12 months are presented in Table 1 in Paper 3. The variables called detachment, positive regard/positive affect, negative regard/negative affect, animation, activity and sustained attention were excluded from further analysis because of ICC $<.70$.

At 12 months corrected age all the patient records were checked with respect to medical diagnoses, and one infant was withdrawn from the study, due to a diagnosis that did not meet the inclusion criteria. Moreover $20 \%$ of all the registration forms in this study have been monitored and approved by the clinical monitor at OUS Ullevål hospital.

\section{6. Study approval and ethical aspects}

The Data Inspectorate and The Regional Committee for Medical Research Ethics (70904193) approved the study. ClinicalTrials.gov Identifier: NCT00245843.

Recruitement of the families of term and preterm infants started when the health of the mothers had stabilized after birth, and the preterm infants were expected to survive. The parents received written and oral information about the study from the research nurse. To confirm their participation, the parents signed the informed consent of participation. 


\section{Summary of main results}

The results from the study are presented below.

\section{1. Paper I}

Infant Behavior \& Development (Accepted for publication 27 september 2011)

\section{Effects of early mother-infant intervention on outcomes in mothers and moderately and late preterm infants at age 1 year: a randomized controlled trial.}

Ingrid H. Ravn, Lars Smith, Nina Aarhus Smeby, Nina Margrethe Kynø, Leiv Sandvik, Eli Haugen Bunch, Rolf Lindemann

The objective of this study was to assess if MITP had positive effects on outcomes in mothers and infants during the infants' first year of life. The study assessed the effect of MITP on maternal depression and stress and on duration of breastfeeding. It also evaluated if MITP had positive effects on mothers' perception of infant temperament and preterm infant communication skills at 12 months.

Mothers and preterm infants, with GA 30-36 weeks, were randomly assigned to MITP (intervention group) or standard care (control group). Mean gestational age in the intervention group was $33.3 \pm 1.5(\mathrm{n}=56)$ and in the control group $33.0 \pm 1.6(\mathrm{n}=50)$. Outcomes were assessed by CES-D, Parenting Stress Index (PSI) WHO breast-feeding categories, Infant Behavior Questionnaire (IBQ) and The Pictorial Infant Communication Scales (PICS).

Mothers in the intervention group reported significantly less postpartum depression one month after discharge $(\mathrm{p}=.04)$ and more breastfeeding at 9 months $(\mathrm{p}=.02)$. The results suggest that MITP reduced postpartum depression and extended the period of breastfeeding. No significant group differences in favor of the intervention group were found on total parenting stress at $6(\mathrm{p}=.08)$ and 12 months $(\mathrm{p}=.46)$. No evidence was found of positive effects of the intervention on self-reported stress in mothers. The mothers in the intervention group reported significantly less infant smile and laughter at $6(\mathrm{p}=.02)$ and 12 months $(\mathrm{p}=.006)$ and less motor activity at 12 months $(\mathrm{p}=.04)$, thus it might be questioned if MITP had any positive effects on mothers' perception of infant temperament. Furthermore results from this study showed no significant differences between the two preterm groups on 
perceived infant communication skills at 12 months $(\mathrm{p}=.86)$, and there was no support for positive effects of the intervention on perceived infant communication.

- Mothers in the intervention group reported significantly less postpartum depression 1 month after discharge compared with mothers in the preterm control group. No significant differences in depression scores were found at 6 and 12 months

- A significant decrease in depression scores was found in both preterm groups from 1 to 12 months.

- Significantly more mothers in the intervention group were breastfeeding their infants at 9 months, and this tendency was also found at 12 months

- There were no significant group-differences in favor of the intervention group in maternal stress scores at 6 and 12 months

- There were no significant group-differences in favor of the intervention group in early infant communication skills at 12 months.

- The hypothesis that MITP might have a positive effect on mothers' perception of infant temperament was not confirmed. The intervention mothers reported significantly less smiling and laughter in their infants at 6 and 12 months, and less activity at 12 months compared with control mothers.

\section{2. Paper II}

Early Child Development and Care. 2011, 1-16, iFirst Article

Stress in fathers of moderately and late preterm infants: a randomised controlled trial Ingrid Helen Ravn, Rolf Lindemann, Nina Aarhus Smeby, Eli Haugen Bunch, Leiv Sandvik, Lars Smith

The purpose of this study was to investigate if fathers of moderately and late preterm infants were more stressed than term fathers at 6 and 12 months by using the Parenting Stress Index. Furthermore, in a randomised controlled trial, this study assessed the effect of the Mother-Infant Transaction Program on fathers' stress, and tested if MITP was effective in reducing stress in fathers of moderate and late preterm infants. Finally it was assessed if high or low exposure to the intervention had differential effects on stress scores in fathers. 
Baseline 82 fathers of infants with gestational age $\geq 30.0$ and $<36$ weeks, were randomized to a preterm intervention group $(n=43)$ and a preterm control group $(n=39)$, and forty-five fatheres were recruited to a term reference group. The number of fathers participating at 6 months was 32 fathers in preterm intervention, 37 fathers in the preterm control group and 39 fathers in the term reference group. The fathers of preterm infants reported higher total stress than fathers of term infants at both 6 months $(\mathrm{p}=.002)$ and 12 months $(\mathrm{p}=.03)$, but no significant differences were found in stress scores between the preterm intervention and control group. The intervention failed to reduce paternal stress. Furthermore, the fathers who participated in six or more sessions reported significantly higher stress in the Parent domain and Total stress, and on the subscales of Mood and Competence compared with fathers who participated in 0-5 intervention sessions. The findings suggest that the intervention actually made the fathers more stressed. The intervention failed to reduce paternal stress, and the results suggest that fathers require different intervention strategies.

- At 6 months the fathers of moderate and late preterm infants in the preterm control group reported significantly higher total stress and more stress in the subscales of parental distress, parent-child dysfunctional interaction, difficult child and defensive scoring as compared with the term fathers

- At 12 months the fathers of moderate and late preterm infants in the preterm control group evidenced significantly more total stress than term fathers and more stress on the subscale of acceptability and demandingness in the Child domain, and on the subscales of competence and isolation in the Parent domain.

- No significant differences were found in stress scores between preterm intervention and control group at 6 and 12 months

- At 12 months, the fathers who had participated in five or less sessions reported significant lower stress scores than fathers who had participated in 6-11 sessions on Total stress, the Parent domain and on the subscales of mood and competence. 


\section{3. Paper III}

Infant Behavior \& Development 34 (2011) 215-225

\section{Effect of early intervention on social interaction between mothers and preterm infants at 12 months of age: A randomized controlled trial}

Ingrid Helen Ravn, Lars Smith, Rolf Lindemann, Nina Aarhus Smeby, Nina Margrethe Kynø, Eli Haugen Bunch, Leiv Sandvik

In a randomized controlled trial at 12-months of age, the effect of the Mother-Infant Transaction Program was assessed on social interaction between mothers and moderately and late preterm infants with gestational age $\geq 30.0$ and $<36$ weeks. The objective of this study was to ascertain if MITP would have a positive effect on social interaction between late and moderately preterm infants and their mothers at 12 months (corrected age). Furthermore, we tested if the MITP would be more appropriate for first-time mothers as compared with experienced mothers. Ninety-three play sessions were videotaped and coded, with 46 mothers-infants in the intervention group and 47 mothers-infants in the control group. The intervention mothers scored higher on maternal sensitivity/responsiveness $(\mathrm{p}=.05)$. Being a first-time mother was a moderator that enhanced the effects of the intervention. First-time mothers were more sensitive/responsive to their infant's cues $(\mathrm{p}=.01)$, and the dyads evinced higher level of synchronicity $(\mathrm{p}=.02)$ as compared with experienced mothers. More positive $\operatorname{mood}(\mathrm{p}=.04)$ and less negative $\operatorname{mood}(\mathrm{p}=.05)$ were observed among their infants. The findings suggest that the intervention contributes to more optimal mother-infant interactions in moderately and late preterm infants of first-time mothers.

- The intervention mothers scored significantly higher than mothers in the preterm control group on maternal sensitivity/responsiveness at 12 months

- First-time mothers were significantly more sensitive/responsive to their infant's cues, and the dyads evinced higher level of synchrony (dyadic mutuality) as compared with experienced mothers.

- More positive mood and less negative mood were observed among infants of firsttime mothers as compared with infants of experienced mothers 


\section{Discussion}

\section{1. Main findings}

This study includes data from a follow-up of newborn moderate and late preterms and term infants and their parents during the infants' first year of life. The general hypothesis of this study was to investigate if the MITP had positive effects on outcomes in mothers (Paper 1 and 3), fathers (Paper 2) and infants (Paper 1 and 3).

One main finding was that MITP had a significant positive effect on postpartum depression and the duration of breastfeeding. Furthermore, mothers in the intervention group were more sensitive and responsive during mother-infant interactions at 12 months. The first-time mothers evinced higher level of dyadic mutuality, and significantly more positive mood and less negative mood were observed among their infants. However, the intervention did not seem to influence the mother's perception of infant's temperament and infant's communication, and no differences were found in stress scores between the preterm groups at 6 and 12 months among the mothers and fathers. In fact fathers who had participated in less intervention sessions, reported significant lower stress scores than fathers who had participated in more sessions. However, at both 6 and 12 months the fathers of moderate and late preterm infants reported significantly more stress as compared with the term fathers. The findings reported in the three papers of this dissertation are closely interrelated, and the discussion is partly set up chronologically, that is, the earlier effects are delineated before the later effects are discussed.

\section{2. Depression}

The MITP is not specially targeting depressed mothers but it does target social interaction between mothers and infants. It was hypothesized that the MITP may reduce maternal depression and help mothers overcome the emotional crisis often associated with preterm birth. This may take place by giving mothers new knowledge and change their responses to the infants' cues, and enable mothers to be more sensitive and confident in caring of their preterm infants (reeducating) (5). This may also change the way the infants behave toward their mothers, and contribute to more enjoyable social interactions, thereby enhancing the mothers' enjoyment of her baby (2), which in return may reduce maternal depression because of better maternal coping and less stress. One month after infant discharge mothers 
in the intervention group reported significantly lower total depression scores, with fewer somatic symptoms (bothered, appetite, effort, sleep, get going) than control mothers (207). The results support the hypothesis that the MITP reduced maternal depression in the intervention group. The present results do not confirm the findings of Newnham et al., they reported no group differences in mean depression scores in mothers of preterm infants at 3 and 6 months (184). Newnham el al. used a different instrument, the Edinburgh Postnatal Depression Scale (208), their sample had lower GA, and they had included some information about kangaroo care (209). Zelkowitz et al. also tested the effects of an early intervention method (6-sessions Cues program designed to teach mothers to recognize signs of distress, and read and respond to infant cues), designed to reduce maternal anxiety and depression and promote sensitive interaction in mothers of VLBW (210). The research group reported that the two group of mothers did not differ in levels of anxiety and depression at 6 to 8 weeks corrected age. Feldman et al. (211) demonstrated that mothers of preterm infant with mean GA 30.6 weeks, who provided kangaroo care (infants were taken out of the incubator, undressed and placed between mothers' breasts skin-to-skin for at least 14 consecutive days), were less depressed during the hospitalization period compared with a control group who received standard incubator care. Different findings might be due to different interventions, or due to time of measurement. The present study did not find any significant differences in depression scores between the groups at 6 and 12 months (Paper I). One explanation for null differences when the infants are getting older may be that maternal depression symptoms tend to decline during the infant's first year of life $(134 ; 212)$. One premise of finding an intervention effect must be that depression scores may be further reduced. Consistent with others studies (134;212), we found a significant decline in total depression scores in both preterm groups from 1 to to 12 months, a finding that lends support to this assumption.

One month after discharge more than every fourth mother in the present control group reported depression symptoms at clinical at-risk levels $(\geq 16)$, which is twice as high (but not significantly higher) as for the mothers in the intervention group. These findings also lend support to an intervention effect. Earlier research suggests that the rate of post partum depression is high in samples composed primarily of mothers of very preterm or very LBW infants (130-132). Rates are as high as 40- $42 \%(131 ; 213)$, compared with about $10 \%$ in mothers of term infants (214). Earlier findings suggest that depression is associated with gestational age, that infants with lower GA probably in general trigger more 
depression symptoms in mothers than infants with higher gestational age. Beegly et al. (215) evaluated the stability and change in the level of maternal depression symtomatology during the first postpartum year. The research group reported that middle-class first-time mothers of healthy, full-term infants with high $(\geq 16)$ CES-D scores at 2 months are significantly more likely to continue to have high levels of depressive symtoms throughout the first postpartum year (215). The present results suggest that high levels of depression are not transient. The findings may be applied to first-time mothers of preterm infants, and demonstrate the importance of identifying interventions that can be used by health providers to reduce high levels of depression.

The mothers' ability to be sensitive to infant cues is essential for interaction quality (128). Postpartum depression (PPD) may interfere with mother-infant interaction $(161 ; 216)$, and is associated with irritability and hostility toward the infant (217) and reduced breastfeeding $(218 ; 219)$. Lower depression scores in the intervention group suggest that these mothers have acquired the ability to be more sensitive to infant cues, which may be associated with higher quality in early mother-infant interactions. At 12 months, observations of play sessions demonstrated that mothers in the intervention group were more sensitive and responsive to their infant cues (220). This finding might be a direct effect of the intervention and consistent with the transactional nature of the MITP. It might also be an indirect effect of lower depression scores in the intervention mothers when the infants were younger and more dependent on nurturing and sensitive caregivers.

It is not possible to rule out baseline imbalance in depression scores between the groups, due to a low but significant higher number of mothers in the intervention group, who had experienced earlier preterm birth that may have caused more depressive symptoms baseline when they give birth to a preterm infant for a second time $(130 ; 131)$. Moreover, in the intervention group there were significantly more mothers of non-Norwegian origin who might face more psychosocial stress with increased risks for baseline depression (221); this could also bias the differences between the groups. Furthermore, one month after discharge the intervention mothers still had one MITP session left. The intervention sessions may bridge the transition from NICU to home, and lower depression symptoms could also be an effect of the number of home visits, not the intervention per se. The risk for PPD is reported to be higher for primiparous mothers (214), and for younger and less educated mothers (222), but there were no imbalance concerning age and years of education in our sample, and the mothers' age and years of education were not low. 


\section{Summary}

Maternal depression affects the mothers' wellbeing, but may also have consequences for the husbands' depression and wellbeing $(124 ; 223)$ and be a risk factor that can impair social interaction between mothers and infants. Depression in mothers is associated with less sensitive and contigent responses and a more intrusive and overstimulating style $(13 ; 14 ; 126 ; 128 ; 129)$, and may contribute to poor attachment between mother and infant (224). The MITP reduced depression scores in mothers, reported one month after discharge. To prevent development of high and persistent symtoms of depression in mothers and to optimize infant development in preterm infants (225), neonatal nurses should start to intervene before the infants are discharged from the hospital, and not just handing over this work to public health nurses (226).

\section{3. Parenting stress in fathers of preterm and term infants}

The birth and upbringing of VLBW infants are associated with long term stress in the families $(138 ; 143 ; 227 ; 228)$, but little is reported about stress in fathers of MLPI. In this study the overall stress scores (total stress) in the fathers of MLPI were significantly higher than for term fathers at both 6 and 12 months (229). The stress level was around the 30 percentile (139); i.e. not particularly high. Nevertheless, the findings indicate that the fathers of MLPI in the present study were exposed to a higher level of stress during the infants' first year of life compared with fathers of term infants (229), and partly corroborate earlier research on preterm infants with lower GA $(145 ; 176 ; 227)$ and substantiate the importance of early intervention to prevent parental stress.

At 6 months, stress in fathers of moderate and late preterm infants was associated with parental distress and stress related to parent-child dysfunctional interaction and difficult child. The distress fathers experience as parents (parental distress) could be explained by lack of parenting competence (145), new roles or conflicts with the mother (139), emotional disturbances (230) or stress associated with transition to parenthood (231). The birth of a first child most likely produces a certain amount of stress at any rate (230), but nearly all the parents in both groups were first-time parents, so this factor could not explain the differences in stress scores between the groups. Higher stress at 6 months was also related to difficult interactions between infants and fathers (parent-child dysfunctional interaction). One might argue that being the social partner of MLPI is less stressful than being the father of an infant with lower GA and more disorganized states of attention (232). Nevertheless the 
present study demonstrated that social interaction with moderately and late preterm infants may also be unrewarding and more stressful than interacting with term infants, and thus lends support to the findings obtained with preterm infants with lower GA $(57 ; 58)$. Furthermore, fathers of first-born preterm infants probably have little confidence and competence in reading and responding to infant behavioral cues, which tend to be small and weak in preterm infants $(55 ; 56)$.

High level of stress in fathers is unfavourable for father-infant interactions, and the way the infant behaves may influence the care the infant receives from the father (3;39). Highly stressed parents tend to be less sensitive, and may easily exceed the thresholds for optimal stimulation because of too low or too high stimulation (17). Consequently the infants are not stimulated or responded to in optimal ways by their fathers, which may start a series of reciprocal unfavourable transactions between fathers and infants $(40 ; 233)$. This is a possibility that also may apply to interactions with MLPI. Fathers also reported more stress associated with the behavioral characterics of their preterm infants (difficult child). This kind of stress might be related to the fathers' attempt to be co-regulators (69), trying to give contigent responses to disorganized preterm infants with less capasity to self-regulate the experiences of events in their environments (68), or it may be related to difficult infant temperament. Preterm infants of lower GA have been reported to have more difficult temperament than term infants $(78 ; 79 ; 234)$. However, earlier research is conflicting, and little is known about temperament in MLPI (80).

At 12 months the fathers still reported significantly higher total stress and stress in the Parent domain (229). These findings suggest that caring of MLPI is associated with longterm stress among the fathers; also reported by other researchers (145). Higher stress scores on the subscale of acceptability suggests that moderate and late preterm infants posssess physical or psychological characteristics that do not match parental expectations. Such stress might be related to unresponsive and fragile infant behavior (150) or difficult temperament (78;234). Higher stress in the area of Acceptability might also be related to poorer infant medical and developmental outcomes, which may increase and be more visible when the infants grew older $(27 ; 30-32 ; 109 ; 235)$, and thus reflecting a realistic concern about the childrens' develoment (148). Stress in the area of demandingness suggest that MLPI make great demands on the fathers in different areas $(139 ; 146)$ and may trigger stress related to the infants' behavioral characteristics and the parents' own child-rearing attitudes. Higher stress in the area of competence and isolation in the Parent domain might be related to stress associated with low parental competence, or perceiving the role of the father as less 
reinforcing. It might also mean more social isolation from friends and families (236) as these fathers were caring for vulnerable infants with special needs in relation to follow-up.

\section{4. Effect of MITP on stress in fathers and mothers}

In contradiction to the previously stated hypotheses, no significant differences in favour of the intervention group were obtained on PSI scores at 6 and 12 months for mothers or fathers $(207 ; 229)$. These findings differ from the results reported by Kaaresen et al. $(176 ; 180)$ and Newnham et al. (184). Both of these research groups testet the effects of a modified MITP on parents of preterms with a predominantly lower GA at 3, 6, 12 and 24 months, and reported significant less stress in the intervention group for both mothers and fathers. At 3 months intervention mothers in the Newnham study were significantly less stressed by infant characteristics (Child domain) (184). At 6 months intervention mothers in the Kaaresen study reported lower scores in Child domain, Parent domain and Total stress, at 12 months parents reported lower stress in the Parent domain and Total stress and the fathers also reported less stress in the Child domain (176). At 24 months parents in the Kaaresen's study reported lower stress scores in the Child domain, Parent domain and total stress (180). The moderate and late preterm infants in the present Ullevål study had higher BW and GA and lower biological risk status as compared with the Kaaresen and Newnham studies, and the general stress level in the parents in this dissertation was low. The ability to reduce parental stress further was therefore probably limited. The maternal intervention group had significantly more mothers with earlier preterm birth and non-Norwegian origin (207), a fact which suggests that these mothers may have had a different stress level in the first place.

In a RCT, Als et al. reported that the Newborn Individualized Developmental Care and Assessment Program (NIDCAP) reduced stress in mothers of preterm infants with GA less than 28 weeks in the Child domain and the Parent domain (237). An other research group reported no significant effects of a NIDCAP intervention on stress in mothers and fathers of preterm infants during the first period in the NICU (238). Zelkowitz et al. (239) tested the effect of a brief intervention (Cues program) at 6 and 8 weeks, but the mothers in the preterm groups did not differ in stress related to infant's appearance and behavior, and Glazebrook et al. (240) reported no measureable effects of The Parent Baby Interaction Programme (PBIP) on parental stress at 3 months. Meijessen et al. (241) reported no effect of a comparable intervention programme, the Infant Behavioural Assessment and 
Intervention Program (IBAIP) at 12 months, however, the IBAIP improved some aspects of maternal stress at 24 months (mood and distractibility) but also evoked feelings of social isolation in mothers of infants with GA $<32$. Earlier reports of the impact of early intervention on stress in parents are inconsistent, and few studies have demonstrated positive effects on parental stress during the infants first year of life.

A surprising finding in this study was that fathers at 12 months, with higher intervention exposure (6-11 sessions), reported significantly higher Total stress and stress in the Parent domain than fathers with low intervention exposure (0-5 sessions). But it should be noted that the overall stress in fathers in the two groups was not high (i.e. around the $20-30 \%$ percentiles according to Abidin). The findings suggest that fathers with low intervention exposure were less stressed than farthers with high exposure, and are not easy to explain. These results contrast with the findings of Kaaresen et al. (176), whom reported a negative relation between numbers of intervention sessions in which fathers participated and the fathers' self-reported stress scores at 12 months. Fathers with high or low intervention exposure might constitute a selected group with higher/lower baseline stress. Only three fathers in this dissertation completed all the sessions, which may be due to a lack of motivation by fathers to participate in the intervention sessisons; also consistent with other studies (242). Fathers in the intervention group might have been stressed because of expectations of more involvement in child care by their spouses (139), and these fathers did report significantly more stress in the Parent domain. Alternatively, the sample size could have been too small, with insufficient power, to detect significant differences between the groups (243). It could also be that the content of MITP, or the way the intervention was delivered in the context of the NICU environments, stressed the fathers, or that higher stress reflected different coping strategies (244). The defensive responding scores among the fathers were above 24 in both groups, but non-signifcant, which indicates that neither groups responded in a defensive manner. Higher stress scores in the "high exposure" group could be a positive effect of the MITP, indicating that higher MITP "dose" has given fathers new knowledge about their preterm infants, and thus might be the first-step in reeducating fathers and change their reportoire of responses toward the infant (5). Fathers may have become more sensitive and realistic to their infants' physiological and social cues. In this way they may more easily have acknowledged that they were stressed by the situation, as compared with control fathers who might have tried to be good fathers and therefore underestimated that they were stressed. The follow-up period could also have been too short 
to change the fathers' pattern of interaction with their infants into favourable transactions, and this change might occur later.

\section{Summary}

Fathers of moderate and late preterm infants experienced more stress related to child and parent characteristics, as compared with term fathers during the infants' first year of life. However the MITP did not reduce stress symptoms in fathers or mothers.

\section{5. Infant temperament}

In the 10th MITP session parents were introduced to the topic of different patterns of infant temperament, and were trained to discern the infants' emerging response style and how the infants' temperament could impact social interaction (2). It was hyphotized that MITP would change the mothers' attitudes, sensitivity and behavior towards the preterms behavioral cues (2), and made mothers more sensitive and attuned to the temperament of their infants. In this way the mothers might give their children more external support and contigent responses, and the infants may develop self-regulatory capasities and easier temperament (69). Infant temperament is influenced by the quality of the infants' experiences (84), and sensitive and stimulating parenting practices seem to modify difficult temperament in children $(86 ; 87)$. Parents wellbeing also seems to be influenced by the infants' temperament, and first-time parents of term infants with more difficult temperament have reported higher levels of parenting stress and depressive symptoms and lower levels of parental efficacy (245).

However, the hypothesis that MITP might have a positive effect on the mothers' perception of infant temperament was not fully supported. Unlike the results from the Vermont study at 6 months $(1 ; 41)$, the intervention mothers did not report their infants to be more approachable and easier/less fussy. No significant differences in favour of the intervention group were found at 6 and 12 months on the subscales of Distress to limitations, Approach, Duration of orientation or Soothability. The results partly support the findings reported by Olafsen et al. (179) and Newnham et al. (184). None of these studies reported favourable effects of MITP on mothers' perception of infants' temperament at 6 or 12 months. At 3 months however, and with a different instrument, Newnham et al. reported that mothers in the intervention group perceived their infants as more easy and approaching with fewer colic eposodes, and less sleep and crying difficulties than the infants in the preterm control group (184). 
In the present study the control mothers reported significantly more Smile and Laughter among their infants at both 6 and 12 months as compared with the intervention mothers. It is difficult to explain how the MITP could have a negative effect on maternal perception of infant temperament. Agreement in rating of positive infant behaviors is reported to be relatively high (246). However, the finding that some of the control mothers reported more Smile and Laughter did not concur with the video observations of the same dyads at 12 months (220). When assessing the extent to which the infants were satisfied with the overall situation, including smiles, laughter, and positive tone of voice, as well as enthusiasm expressed with arms, legs, and body tone (199), it was observed more positive mood in the infants of first-time mothers in the intervention group. Researchers have been skeptical about the reliability of mothers' perception of their own own infants' temperament $(247 ; 248)$. Small and weak behavioral cues and responses from preterm infants can also make it difficult for parents to read their cues $(17 ; 18)$. Furthermore, mothers with higher levels of stress $(15 ; 249)$ or depression $(126 ; 250)$ are reported to be less sensitive during interactions with their infants, which can make mothers less competent observers of their own infants' behavior. In this dissertation the global video observations of maternal and infant behavior were challenging, and some of the variables were excluded from the analysis due to low reliability (ICC < .70.) (220).

Similar finding were reported by Meijssen et al (251). This research group tested the effect of IPAIP on a group of preterm infants. In a micro-analytic observation of very preterm born infants at 6 months, less positive behaviors were found in the intervention infants compared with control infants (251). However at 24 months, based on the mothers' reporting, the intervention mothers perceived their preterm born children as happier and less hyperactive/distractable (241). The differences may be due to a delayed positive intervention effect, but may also be due to the reliability of maternal reports versus video observations.

The activity dimension of the IBQ included infants' gross motor activity, including movement of arms and legs, squiring and locomotor activity, and we found significantly less activity in the intervention group at 12 months (207). In a meta-analysis, Bhutta et al. reported an increased incidence of ADHD in preterm-born children up to school age (252). Less activity in the intervention group at 12 months could be a positive effect of the MITP, supposing that higher activity in the control group consisted of fussy and picky behavior possibly related to hyperactivity and ADHD (253). Lindstrom et al. reported that the association of preterm birth and ADHD is moderated by the degree of prematurity, but 
suggested that even moderately and late preterm born infants have an increased risk for ADHD (253). Kivijarvi et al. (86) suggested that there might be a relationship between maternal sensitivity and infants' activity among term infants, and reported that term infants of more sensitive mothers at 12 months were less active than infants of less sensitive mothers. These researchers suggested that sensitive mothers structure the environment in a way so that the infants' activity level remained low. The intervention mothers in the present study scored significantly higher on maternal sensitivity and responsiveness at 12 months (220), which suggests that intervention mothers were more attuned to the infants' temperament and possibly more able to structure the environment of the infants. Less activity could also be a negative effect of the intervention, indicating that intervention infants were more passive and less active and happy, as reported by the mothers at 12 months.

\section{Summary}

The research undertaken for this dissertation cannot draw definitive conclusions about the effects of the MIPT on mothers' perception of infant temperament.

\section{6. Breastfeeding}

Breastfeeding implicates close physical contact and intimate interplay between mothers and infants. One of the aims of the MITP was to enhance the quality of the mother-infant transaction and make mothers more sensitive and responsive to infants' physical and social cues (1). One of the hypotheses in Paper I was to assess if the MITP had a positive effect on breastfeeding. To our knowledge this is the first RCT testing the effect of MITP on breastfeeding. The results showed that significantly more mothers in the intervention group were breastfeeding their infants at 9 month; and a similar tendency was found at 12 month (207). These findings show that the MITP had a positive effect on duration of breastfeeding of MLPI. Mothers in the intervention group were also more sensitive and responsive to infant cues when observed at 12 months (220), and possibly more aware of the infants' nutritional needs and more likely to breastfeed their preterm infants. Earlier research has demonstrated a positive association between initiating and duration of breastfeeding and maternal sensitivity (160-162). Breastfeeding seems to have a more relaxing effect on the dyad than bottle feeding (161), and maternal sensitivity may have been further enhanced through intimate and positive social interaction with their infants during breastfeeding 
(163). This is in line with the transactional model that the relationship between infants and parents is a birelational and dynamically interaction systems where the infant influences the care he receives by the way he behaves (5).

Lower depression scores in the intervention mothers one month after discharge may also explain some of the differences in the breastfeeding practice (207), as postpartum depression is a disorder that can interfere with mother-infant relationship and sensitive caregiving (126). The immediate postnatal period is reported to be a critical time for duration of breastfeeding $(14 ; 168)$. Postpartum depression is reported to have a negative impact on breastfeeding, and mothers with higher depression scores were significantly more likely to discontinue breastfeeding $(165 ; 218)$. However, some research report that severity of depression is not related to breastfeeding (167).

\section{Summary}

Despite a long breastfeeding tradition in Scandinavia with documented beneficial effects on outcome, preterm infants are breastfed for a shorter time compared with term infants (254). The MITP had a positive effect on duration of breastfeeding, which suggest that breastfeeding is related to dyadic processes.

\section{7. Early infant communication skills at 12 months}

Joint attention skills are considered to be critical for language and cognitive development, and by 12 months infants generally become increasingly skilled to coordinate visual attention to objects and events with attention to another person during social interactions (46-48;255). Very low-birth weight infants seem to have more difficulties in joint attention interactions (65), and the aim of MITP was to establish a good pattern of interaction between parents and preterm infants and enhance early social-communication skills. However, the intervention infants were not rated by their parents as displaying better communication skill in the area of Initiating/responding to joint attention or Initiating behaviour regulation/request (207). These results are not consistent with the findings of Olafsen et al. who reported that intervention infants scored significantly higher on videobased scoring of Initiating Joint Attention, Initiating Object Requests and Responding to Social Interaction (177). Neither the parents' rating data in the present study nor Olafsen et al.'s observational data found an intervention effect on Response to Joint Attention.

However, a later publication by Olafsen et al. reported that preterm intervention infants with 
low regulatory competence had significantly higher responding to joint attention compared to the preterm control group and could be an effect of the intervention (256).

Joint attention skills and dyadic mutuality are not identical concepts, but both concepts imply ways of communication. During the video observations at 12 months in the present study, it was observed higher dyadic mutuality in mother-infant play in the intervention group among first-time mothers (representing $74 \%$ of the total sample) (220). Dyadic mutuality reflects reciprocal play and communication, where mother and infant often are engaged in the same activity and shared experiences with the toys or activities (199). Thus, parents' subjective assessment of infants' communication skills, parallel to mothers' perception of infant temperament, was not supported by the video observations at 12 months (220).

Based on the mothers' observations, the effects of the intervention seem primarily to be on the mothers" "behavior" (depression and breastfeeding) and less on the interaction between mothers and infants (perception of infant temperament and social-communication). It could be that MITP did not have an effect, that the instruments were not sensitive, or that early or late effects of the MITP depends upon the nature of the outcome. Achenbach et al. and Nordhov et al. both reported positive longterm effects of the MITP on cognitive development $(175 ; 182)$ and less behavioral problems at five years (183), and suggest that a "sleeper effect" might have contributed to delayed effects. Thus, a longer period of followup may be needed to find intervention effects on certain aspects of infant development.

\section{8. Social interaction}

Development of early self-regulation, social understanding, emotional regulation, cognitive development and secure attachment takes place during social interacting with caregivers in a context in which the infant is reared. Sensitive and responsive caregiving is tuned to the infants' needs, moods and interest in interaction with parents who respond in an appropriate and timely way to the infant's cues $(6-12 ; 40 ; 257 ; 258)$. In agreement with the findings of earlier MITP studies, reporting more responsive mothers and enhanced dyadic interaction at 3 months and mutual attending at 6 months (184), as well as positive effect on regulatory competence in preterm infants at 12 months (59), the present study reported beneficial effects of the MITP on different aspects of early social interaction between mothers and MLPI at 12 months (220). The mothers were more sensitive and responsive to preterm infant cues, and a similar but non-significant trend in favour of the intervention group was 
found on maternal behavior of Intrusiveness, Positive mood in the infant, and Dyadic mutuality. Being first-time mother enhanced the effects of the intervention on the quality of mother-infant interaction, as first-time mothers in the intervention group were significantly more sensitive/responsive, and the mothers and infants were more tuned to each other's signals (dyadic mutuality). Being first-time mothers seem to be a moderator of the intervention effect, also reported by other researchers (159). Mills-Koonce et al. suggested that sensitive parenting is not only a trait characteristic of the mother, but also a response to the changing physical and emotional need of her infant (259). The direction of effects in the present study is consistent with the theoretical assumptions of the intervention and the transactional model of development $(2 ; 3 ; 5 ; 172)$, which suggests that the group differences can be attributed to effects of the intervention.

The infants of first-time mothers in the intervention group expressed significantly more positive and less negative mood (220). These findings implicate that positive infant mood may be a response to sensitive/responsive caregiving $(260 ; 261)$, and thus be linked to dyadic mutuality where mothers and infants in the intervention group had more moments of shared emotions and pleasureable activities during play. Preterm infants are reported to have a narrow range for optial stimulation of attentiveness and positive affect (17), and more easily become less attentive and show less positive affect such as smiling and laughing when the threshold for stimulation is exceeded $(260 ; 261)$. Sensitive caregiving is fundamental to the infant's growing capacity for self-regulation (257). Kivijarvi et al. have reported an association between maternal sensitivity in first-time mothers and infant temperament (infant mood) in healthy term infants at 12 months (262). They argued that infants' emotional responses to the mothers' behavior partly depend on the infants' temperament, but is also related to maternal sensitivity. The present findings suggest that MITP made mothers more sensitive to the infants' threshold of stimulation, and that the program assisted in developing the infants' self-regulation of affect and emotions through sensitive caregiving $(68 ; 69)$. The MITP seemed to have particularly positive effects on several interaction variables in first-time mothers.

Mothers with higher symptoms of depression $(161 ; 216 ; 217)$ or stress $(15 ; 249)$ are reported to be less sensitive to infants' signals, which may interfere with the mother-infant interactions; however, depressive symptoms and maternal sensitivity are not always linked (263). One month after discharge the intervention mothers reported lower scores of depression (207). So less symptoms of depression may have moderated the positive effects 
of the intervention on early mother-infant interactions, and thus started early positive transactions betwen mothers and infants in the intervention group (233).

\section{Summary}

The use of the MITP may lead to an early sensitive caregiving environment for MLPI and contribute to better developmental outcome among preterm infants at risk for adverse developmental outcomes.

\section{Methodological considerations}

\section{1. Recruitment and follow-up}

The recruitement and follow-up of parents and preterm infants up to 12 months corrected age was time-consuming; altogether it took two years. We are aware of the term "moderate and late preterm" not fully covering the entire group of preterm infants who participated in the present study, since approximately $25 \%$ of the infants were preterm infants with GA between 30.0 and 31.6 gestational weeks.

Despite careful planning and implementation of the study, it was difficult to achieve a strict randomized controlled design in the social context of the NICU environment.

Implementation and the logistics of the intervention were a challenging task, especially since the intervention was a semistructural intervention implemented in the "noise" of the social contexts of NICU and the home environment (264). Sometimes, before the intervention session, the intervention nurses had to take care of critical intensive care patients; some infants slept a little during the intervention; parents were sometimes disturbed by siblings or relatives, and questions about infants' health or breastfeeding were raised during the intervention sessions. However, it may also be an advantage to test the intervention in a clinical setting under the same conditions and with the same sample (families of Norwegian and non-Norwegian origin) that will be present if/when the MITP is implemented in a NICU.

The MITP had a predetermined content and followed a standard protocol (2), and the intervention nurses were well trained to ensure that the intervention was implemented as planned. Due to holidays, sickleave and shift work, the enrolment had to be stopped for 2 short periods, as no nurses were available if families had been recruited to the intervention group. For the same reason, not all the families were followed up by the same intervention 
nurse through all 11 sessions. Control of spillover effects is difficult in behavioral research (264), and this could bias the absence of differences between the groups on some of the outcomes. To reduce the spillover effects of the intervention content to the control group (leak between nurses and/or parents who share knowledge), intervention nurses and parents in the intervention group were requested not to share the content of the MITP with other parents.

The author, but not the parents or nurses, was blind to group allocation. Making parents blind to group allocation by presenting a placebo condition could have improved the design, reduced potential response bias, and controlled for the extra attention provided by the intervention nurse $(239 ; 243 ; 264)$. However, there were not enough resources to implement a double-blind design.

Despite relatively small and slightly different samples, the demographic and clinical status of mothers, fathers and infants in the preterm groups was generally well balanced at baseline and at 12 months $(207 ; 220 ; 229)$. Nevertheless, some differences were found in years of maternal education in mothers, numbers of cesarean and earlier preterm births, and number of mothers with non-Norwegian background.

Both parents were asked to participate in the study, the intervention and the follow-up, but only three fathers completed the full intervention. The participating of fathers was generally lower than for mothers (52\% vs. $65 \%$ accepted). Health systems in general probably focus more on mothers and infants during the pre-and perintal period, and this may also have been the case in the enrolement process and influenced fathers' motivation and willingness to participate in the intervention.

The relative small sample size and low participation of both mothers and fathers limit the degree to which the findings of this study can be generalized to settings and samples of a broader population (243). No significant differences were found between non-consenting and consenting preterm groups in terms of birth weight, GA and gender. It would however been desirable with more data on non-participants to rule out a systematic bias during recruitement that could compromise statistical and clinical conclusions (243). However, Norwegian regulations restrict collection of data of non-participants. In retrospect the number of term mothers and fathers invited for each participant should be stated, like we did for parents of pretem infants. Similarily, analyzing data of parents who were lost to followup, could have told us if the samples were biased because of selective attrition, as often is the case in longitudinal samples (265). 
To detect differences of clinical interest between the groups, clinical trials must have sufficient statistical power (243). This study, with a relatively small sample size of fathers, might have been underpowered to detect clinically significant differences on some of the stress outcome variables, as large differences are required to reach statistical differences in small studies (243). The findings must also be interpreted with caution due to multiple statistical testing.

\section{2. Global video observations}

Valid and reliable observations of behavior provide useful information that cannot be gained by ordinary questionnaires. The global rating of maternal and infant behavior during play interactions was carried out in a hospital laboratory. Although this behavior might not be completely representative of mothers' and infants' behavioral repertoire, as compared with observations in their natural environment (206), the conditions were the same for both groups of preterm infants. The tester (the author) tried to reduce the effects of participant reactivity (202) and attempted to establish a relaxing and confident atsmosphere between the tester and the participants.

Valid and reliable observations also depend on a good coding system, suited to pick up the behavior of interest. The global rating of maternal and infant behavior during play interactions was carried out according to the "Qualitative Ratings for Parent-Child Interaction at 3-15 months of age" $(199 ; 200)$ as reported in Paper 3, and has been used in several earlier studies (266). Intraclass correlation coefficient statistics (ICC) was used to examine interrater agreement of scores (206), but some of the video observationes were harder to score. Thus achieving interobserver reliability $>.70$ on some of the dyadic behaviors was hard to accomplish (220).

\section{Conclusions}

\section{1. Clinical implications}

The general consensus is that MLPI are at increased risk for short-term and longterm developmental problems $(27 ; 28 ; 30-32 ; 34 ; 109)$, but due to variation in study population, methods and paucity of data, more research is needed to draw reliable conclusions about developmental outcomes (267). Furthermore, the birth and follow-up of preterm infants may 
be a source of considerable concern and stress $(137 ; 138 ; 140 ; 142 ; 143 ; 229)$ and depression for mothers and fathers during the infants' first year of life (130-132;207).

One important aspect of the transactional model is that early development is an outcome of the ongoing interplay of conditions of the infants and the conditions of the parents $(3 ; 39 ; 40)$. An important prerequisite for good follow-up of MLPI implies that parents take an early active part in the infant care during the NICU stay (268), and learn to understand the infants' individuality and how to interpret their signals and cues. Thus, there is a need for an early intervention like MITP that aims to sensitize parents to preterm infants' cues.

Furthermore, neonatal intensive care units must be organized with emphasis on meeting the needs of MLPI and their parents. According to "Professional guidelines for follow-up of preterm infants" (185), qualified and competent nursing staff working in NICUs should pay more attention to infant development and mental health and well being in mothers and fathers. NICUs require extremely well eductated neonatal nurses, not only specialized in advanced neonatal technology, but also specialized in infant development and how to take care of developmental and psychological issues in fragile infants and parents in a professional manner.

Some of the findings in the present study (220) and in an earlier MITP study (184), suggest that implementing the MITP in NICU may contribute to a more sensitive, responsive and stimulating caregiving/parenting during the infants' first year of life. This study demonstrated beneficial effects of the MITP on social interaction between mothers and preterm infants at 12 months, and especially in first-time mothers. First-time mothers seem to be an important target group for MITP in NICU. Furthermore, it was demonstrated that MITP extended the period of breastfeeding and reduced postpartum depression in the first postpartum period (207). This is a time when PPD in preterm mothers is reported to be high $(130 ; 131)$, and PPD is reported to have significant negative impact on mother-infant interactions (126) and infant development (127). The present findings benefit mothers as well as moderate and late preterm infants, and are scientific arguments for implementing the MITP in NICU.

More stress in fathers of MLPI compared with term fathers at both 6 and 12 months calls for more attention to stress in fathers during the NICU stay, and highligths the importance of including fathers in follow-up programs after birth of a preterm infant. However, the MITP did not reduce parenting stress at 6 and 12 months, and fathers with higher intervention exposure reported more stress. These findings question whether the MITP is effective when it comes to reducing stress in fathers or mothers, and further research is needed. 
Community health care providers have the primary responsibility for follow-up of preterm infants and their parents when they are discharged from the hospital (185). Some municipalities have organized public health nurses and well baby clinics with primary responsibility for follow-up of preterm infants. The implementation of MITP may facilitate the transitions from specialist health services to community health services for MLPI and their parents, and may also contribute to a greater and earlier focus on developmental issues in neonatal intensive care units before the infants are discharged from the hospital.

\section{2. Suggestion for further research}

This study suggests several areas for future research. The "Vermont study" reported positive long-term effects of MITP on cognitive development at 3, 4, 7 and 9 years $(41 ; 174 ; 175)$. "Project Early Intervention" reported positive longterm effects on parenting stress at two years (180), nurturant child-rearing attitudes at 12 and 24 months (181), and positive effects on cognitive outcomes and parent reported infant behavior at 5 years (269) but not at two years (180). Meijssen et al., with an other intervention, reported that IBAIP improved some aspects of maternal stress at 24 months, but not at 12 months (241). More research is needed on the long-term effects of the Mother-Infant transaction program, such as long-term effects on parental stress, parents' perception of infant communication and cognitive development in MLPI. A three-year follow-up of stress in parents at three years is underway, but the results are not yet published (270).

In view of the relative small group of fathers, and finding more stress in fathers with higher "intervention dose", this study clearly need to be replicated. Many of the fathers communicated that they would like to participate in the video observations. Surely the effects of the MITP on social interaction between fathers and infants would be of interest as there is litte research on father-infants interactions. An other important area of research is to develop and identify (new) interventions, which may contribute to optimal development of vulnerable MLPI and improve parenting and wellbeing in parents. 


\section{3. Main conclusions}

This dissertation focused on the effects of an early intervention program on outcomes in mothers, fathers and moderate and late preterm infants during the infants first year of life. The RCT study showed that the Mother-infant transaction program reduced postpartum depression in mothers one month after discharge from the hospital, and extended the period of breastfeeding. Moreover, at 12 months, mothers in the intervention group were more sensitive and responsive during mother-infant interactions, first-time mothers also evinced higher level of dyadic mutuality and we observed more positive mood and less negative mood among their infants. These are important findings that may contribute to better infant development.

Being parents of moderate and late preterm infants seem to be associated with longterm stress in fathers. At both 6 and 12 months, fathers of moderate and late preterm infants reported more total stress than fathers of term infants. Higher stress at 6 months was associated with difficult interactions between fathers and infants, but was also associated with behavioral characterics of their preterm infants and parenthood. At 12 month, fathers still reported higher stress in the Parent domain and higher total stress. These findings underline the importance of including fathers in follow-up programs after birth of a preterm infant.

The Mother-infant transaction program did not seem to influence mothers' perception of infant's temperament and infant's communication skills. Futhermore, the MITP did not reduce stress in mothers and fathers at 6 and 12 months. What was especially noteworthy was that fathers, who had participated in more intervention sessions, reported higher stress scores than fathers who had participated in fewer sessions, and we have to raise the question why these fathers were more stressed. More research is needed about the long-term outcomes of the Mother-Infant transaction program. 


\section{Reference List}

(1) Nurcombe B, Howell DC, Rauh VA, Teti DM, Ruoff P, Brennan J. An intervention program for mothers of low-birthweight infants: preliminary results. J Am Acad Child Psychiatry 1984 May;23(3):319-25.

(2) Rauh VA, Nurcombe B, Achenbach T, Howell C. The Mother-Infant Transaction Program. The content and implications of an intervention for the mothers of lowbirthweight infants. Clin Perinatol 1990 Mar;17(1):31-45.

(3) Als H, Tronick E, Adamson L, Brazelton TB. The behavior of the full-term but underweight newborn infant. Dev Med Child Neurol 1976 Oct;18(5):590-602.

(4) Schaffer HR. Social interaction and the beginnings of communication. In: Slater A, Bremner G, editors. An introduction to developmental pschychology. 2nd ed. Victoria: Blackwell Publishing; 2005. p. 165-85.

(5) Sameroff AJ. Ports of entry and the dynamics of mother-infant interventions. In: Sameroff AJ, Mc Donough SC, Rosenblum KL, editors. Treating parent-infant relationship problems. Strategies for intervention.New York, London: The Guildford Press; 2005. p. 3-28.

(6) Tamis-LeMonda CS, Bornstein MH. Maternal responsiveness and early language acquisition. Adv Child Dev Behav 2002;29:89-127.

(7) Cusson RM. Factors influencing language development in preterm infants. J Obstet Gynecol Neonatal Nurs 2003 May;32(3):402-9.

(8) Jenkins LE. The relation of early maternal verbal stimulation with the language and cognitive development of preterm children. Dissertation Abstracts International: Section B: The Sciences and Engineering Vol 65(6-B),2004, pp 2004;3199.(6-B):3199.

(9) Bigelow AE, MacLean K, Proctor J, Myatt T, Gillis R, Power M. Maternal sensitivity throughout infancy: Continuity and relation to attachment security. Infant Behav Dev 2010 Feb;33(1):50-60.

(10) Beckwith L, Rodning C. Dyadic processes between mothers and preterm infants: Development at ages 2 to 5 years. Infant Mental Health Journal Vol 17(4), Win 1996, pp 1996;322-333.(4):322-33.

(11) Forcada-Guex M, Pierrehumbert B, Borghini A, Moessinger A, Muller-Nix C. Early dyadic patterns of mother-infant interactions and outcomes of prematurity at 18 months. Pediatrics 2006 Jul;118(1):e107-e114.

(12) Smith KE, Landry SH, Swank PR. The role of early maternal responsiveness in supporting school-aged cognitive development for children who vary in birth status. Pediatrics 2006 May;117(5):1608-17.

(13) Field TM, Hossain Z, Malphurs J. "Depressed" fathers' interactions with their infants. Infant Ment Health J 1999;20(3):322-32. 
(14) Field T. Postpartum depression effects on early interactions, parenting, and safety practices: a review. Infant Behav Dev 2010 Feb;33(1):1-6.

(15) Crnic KA, Greenberg MT, Ragozin AS, Robinson NM, Basham RB. Effects of stress and social support on mothers and premature and full-term infants. Child Dev 1983 Feb;54(1):209-17.

(16) Crnic KA, Greenberg MT, Robinson NM, Ragozin AS. Maternal stress and social support: effects on the mother-infant relationship from birth to eighteen months. Am J Orthopsychiatry 1984 Apr;54(2):224-35.

(17) Field TM. Infant arousal, attention and affect during early interaction. In: Lipsitt LP, Rove-Collier C, editors. Advances in Infancy Research.Norwood: NJ: Ablex; 1981. p. 57-100.

(18) Barnard KE, Kelly JF. Assessment of parent-child interaction. In: Shonkoff JP, Meisel SJ, editors. Handbook of Early Childhood Intervention. 2nd ed. Cambridge: Cambridge University Press; 2000. p. 258-89.

(19) Prizant BM, Wetherby AM, Roberts JE. Communication problems. In: Zeanah CHJr, editor. Handbook of infant mental health. 2nd ed. New york, London: The Guildford Press; 2005. p. 282-97.

(20) Kinney HC. The near-term (late preterm) human brain and risk for periventricular leukomalacia: a review. Semin Perinatol 2006 Apr;30(2):81-8.

(21) The Medical birth Registry of Norway. 2011. http://mfr-nesstar.uib.no/mfr/, The Norwegian Institute of Public Health.

Ref Type: Online Source

(22) Goldenberg RL, Culhane JF. Low birth weight in the United States. Am J Clin Nutr 2007 Feb;85(2):584S-90S.

(23) Reddy UM, Ko CW, Raju TN, Willinger M. Delivery indications at late-preterm gestations and infant mortality rates in the United States. Pediatrics 2009 Jul;124(1):234-40.

(24) Medical Birth Registry of Norway (MBRN). Preterm infants with gestational age 30 - 36 weeks in the period 1999-2006. 2008.

(25) Morse SB, Zheng H, Tang Y, Roth J. Early school-age outcomes of late preterm infants. Pediatrics 2009 Apr;123(4):e622-e629.

(26) Steetskamp J, Puhl AG, Zelazny J, Skala C, Kolbl H, Bahlmann F. [Clinical and Economic Challenges of Moderate Preterm Babies Born between 32+0 and 36+6 Weeks of Gestation]. Z Geburtshilfe Neonatol 2011 Aug;215(4):158-62.

(27) Caravale B, Tozzi C, Albino G, Vicari S. Cognitive development in low risk preterm infants at 3-4 years of life. Arch Dis Child Fetal Neonatal Ed 2005 Nov;90(6):F474-F479. 
(28) Davidoff MJ, Dias T, Damus K, Russell R, Bettegowda VR, Dolan S, et al. Changes in the gestational age distribution among U.S. singleton births: impact on rates of late preterm birth, 1992 to 2002. Semin Perinatol 2006 Feb;30(1):8-15.

(29) Petrini JR, Dias T, McCormick MC, Massolo ML, Green NS, Escobar GJ. Increased risk of adverse neurological development for late preterm infants. $\mathrm{J}$ Pediatr 2009 Feb;154(2):169-76.

(30) Moster D, Lie RT, Markestad T. Long-term medical and social consequences of preterm birth. N Engl J Med 2008 Jul 17;359(3):262-73.

(31) McGowan JE, Alderdice FA, Holmes VA, Johnston L. Early childhood development of late-preterm infants: a systematic review. Pediatrics 2011 Jun;127(6):1111-24.

(32) Woythaler MA, McCormick MC, Smith VC. Late preterm infants have worse 24month neurodevelopmental outcomes than term infants. Pediatrics 2011 Mar;127(3):e622-e629.

(33) Nepomnyaschy L, Hegyi T, Ostfeld BM, Reichman NE. Developmental Outcomes of Late-Preterm Infants at 2 and 4 Years. Matern Child Health J 2011 Jul 17.

(34) Teune MJ, Bakhuizen S, Gyamfi BC, Opmeer BC, van Kaam AH, van Wassenaer AG, et al. A systematic review of severe morbidity in infants born late preterm. Am J Obstet Gynecol 2011 Oct;205(4):374-9.

(35) Escobar GJ, McCormick MC, Zupancic JA, Coleman-Phox K, Armstrong MA, Greene JD, et al. Unstudied infants: outcomes of moderately premature infants in the neonatal intensive care unit. Arch Dis Child Fetal Neonatal Ed 2006 Jul;91(4):F238-F244.

(36) Boyle JD, Boyle EM. Born just a few weeks early: does it matter? Arch Dis Child Fetal Neonatal Ed 2011 Aug 24.

(37) Sameroff AJ, Chandler MJ. Reproductive Risk and the Continuum of caretaking Casuality. In: Horowitz FD, Hetherington M, Scarr-Salapatek S, Siegel G, editors. Review of child development research.Chicago: University of Chicago Press; 1975. p. 187-244.

(38) Fiese BH, Sameroff AJ. Family context in pediatric psychology: a transactional perspective. J Pediatr Psychol 1989 Jun;14(2):293-314.

(39) Vallotton CD. Do infants influence their quality of care? Infants' communicative gestures predict caregivers' responsiveness. Infant Behav Dev 2009 Dec;32(4):351-65.

(40) Sameroff AJ, Mc Donough SC, Rosenblum KL. Treating Parent-Infant relationship problems. Strategies for intervention. New York: The Guildford Press; 2005 . 
(41) Rauh VA, Achenbach TM, Nurcombe B, Howell CT, Teti DM. Minimizing adverse effects of low birthweight: four-year results of an early intervention program. Child Dev 1988 Jun;59(3):544-53.

(42) Smith L, Ulvund SE. Spebarnalderen. 2nd ed. Gyldendal Akademisk; 2004.

(43) Rochat P. Early Social Cognition: Understanding Others in the First Months of Life. Mahwah, NJ: Lawrence Erlbaum Associates; 1999.

(44) Weinberg MK, Tronick EZ, Cohn JF, Olson KL. Gender differences in emotional expressivity and self-regulation during early infancy. Dev Psychol 1999 Jan;35(1):175-88.

(45) Carpenter M, Nagell K, Tomasello M. Social cognition, joint attention, and communicative competence from 9 to 15 months of age. Monogr Soc Res Child Dev 1998;63(4):i-143.

(46) Tomasello M, Farrar MJ. Joint attention and early language. Child Dev 1986 Dec;57(6):1454-63.

(47) Smith L, Ulvund SE, Lindemann R. The Role of Joint Attention in Later Development Among Preterm Children: Linkages Between Early and Middle Childhood. Social Development 2003 May;12(2):222-34.

(48) Mundy P, Block J, Delgado C, Pomares Y, Van Hecke AV, Parlade MV. Individual differences and the development of joint attention in infancy. Child Dev 2007 May;78(3):938-54.

(49) Bakeman R, Adamson LB. Coordinating attention to people and objects in motherinfant and peer-infant interaction. Child Dev 1984 Aug;55(4):1278-89.

(50) Landry SH. Preterm infants' responses in early joint attention interactions. Infant Behavior \& Development 1986;9:1-14.

(51) Salerni N, Suttora C, D'Odorico L. A comparison of characteristics of early communication exchanges in mother-preterm and mother-full-term infant dyads. [References]. First Language Vol 27(4), Oct 2007, pp 2007;329-346.(4):329-46.

(52) Forcada-Guex M, Borghini A, Pierrehumbert B, Ansermet F, Muller-Nix C. Prematurity, maternal posttraumatic stress and consequences on the mother-infant relationship. Early Hum Dev 2011 Jan;87(1):21-6.

(53) Crnic KA, Ragozin AS, Greenberg MT, Robinson NM, Basham RB. Social interaction and developmental competence of preterm and full-term infants during the first year of life. Child Dev 1983 Oct;54(5):1199-210.

(54) Chapieski ML, Evankovich KD. Behavioral effects of prematurity. Semin Perinatol 1997 Jun;21(3):221-39.

(55) Eckerman CO, Oehler JM. Very-low-birthweight newborns and parents as early social partners. In: Friedman SL, Sigman MD, editors. The psychological 
development of low birthweight children.Norwood, New Jersey: Ablex Publishing Corporation; 1992. p. 91-123.

(56) Lester B, Tronick E. Behavioral assessment scales: The NICU Network Neurobehavioral Scale, the Neonatal Behavioral Assessment Scale, and the Assessment of the Preterm Infant's Behavior. In: Zeskind PS, Singer LT, editors. Biobehavioral assessment of the infant. New York: Guildford; 2001. p. 363-80.

(57) van Beek Y, Hopkins B, Hoeksma JB. The development of communication in preterm infant-mother dyads. Behaviour Vol 129(1-2), May 1994, pp 1994;3561.(1-2):35-61.

(58) Raju TN, Higgins RD, Stark AR, Leveno KJ. Optimizing care and outcome for late-preterm (near-term) infants: a summary of the workshop sponsored by the National Institute of Child Health and Human Development. Pediatrics 2006 Sep;118(3):1207-14.

(59) Olafsen KS. Precursors of regulatory competence in term and preterm infants. The influence of a sensitizing intervention on temperament and social communication during the first year of life. University of Tromsø. Faculty of Medicine. Institute of Clinical Medicine. Center for Child and Adolescent Mental Health; 2008.

(60) van Beek Y, Samsom JF. Communication in preterm infants: Why is it different? Early Development \& Parenting 1994;3(1):37-50.

(61) Harrison MJ. A comparison of parental interactions with term and preterm infants. US: John Wiley and Sons.; 1990.

(62) Feldman R. Maternal versus child risk and the development of parent-child and family relationships in five high-risk populations. Dev Psychopathol 2007;19(2):293-312.

(63) Reissland N, Stephenson T. Turn-taking in early vocal interaction: a comparison of premature and term infants' vocal interaction with their mothers. Child Care Health Dev 1999 Nov;25(6):447-56.

(64) Gerner E. Emotional interaction in a group of preterm infants at 3 and 6 months of corrected age. US: John Wiley and Sons.; 1999.

(65) Garner PW, Landry SH, Richardson MA. The development of joint attention skills in very-low-birth-weight infants across the first 2 years. Infant behaviour and development 1991;14:489-95.

(66) De SL, De G, I, Beyers W, Striano T, Roeyers H. Preverbal skills as mediators for language outcome in preterm and full term children. Early Hum Dev 2011 Apr;87(4):265-72.

(67) Als H, Duffy FH, McAnulty GB. Behavioral differences between preterm and fullterm newborns as measured with the APIB sytem soces: I. Infant Behav Dev 1988;11:305-18. 
(68) Clark CA, Woodward LJ, Horwood LJ, Moor S. Development of emotional and behavioral regulation in children born extremely preterm and very preterm: biological and social influences. Child Dev 2008 Sep;79(5):1444-62.

(69) Feldman R, Greenbaum CW, Yirmiya N. Mother-infant affect synchrony as an antecedent of the emergence of self-control. Dev Psychol 1999 Jan;35(1):223-31.

(70) Rothbart MK, Derryberry D. Development of individual differences in temperament. In: Lamb ME, Brown, editors. Advances in developmental psychology.Hillsdale, NY: Erlbaum; 1981. p. 37-86.

(71) Bradley RH, Corwyn RF. Infant temperament, parenting, and externalizing behavior in first grade: a test of the differential susceptibility hypothesis. J Child Psychol Psychiatry 2008 Feb;49(2):124-31.

(72) Pluess M, Belsky J. Differential susceptibility to parenting and quality child care. Dev Psychol 2010 Mar;46(2):379-90.

(73) Pluess M, Belsky J. Differential susceptibility to rearing experience: the case of childcare. J Child Psychol Psychiatry 2009 Apr;50(4):396-404.

(74) Belsky J, Pluess M. Beyond diathesis stress: differential susceptibility to environmental influences. Psychol Bull 2009 Nov;135(6):885-908.

(75) Pluess M, Belsky J. Children's differential susceptibility to effects of parenting. Family Science 2010;1(1):14-25.

(76) Mantymaa M, Puura K, Luoma I, Salmelin RK, Tamminen T. Mother's early perception of her infant's difficult temperament, parenting stress and early motherinfant interaction. Nord J Psychiatry 2006;60(5):379-86.

(77) Gray PH, Edwards DM, O'Callaghan MJ, Cuskelly M. Parenting stress in mothers of preterm infants during early infancy. Early Hum Dev 2011 Jul 20.

(78) Hughes MB, Shults J, McGrath J, Medoff-Cooper B. Temperament characteristics of premature infants in the first year of life. J Dev Behav Pediatr 2002 Dec;23(6):430-5.

(79) Langkamp DL, Kim Y, Pascoe JM. Temperament of preterm infants at 4 months of age: Maternal ratings and perceptions. Journal of Developmental \& Behavioral Pediatrics Vol 19(6), Dec 1998, pp 1998;391-396.(6):391-6.

(80) Voegtline KM, Stifter CA. Late-preterm birth, maternal symptomatology, and infant negativity. Infant Behav Dev 2010 Dec;33(4):545-54.

(81) Oberklaid F, Prior M, Nolan T, Smith P, Flavell H. Temperament in infants born prematurely. J Dev Behav Pediatr 1985 Apr;6(2):57-61.

(82) Ross G. Temperament of preterm infants: its relationship to perinatal factors and one-year outcome. J Dev Behav Pediatr 1987 Apr;8(2):106-10. 
(83) Larroque B, N'guyen The Tich, Guedeney A, Marchand L, Burguet A. Temperament at 9 months of very preterm infants born at less than 29 weeks' gestation: the Epipage study. J Dev Behav Pediatr 2005 Feb;26(1):48-55.

(84) Saudino KJ. Behavioral genetics and child temperament. J Dev Behav Pediatr 2005 Jun;26(3):214-23.

(85) Rothbart MK. Becoming who we are. Temperament and personality in development. New York, London: The Guildford Press; 2011.

(86) Kivijarvi M, Raiha H, Kaljonen A, Tamminen T, Piha J. Infant temperament and maternal sensitivity behavior in the first year of life. Scand J Psychol 2005 Oct;46(5):421-8.

(87) Jaffee SR. Sensitive, stimulating caregiving predicts cognitive and behavioral resilience in neurodevelopmentally at-risk infants. Dev Psychopathol 2007;19(3):631-47.

(88) Refuerzo JS, Momirova V, Peaceman AM, Sciscione A, Rouse DJ, Caritis SN, et al. Neonatal outcomes in twin pregnancies delivered moderately preterm, late preterm, and term. Am J Perinatol 2010 Aug;27(7):537-42.

(89) Buus-Frank ME. The great imposter. Adv Neonatal Care 2005 Oct;5(5):233-6.

(90) Adams-Chapman I. Neurodevelopmental outcome of the late preterm infant. Clin Perinatol 2006 Dec;33(4):947-64.

(91) Pollak S, Cicchetti D, Klorman R. Stress, memory, and emotion: developmental considerations from the study of child maltreatment. Dev Psychopathol 1998;10(4):811-28.

(92) Minde K. Prematurity and serious medical conditions in infancy: Implications for development, behavior, and intervention. In: Zeanah $\mathrm{CH}$, editor. Handbook of infant mental health. 2nd ed. New York, London: Guildford; 2005. p. 176-94.

(93) Kiechl-Kohlendorfer U, Ralser E, Pupp PU, Reiter G, Trawoger R. Adverse neurodevelopmental outcome in preterm infants: risk factor profiles for different gestational ages. Acta Paediatr 2009 May;98(5):792-6.

(94) Oddie SJ, Hammal D, Richmond S, Parker L. Early discharge and readmission to hospital in the first month of life in the Northern Region of the UK during 1998: a case cohort study. Arch Dis Child 2005 Feb;90(2):119-24.

(95) Escobar GJ, Greene JD, Hulac P, Kincannon E, Bischoff K, Gardner MN, et al. Rehospitalisation after birth hospitalisation: patterns among infants of all gestations. Arch Dis Child 2005 Feb;90(2):125-31.

(96) Lindstrom K, Winbladh B, Haglund B, Hjern A. Preterm infants as young adults: a Swedish national cohort study. Pediatrics 2007 Jul;120(1):70-7. 
(97) Altman M, Vanpee M, Cnattingius S, Norman M. Moderately preterm infants and determinants of length of hospital stay. Arch Dis Child Fetal Neonatal Ed 2009 Nov;94(6):F414-F418.

(98) Shapiro-Mendoza CK, Tomashek KM, Kotelchuck M, Barfield W, Weiss J, Evans S. Risk factors for neonatal morbidity and mortality among "healthy," late preterm newborns. Semin Perinatol 2006 Apr;30(2):54-60.

(99) Paul IM, Lehman EB, Hollenbeak CS, Maisels MJ. Preventable newborn readmissions since passage of the Newborns' and Mothers' Health Protection Act. Pediatrics 2006 Dec;118(6):2349-58.

(100) Altman M, Vanpee M, Cnattingius S, Norman M. Neonatal morbidity in moderately preterm infants: a Swedish national population-based study. J Pediatr 2011 Feb;158(2):239-44.

(101) Amiel-Tison C, Allen MC, Lebrun F, Rogowski J. Macropremies: underprivileged newborns. Ment Retard Dev Disabil Res Rev 2002;8(4):281-92.

(102) Wang ML, Dorer DJ, Fleming MP, Catlin EA. Clinical outcomes of near-term infants. Pediatrics 2004 Aug;114(2):372-6.

(103) Escobar GJ, Clark RH, Greene JD. Short-term outcomes of infants born at 35 and 36 weeks gestation: we need to ask more questions. Semin Perinatol 2006 Feb;30(1):28-33.

(104) Kirkby S, Greenspan JS, Kornhauser M, Schneiderman R. Clinical outcomes and cost of the moderately preterm infant. Adv Neonatal Care 2007 Apr;7(2):80-7.

(105) Marret S, Ancel PY, Marpeau L, Marchand L, Pierrat V, Larroque B, et al. Neonatal and 5-year outcomes after birth at 30-34 weeks of gestation. Obstet Gynecol 2007 Jul;110(1):72-80.

(106) Engle WA, Tomashek KM, Wallman C. "Late-preterm" infants: a population at risk. Pediatrics 2007 Dec;120(6):1390-401.

(107) Shapiro-Mendoza CK, Tomashek KM, Kotelchuck M, Barfield W, Nannini A, Weiss J, et al. Effect of late-preterm birth and maternal medical conditions on newborn morbidity risk. Pediatrics 2008 Feb;121(2):e223-e232.

(108) Barros MC, Mitsuhiro S, Chalem E, Laranjeira RR, Guinsburg R. Neurobehavior of Late Preterm Infants of Adolescent Mothers. Neonatology 2010 Aug 24;99(2):133-9.

(109) Petrini JR, Dias T, McCormick MC, Massolo ML, Green NS, Escobar GJ. Increased risk of adverse neurological development for late preterm infants. $\mathrm{J}$ Pediatr 2009 Feb;154(2):169-76.

(110) Lindstrom K, Lindblad F, Hjern A. Psychiatric morbidity in adolescents and young adults born preterm: a Swedish national cohort study. Pediatrics 2009 Jan;123(1):e47-e53. 
(111) Huddy CL, Johnson A, Hope PL. Educational and behavioural problems in babies of 32-35 weeks gestation. Arch Dis Child Fetal Neonatal Ed 2001 Jul;85(1):F23F28.

(112) Chyi LJ, Lee HC, Hintz SR, Gould JB, Sutcliffe TL. School outcomes of late preterm infants: special needs and challenges for infants born at 32 to 36 weeks gestation. J Pediatr 2008 Jul;153(1):25-31.

(113) Romeo DM, Di SA, Conversano M, Ricci D, Mazzone D, Romeo MG, et al. Neurodevelopmental outcome at 12 and 18 months in late preterm infants. Eur J Paediatr Neurol 2010 Nov;14(6):503-7.

(114) van Baar AL, Vermaas J, Knots E, de Kleine MJ, Soons P. Functioning at school age of moderately preterm children born at 32 to 36 weeks' gestational age. Pediatrics 2009 Jul;124(1):251-7.

(115) Ainsworth MD. The development of infant-mother attachment. In: B.M.Caldwell, H.N.Ricciuti, editors. Review of child development research. Chicago: University of Chicago Press; 1973. p. 1-94.

(116) Lewis ML. The cultural context of Infant Mental Health: The Developmental Niche of Infant-Caregiver relationships. In: Zeanah CH, editor. Handbook of Infant Mental Health. 2nd ed. ed. New York: The Guildford Press; 2005. p. 91107.

(117) Milgrom J, Newnham C, Anderson PJ, Doyle LW, Gemmill AW, Lee K, et al. Early sensitivity training for parents of preterm infants: impact on the developing brain. Pediatr Res 2010 Mar;67(3):330-5.

(118) Landry SH, Smith KE, Swank PR. Responsive parenting: establishing early foundations for social, communication, and independent problem-solving skills. Dev Psychol 2006 Jul;42(4):627-42.

(119) Treyvaud K, Anderson VA, Howard K, Bear M, Hunt RW, Doyle LW, et al. Parenting behavior is associated with the early neurobehavioral development of very preterm children. Pediatrics 2009 Feb;123(2):555-61.

(120) Field T. Early interactions and interaction coaching of high-risk infants and parents.New Jersey: Lawrence Erlbaum Associates; 1983. p. 1-34.

(121) Muller-Nix C, Forcada-Guex M, Pierrehumbert B, Jaunin L, Borghini A, Ansermet F. Prematurity, maternal stress and mother-child interactions. Early Hum Dev 2004 Sep;79(2):145-58.

(122) Als H, Butler S, Kosta S, McAnulty G. The Assessment of Preterm Infants' Behavior (APIB): furthering the understanding and measurement of neurodevelopmental competence in preterm and full-term infants. Ment Retard Dev Disabil Res Rev 2005;11(1):94-102.

(123) Dave S, Petersen I, Sherr L, Nazareth I. Incidence of maternal and paternal depression in primary care: a cohort study using a primary care database. Arch Pediatr Adolesc Med 2010 Nov;164(11):1038-44. 
(124) Paulson JF, Bazemore SD. Prenatal and postpartum depression in fathers and its association with maternal depression: a meta-analysis. JAMA 2010 May 19;303(19):1961-9.

(125) Bekkhus M, Rutter M, Barker ED, Borge AI. The role of pre- and postnatal timing of family risk factors on child behavior at 36 months. J Abnorm Child Psychol 2011 May;39(4):611-21.

(126) Beck CT. The effects of postpartum depression on maternal-infant interaction: a meta-analysis. Nurs Res 1995 Sep;44(5):298-304.

(127) Beck CT. The effects of postpartum depression on child development: a metaanalysis. Arch Psychiatr Nurs 1998 Feb;12(1):12-20.

(128) Field T. Infant of depressed mothers. Infant Behavior and Development 1995;18:113.

(129) Mills-Koonce WR, Gariepy JL, Sutton K, Cox MJ. Changes in maternal sensitivity across the first three years: are mothers from different attachment dyads differentially influenced by depressive symptomatology? Attach Hum Dev 2008 Sep;10(3):299-317.

(130) Gennaro S. Postpartal anxiety and depression in mothers of term and preterm infants. Nurs Res 1988 Mar;37(2):82-5.

(131) Vigod SN, Villegas L, Dennis CL, Ross LE. Prevalence and risk factors for postpartum depression among women with preterm and low-birth-weight infants: a systematic review. BJOG 2010 Apr;117(5):540-50.

(132) Drewett R, Blair P, Emmett P, Emond A. Failure to thrive in the term and preterm infants of mothers depressed in the postnatal period: a population-based birth cohort study. J Child Psychol Psychiatry 2004 Feb;45(2):359-66.

(133) Korja R, Savonlahti E, Ahlqvist-Bjorkroth S, Stolt S, Haataja L, Lapinleimu H, et al. Maternal depression is associated with mother-infant interaction in preterm infants. Acta Paediatr 2008 Jun;97(6):724-30.

(134) Miles MS, Holditch-Davis D, Schwartz TA, Scher M. Depressive symptoms in mothers of prematurely born infants. J Dev Behav Pediatr 2007 Feb;28(1):36-44.

(135) Carvalho AE, Martinez FE, Linhares MB. Maternal anxiety and depression and development of prematurely born infants in the first year of life. Span J Psychol 2008 Nov;11(2):600-8.

(136) Osofsky JD, Thompson MD. Adaptive and maladaptive parenting: perspectives on risk and protective factors. In: Shonkoff JP, Meisel SJ, editors. Handbook of early childhood intervention. 2nd ed. Cambridge: Cambridge University Press; 2000. p. 54-75.

(137) Davis L, Edwards H, Mohay H, Wollin J. The impact of very premature birth on the psychological health of mothers. Early Hum Dev 2003 Aug;73(1-2):61-70. 
(138) Cronin CM, Shapiro CR, Casiro OG, Cheang MS. The impact of very low-birthweight infants on the family is long lasting. A matched control study. Arch Pediatr Adolesc Med 1995 Feb;149(2):151-8.

(139) Abidin RR. Parenting stress index. 3rd ed. PAR Psychological Assessment Resources, Inc.; 1995.

(140) Singer LT, Salvator A, Guo S, Collin M, Lilien L, Baley J. Maternal psychological distress and parenting stress after the birth of a very low-birth-weight infant. JAMA 1999 Mar 3;281(9):799-805.

(141) Holditch-Davis D, Bartlett TR, Blickman AL, Miles MS. Posttraumatic stress symptoms in mothers of premature infants. J Obstet Gynecol Neonatal Nurs 2003 Mar;32(2):161-71.

(142) Moore M, Gerry TH, Klein N, Minich N, Hack M. Longitudinal changes in family outcomes of very low birth weight. J Pediatr Psychol 2006 Nov;31(10):1024-35.

(143) Garel M, Dardennes M, Blondel B. Mothers' psychological distress 1 year after very preterm childbirth. Results of the EPIPAGE qualitative study. Child Care Health Dev 2007 Mar;33(2):137-43.

(144) Singer LT, Fulton S, Kirchner HL, Eisengart S, Lewis B, Short E, et al. Longitudinal predictors of maternal stress and coping after very low-birth-weight birth. Arch Pediatr Adolesc Med 2010 Jun;164(6):518-24.

(145) Olshtain-Mann O, Auslander GK. Parents of preterm infants two months after discharge from the hospital: are they still at (parental) risk? Health Soc Work 2008 Nov;33(4):299-308.

(146) Halpern LF, Brand KL, Malone AF. Parenting stress in mothers of very-low-birthweight (VLBW) and full-term infants: a function of infant behavioral characteristics and child-rearing attitudes. J Pediatr Psychol 2001 Mar;26(2):93104.

(147) Jackson K, Ternestedt BM, Magnuson A, Schollin J. Parental stress and toddler behaviour at age 18 months after pre-term birth. Acta Paediatr 2007 Feb;96(2):227-32.

(148) Brummelte S, Grunau RE, Synnes AR, Whitfield MF, Petrie-Thomas J. Declining cognitive development from 8 to 18 months in preterm children predicts persisting higher parenting stress. Early Hum Dev 2011 Apr;87(4):273-80.

(149) Singer LT, Fulton S, Davillier M, Koshy D, Salvator A, Baley JE. Effects of infant risk status and maternal psychological distress on maternal-infant interactions during the first year of life. J Dev Behav Pediatr 2003 Aug;24(4):233-41.

(150) Thomas KA, Renaud MT, Depaul D. Use of the parenting stress index in mothers of preterm infants. Adv Neonatal Care 2004 Feb;4(1):33-41. 
(151) Thompson RJ, Oehler JM, Catlett AT, Johndrow DA. Maternal Psychological adjustment to the birth of an infant weighing 1,500 grams or less. Infant and Child Development 1993;16:471-85.

(152) Meyer EC, Garcia Coll CT, Seifer R, Ramos A, Kilis E, Oh W. Psychological distress in mothers of preterm infants. J Dev Behav Pediatr 1995 Dec;16(6):412-7.

(153) Robson AL. Low birth weight and parenting stress during early childhood. J Pediatr Psychol 1997 Jun;22(3):297-311.

(154) Ostberg M, Hagekull B. A structural modeling approach to the understanding of parenting stress. J Clin Child Psychol 2000 Dec;29(4):615-25.

(155) Benzies KM, Harrison MJ, Magill-Evans J. Parenting stress, marital quality, and child behavior problems at age 7 years. Public Health Nurs 2004 Mar;21(2):11121 .

(156) Shah PS. Parity and low birth weight and preterm birth: a systematic review and meta-analyses. Acta Obstet Gynecol Scand 2010 Jul;89(7):862-75.

(157) Gameiro S, Moura-Ramos M, Canavarro MC. Maternal adjustment to the birth of a child: Primiparity versus multiparity. [References]. Journal of Reproductive and Infant Psychology Vol 27(3), Aug 2009, pp 2009;269-286.(3):269-86.

(158) George L. Lack of preparedness: experiences of first-time mothers. MCN Am J Matern Child Nurs 2005 Jul;30(4):251-5.

(159) Stolk MN, Mesman J, van Zeijl J, Alink LRA, Bakermans-Kranenburg MJ, van IJzendoorn $\mathrm{MH}$, et al. Early parenting intervention: Family risk and first-time parenting related to intervention effectiveness. J Child Fam Stud 2008;17:55-83.

(160) Britton JR, Britton HL, Gronwaldt V. Breastfeeding, sensitivity, and attachment. Pediatrics 2006 Nov;118(5):e1436-e1443.

(161) Field T, Diego M, Hernandez-Reif M, Figueiredo B, Ezell S, Siblalingappa V. Depressed mothers and infants are more relaxed during breastfeeding versus bottlefeeding interactions: brief report. Infant Behav Dev 2010 Apr;33(2):241-4.

(162) Kim P, Feldman R, Mayes LC, Eicher V, Thompson N, Leckman JF, et al. Breastfeeding, brain activation to own infant cry, and maternal sensitivity. J Child Psychol Psychiatry 2011 Apr 18.

(163) Pearson RM, Lightman SL, Evans J. The impact of breastfeeding on mothers' attentional sensitivity towards infant distress. Infant Behav Dev 2011 Feb;34(1):200-5.

(164) Field T. Postpartum depression effects on early interactions, parenting, and safety practices: a review. Infant Behav Dev 2010 Feb;33(1):1-6.

(165) Dennis CL, McQueen K. Does maternal postpartum depressive symptomatology influence infant feeding outcomes? Acta Paediatr 2007 Apr;96(4):590-4. 
(166) Akman I, Kuscu MK, Yurdakul Z, Ozdemir N, Solakoglu M, Orhon L, et al. Breastfeeding duration and postpartum psychological adjustment: role of maternal attachment styles. J Paediatr Child Health 2008 Jun;44(6):369-73.

(167) McCarter-Spaulding D, Horowitz JA. How does postpartum depression affect breastfeeding? MCN Am J Matern Child Nurs 2007 Jan;32(1):10-7.

(168) Baxter J, Cooklin AR, Smith J. Which mothers wean their babies prematurely from full breastfeeding? An Australian cohort study. Acta Paediatr 2009 Aug;98(8):1274-7.

(169) van RL, Oenema A, Steegers EA, Moll HA, Jaddoe VW, Hofman A, et al. Are starting and continuing breastfeeding related to educational background? The generation R study. Pediatrics 2009 Jun;123(6):e1017-e1027.

(170) Milgrom J, McCloud P. Parenting stress and postnatal depression. Stress Medicine 1996;12:177-86.

(171) Beckwith L. Preventive Science and Prevention Programs. In: Charles H, Zeanah CHJr, editors. Handbook of Infant Mental Health. 2nd ed. New York/London: The Guildford Press; 2005. p. 439-56.

(172) Bromwich RM. Focus on maternal behavior in infant intervention. Am J Orthopsychiatry 1976 Jul;46(3):439-46.

(173) Bromwich R. Working with families and their infants at risk. Austin: TX: Pro-Ed; 1981.

(174) Achenbach TM, Phares V, Howell CT, Rauh VA, Nurcombe B. Seven-year outcome of the Vermont Intervention Program for Low-Birthweight Infants. Child Dev 1990 Dec;61(6):1672-81.

(175) Achenbach TM, Howell CT, Aoki MF, Rauh VA. Nine-year outcome of the Vermont intervention program for low birth weight infants. Pediatrics 1993 Jan;91(1):45-55.

(176) Kaaresen PI, Ronning JA, Ulvund SE, Dahl LB. A randomized, controlled trial of the effectiveness of an early-intervention program in reducing parenting stress after preterm birth. Pediatrics 2006 Jul;118(1):9-19.

(177) Olafsen KS, Ronning JA, Kaaresen PI, Ulvund SE, Handegard BH, Dahl LB. Joint attention in term and preterm infants at 12 months corrected age: the significance of gender and intervention based on a randomized controlled trial. Infant Behav Dev 2006 Dec;29(4):554-63.

(178) Olafsen KS, Ronning JA, Dahl LB, Ulvund SE, Handegard BH, Kaaresen PI. Infant responsiveness and maternal confidence in the neonatal period. Scand J Psychol 2007 Dec;48(6):499-509.

(179) Olafsen KS, Kaaresen PI, Handegard BH, Ulvund SE, Dahl LB, Ronning JA. Maternal ratings of infant regulatory competence from 6 to 12 months: influence 
of perceived stress, birth-weight, and intervention: a randomized controlled trial. Infant Behav Dev 2008 Sep;31(3):408-21.

(180) Kaaresen PI, Ronning JA, Tunby J, Nordhov SM, Ulvund SE, Dahl LB. A randomized controlled trial of an early intervention program in low birth weight children: outcome at 2 years. Early Hum Dev 2008 Mar;84(3):201-9.

(181) Nordhov SM, Kaaresen PI, Ronning JA, Ulvund SE, Dahl LB. A randomized study of the impact of a sensitizing intervention on the child-rearing attitudes of parents of low birth weight preterm infants. Scand J Psychol 2010 Feb 9;51(5):385-91.

(182) Nordhov SM, Ronning JA, Dahl LB, Ulvund SE, Tunby J, Kaaresen PI. Early intervention improves cognitive outcomes for preterm infants: randomized controlled trial. Pediatrics 2010 Nov;126(5):e1088-e1094.

(183) Nordhov SM, Rønning JA, Ulvund SE, Dahl LB, Kaaresen PI. Early intervention improves behavioural outcomes for preterm infants: Randomized controlled trial. Pediatrics. In press 2012.

(184) Newnham CA, Milgrom J, Skouteris H. Effectiveness of a modified Mother-Infant Transaction Program on outcomes for preterm infants from 3 to 24 months of age. Infant Behav Dev 2009 Jan;32(1):17-26.

(185) Markestad T, Halvorsen B. Professional guidelines for follow-up of preterm infants. The Norwegian Directorate for Health and Social Affairs; 2007.

(186) Johnson-Crowley NR, Conrad L. Systematic assessment and home follow-up: A basis for monitoring the newborn and infant's integration into the family. In: Kenner C, Lott JW, editors. Comprehensive neonatal nursing. A physiologic perspective. 3rd ed. Philadelphia, London, New York, St Louis, Sydney, Toronto: Saunders; 2003. p. 876-92.

(187) Anderson LS, Riesch SK, Pridham KA, Lutz KF, Becker PT. Furthering the understanding of parent-child relationships: a nursing scholarship review series. Part 4: parent-child relationships at risk. J Spec Pediatr Nurs 2010 Apr;15(2):11134.

(188) Pridham KA, Lutz KF, Anderson LS, Riesch SK, Becker PT. Furthering the understanding of parent-child relationships: a nursing scholarship review series. Part 3: Interaction and the parent-child relationship--assessment and intervention studies. J Spec Pediatr Nurs 2010 Jan;15(1):33-61.

(189) Santacroce SJ, Maccarelli LM, Grey M. Intervention fidelity. Nurs Res 2004 Jan;53(1):63-6.

(190) Radloff LS. The CES-D Scale: A self-report depression scale for research in the general population. Applied Psychological Measurement 1977;1:385-401.

(191) World Health Organization. Indicators for assessing breastfeeding practices. http://www.emro.who.int/CAH/pdf/bfindicators.pdf . 1991.

Ref Type: Online Source 
(192) World Health Organization. Indicators for assessing infant and young feeding practices. Part 1 Definitions. http://www.ifpri.org/publication/indicators-assessinginfant-and-young-child-feeding-practices . 2008.

Ref Type: Internet Communication

(193) Rothbart MK. Measurement of temperament in infancy. Child Dev 1981;52:56978 .

(194) Torgersen AM. Temperament Questionnaire for infants between 3-12 months. A Norwegian translation of M.K. Rothbarts IBQ. 1985.

Ref Type: Unpublished Work

(195) Rothbart MK. Longitudinal observation of infant temperament. Dev Psychol 1986;22(3):356-65.

(196) Delgado C, Mundy P, Block J. Pictorial Infant Communication Scale, Version 1.3. 2001.

Ref Type: Unpublished Work

(197) Thorp D, Mundy P. Observational and Parent Report Measures of Social Communication Skills in Young Children with Autism. 2010.

Ref Type: Unpublished Work

(198) Mundy P, Sigman M. Joint attention, social competence, and developmental psychopathology. In: Cicchetti D, Cohen DJ, editors. Developmental psychopatology. 2nd ed. Hoboken, NJ: Wiley; 2006. p. 293-332.

(199) Cox MJ, Crnic K. Qualitative ratings for parent-child interaction at 3-15 months of age. 2006.

Ref Type: Internet Communication

(200) Owen MT. The NICHD Study of early Child Care Mother-Infant Interaction Scales. 1992.

Ref Type: Unpublished Work

(201) NICHD Early Child Care Research Network. Child care and mother-child interaction in the first 3 years of life. In: The NICHD early Child Care Research Network, editor.New York, London: The Guildford Press; 2005. p. 231-45.

(202) Haidet KK, Tate J, Divirgilio-Thomas D, Kolanowski A, Happ MB. Methods to improve reliability of video-recorded behavioral data. Res Nurs Health 2009 Aug;32(4):465-74.

(203) NICHD Early Child Care Research Network. Child care and mother-child interaction in the first three years of life. Dev Psychol 1999;35:1399-413.

(204) Polit DF, Beck CT. Nursing research. Generating and assessing evidence for practice. 8th ed. Wolters Kluwer I Lippingcott Williams \& Wilkins; 2008.

(205) Nakagawa S. A farewell to Bonferroni: the problems of low statistical power and publication bias. Behavioral Ecology 2004;15(6):1044-5. 
(206) Sattler JM, Hoge RD. Observational methods. In: Sattler JM, Hoge RD, editors. Assessment of children. Behavioral, social, and clinical foundations. Fifth Edition ed. San Diego: Jerome M. Sattler, Publisher, Inc.; 2006. p. 229-68.

(207) Ravn IH, Smith L, Smeby NA, Kynoe NM, Sandvik L, Bunch EH, et al. Effects of early mother-infant intervention on outcomes in mothers and moderately and late preterm infants at age 1 year: A randomized controlled trial. Infant Behavior \& Development doi: 101016 /j infbeh 201109 006. In press 2011.

(208) Cox JL, Holden JM, Sagovsky R. Detection of postnatal depression. Development of the 10-item Edinburgh Postnatal Depression Scale. Br J Psychiatry 1987 Jun;150:782-6.

(209) Blomqvist YT, Nyqvist KH. Swedish mothers' experience of continuous Kangaroo Mother Care. J Clin Nurs 2011 May;20(9-10):1472-80.

(210) Zelkowitz P, Feeley N, Shrier I, Stremler R, Westreich R, Dunkley D, et al. The cues and care randomized controlled trial of a neonatal intensive care unit intervention: effects on maternal psychological distress and mother-infant interaction. J Dev Behav Pediatr 2011 Oct;32(8):591-9.

(211) Feldman R, Eidelman AI, Sirota L, Weller A. Comparison of skin-to-skin (kangaroo) and traditional care: parenting outcomes and preterm infant development. Pediatrics 2002 Jul;110(1 Pt 1):16-26.

(212) Carvalho AE, Martinez FE, Linhares MB. Maternal anxiety and depression and development of prematurely born infants in the first year of life. Span J Psychol 2008 Nov;11(2):600-8.

(213) Pridham K, Brown R, Clark R, Limbo RK, Schroeder M, Henriques J, et al. Effect of guided participation on feeding competencies of mothers and their premature infants. Res Nurs Health 2005 Jun;28(3):252-67.

(214) Glavin K, Smith L, Sorum R. Prevalence of postpartum depression in two municipalities in Norway. Scand J Caring Sci 2009 Dec;23(4):705-10.

(215) Beeghly M, Weinberg MK, Olson KL, Kernan H, Riley J, Tronick EZ. Stability and change in level of maternal depressive symptomatology during the first postpartum year. J Affect Disord 2002 Sep;71(1-3):169-80.

(216) Cho J, Holditch-Davis D, Miles MS. Effects of maternal depressive symptoms and infant gender on the interactions between mothers and their medically at-risk infants. J Obstet Gynecol Neonatal Nurs 2008 Jan;37(1):58-70.

(217) Lovejoy MC, Graczyk PA, O'Hare E, Neuman G. Maternal depression and parenting behavior: a meta-analytic review. Clin Psychol Rev 2000 Aug;20(5):561-92.

(218) Akman I, Kuscu MK, Yurdakul Z, Ozdemir N, Solakoglu M, Orhon L, et al. Breastfeeding duration and postpartum psychological adjustment: role of maternal attachment styles. J Paediatr Child Health 2008 Jun;44(6):369-73. 
(219) Dennis CL, McQueen K. The relationship between infant-feeding outcomes and postpartum depression: a qualitative systematic review. Pediatrics 2009 Apr;123(4):e736-e751.

(220) Ravn IH, Smith L, Lindemann R, Smeby NA, Kyno NM, Bunch EH, et al. Effect of early intervention on social interaction between mothers and preterm infants at 12 months of age: A randomized controlled trial. Infant Behav Dev 2011 Apr;34(2):215-25.

(221) Fung K, Dennis CL. Postpartum depression among immigrant women. Curr Opin Psychiatry $2010 \mathrm{Jul} ; 23(4): 342-8$.

(222) Darcy JM, Grzywacz JG, Stephens RL, Leng I, Clinch CR, Arcury TA. Maternal depressive symptomatology: 16-month follow-up of infant and maternal healthrelated quality of life. J Am Board Fam Med 2011 May;24(3):249-57.

(223) Mao Q, Zhu LX, Su XY. A comparison of postnatal depression and related factors between Chinese new mothers and fathers. J Clin Nurs 2011 Mar;20(5-6):645-52.

(224) Martins C, Gaffan EA. Effects of early maternal depression on patterns of infantmother attachment: a meta-analytic investigation. J Child Psychol Psychiatry 2000 Sep;41(6):737-46.

(225) Silverstein M, Feinberg E, Hegel M. Preventing depression of mothers of preterm infants. Psychiatr Serv 2011 Jan;62(1):101.

(226) Glavin K, Smith L, Sorum R, Ellefsen B. Redesigned community postpartum care to prevent and treat postpartum depression in women - a one-year follow-up study. J Clin Nurs 2010 Aug 18.

(227) Kersting A, Dorsch M, Wesselmann U, Ludorff K, Witthaut J, Ohrmann P, et al. Maternal posttraumatic stress response after the birth of a very low-birth-weight infant. J Psychosom Res 2004 Nov;57(5):473-6.

(228) Singer LT, Fulton S, Kirchner HL, Eisengart S, Lewis B, Short E, et al. Parenting very low birth weight children at school age: maternal stress and coping. J Pediatr 2007 Nov;151(5):463-9.

(229) Ravn IH, Lindemann R, Smeby NA, Bunch EH, Sandvik L, Smith L. Stress in fathers of moderately and late preterm infants: A randomised controlled trial. Early Child Development and Care, DOI: 10 1080/03004430 20115642792011.

(230) Jeffcoate JA, Humphrey ME, Lloyd JK. Role perception and response to stress in fathers and mothers following pre-term delivery. Soc Sci Med 1979 Mar;13A(2):139-45.

(231) Deave T, Johnson D, Ingram J. Transition to parenthood: the needs of parents in pregnancy and early parenthood. BMC Pregnancy Childbirth 2008;8:30.

(232) Mulder H, Pitchford NJ, Hagger MS, Marlow N. Development of executive function and attention in preterm children: a systematic review. Dev Neuropsychol 2009 Jul;34(4):393-421. 
(233) Sameroff A, Fiese BH. Transactional regulation. The developmental ecology of early intervention. In: Shonkoff JP, Meisel SJ, editors. Handbook of early childhood intervention. 2nd ed. Cambridge: Cambridge University Press; 2003. p. 135-59.

(234) Langkamp DL, Kim Y, Pascoe JM. Temperament of preterm infants at 4 months of age: maternal ratings and perceptions. J Dev Behav Pediatr 1998 Dec;19(6):391-6.

(235) Russell RB, Green NS, Steiner CA, Meikle S, Howse JL, Poschman K, et al. Cost of hospitalization for preterm and low birth weight infants in the United States. Pediatrics 2007 Jul;120(1):e1-e9.

(236) Tommiska V, Ostberg M, Fellman V. Parental stress in families of 2 year old extremely low birthweight infants. Arch Dis Child Fetal Neonatal Ed 2002 May;86(3):F161-F164.

(237) Als H, Gilkerson L, Duffy FH, McAnulty GB, Buehler DM, Vandenberg K, et al. A three-center, randomized, controlled trial of individualized developmental care for very low birth weight preterm infants: medical, neurodevelopmental, parenting, and caregiving effects. J Dev Behav Pediatr 2003 Dec;24(6):399-408.

(238) van der Pal SM, Maguire CM, le CS, Wit JM, Walther FJ, Bruil J. Parental experiences during the first period at the neonatal unit after two developmental care interventions. Acta Paediatr 2007 Nov;96(11):1611-6.

(239) Zelkowitz P, Feeley N, Shrier I, Stremler R, Westreich R, Dunkley D, et al. The Cues and Care Randomized Controlled Trial of a Neonatal Intensive Care Unit Intervention: Effects on Maternal Psychological Distress and Mother-Infant Interaction. J Dev Behav Pediatr 2011 Jun 30.

(240) Glazebrook C, Marlow N, Israel C, Croudace T, Johnson S, White IR, et al. Randomised trial of a parenting intervention during neonatal intensive care. Arch Dis Child Fetal Neonatal Ed 2007 Nov;92(6):F438-F443.

(241) Meijssen DE, Wolf MJ, Koldewijn K, van Wassenaer AG, Kok JH, van Baar AL. Parenting stress in mothers after very preterm birth and the effect of the Infant Behavioural Assessment and Intervention Program. Child Care Health Dev 2011 Mar;37(2):195-202.

(242) Doherty WJ, Erickson MF, LaRossa R. An intervention to increase father involvement and skills with infants during the transition to parenthood. J Fam Psychol 2006 Sep;20(3):438-47.

(243) Friedman LM, Furberg CD, DeMets DL. Fundamentals of clinical trials. 3rd ed. New York: 1998.

(244) Spear ML, Leef K, Epps S, Locke R. Family reactions during infants' hospitalization in the neonatal intensive care unit. Am J Perinatol 2002 May;19(4):205-13. 
(245) Solmeyer AR, Feinberg ME. Mother and father adjustment during early parenthood: The roles of infant temperament and coparenting relationship quality. Infant Behav Dev 2011 Dec;34(4):504-14.

(246) Stifter CA, Willoughby MT, Towe-Goodman N. Agree or Agree to Disagree? Assessing the Convergence between Parents and Observers on Infant Temperament. Infant Child Dev 2008 Aug 1;17(4):407-26.

(247) Seifer R, Sameroff AJ, Barrett LC, Krafchuk E. Infant temperament measured by multiple observations and mother report. Child Dev 1994 Oct;65(5):1478-90.

(248) Saudino KJ, Cherny SS, Plomin R. Parent ratings of temperament in twins: explaining the 'too low' DZ correlations. Twin Res 2000 Dec;3(4):224-33.

(249) Crnic. Maternal stress and social support: Effects on the mother-infant relationship from birth to eighteen months. US: American Psychological Assn/Educational Publishing Foundation.; 1984.

(250) Field T. Postpartum depression effects on early interactions, parenting, and safety practices: a review. Infant Behav Dev 2010 Feb;33(1):1-6.

(251) Meijssen D, Wolf MJ, Koldewijn K, Houtzager BA, van WA, Tronick E, et al. The effect of the Infant Behavioral Assessment and Intervention Program on motherinfant interaction after very preterm birth. J Child Psychol Psychiatry 2010 Nov;51(11):1287-95.

(252) Bhutta AT, Cleves MA, Casey PH, Cradock MM, Anand KJ. Cognitive and behavioral outcomes of school-aged children who were born preterm: a metaanalysis. JAMA 2002 Aug 14;288(6):728-37.

(253) Lindstrom K, Lindblad F, Hjern A. Preterm birth and attentiondeficit/hyperactivity disorder in schoolchildren. Pediatrics 2011 May;127(5):85865 .

(254) Flacking R, Hedberg NK, Ewald U. Effects of socioeconomic status on breastfeeding duration in mothers of preterm and term infants. Eur J Public Health 2007 Mar 28.

(255) Carpenter JS, Andrykowski MA, Wilson J, Hall LA, Rayens MK, Sachs B, et al. Psychometrics for two short forms of the Center for Epidemiologic StudiesDepression Scale. Issues Ment Health Nurs 1998 Sep;19(5):481-94.

(256) Olafsen KS, Ronning JA, Handegard BH, Ulvund SE, Dahl LB, Kaaresen PI. Regulatory competence and social communication in term and preterm infants at 12 months corrected age. Results from a randomized controlled trial. Infant Behav Dev. In press 2011.

(257) Shonkoff JP, Phillip DA. Acquiring self-regulation. In: J.P.Shonkoff, D.A.Phillips, editors. From Neurons to Neighborhoods. The Science of Early Child Development.Washington, D.C: National Academy Press; 2000. p. 93-123. 
(258) Fuertes M, Santos PL, Beeghly M, Tronick E. More than maternal sensitivity shapes attachment: infant coping and temperament. Ann N Y Acad Sci 2006 Dec;1094:292-6.

(259) Mills-Koonce WR, Gariepy JL, Propper C, Sutton K, Calkins S, Moore G, et al. Infant and parent factors associated with early maternal sensitivity: a caregiverattachment systems approach. Infant Behav Dev 2007 Feb;30(1):114-26.

(260) Field TM. Effects of early separation, interactive deficits, and experimental manipulations on infant-mother face-to-face interaction. Child Dev 1977;48:76371.

(261) Field T, Ting G, Shuman HH. The onset of rhythmic activities in normal and highrisk infants. Dev Psychobiol 1979 Mar;12(2):97-100.

(262) Kivijarvi M, Voeten MJM, Niemela P, Raiha H, Lertola K, Piha J. Maternal sensitivity behavior and infant behavior in early interaction. Infant Ment Health J 2001;22(6):627-40.

(263) Sidor A, Kunz E, Schweyer D, Eickhorst A, Cierpka M. Links between maternal postpartum depressive symptoms, maternal distress, infant gender and sensitivity in a high-risk population. Child Adolesc Psychiatry Ment Health 2011;5(1):7.

(264) McCall RB, Green BL. Beyond the Methodlogical Gold Standards of Behavioral Research: Considerations for Practice and Policy. Social Policy Report Society for Research in Child Development 2004;18??(2):3-19.

(265) Berk LE. Research strategies. In: Laura E.Beck, editor. Child development. Eight edition ed. Boston, New York, San Fransico: Allyn and Bacon; 2009. p. 40-69.

(266) Child care and child development. Results from the NICHD Study of Early Child care and Youth development. New York: The Guildford Press; 2005.

(267) Samra HA, McGrath JM, Wehbe M. An integrated review of developmental outcomes and late-preterm birth. J Obstet Gynecol Neonatal Nurs 2011 Jul;40(4):399-411.

(268) Nyqvist KH, Engvall G. Parents as their infant's primary caregivers in a neonatal intensive care unit. J Pediatr Nurs 2009 Apr;24(2):153-63.

(269) Nordhov SM, Ronning JA, Dahl LB, Ulvund SE, Tunby J, Kaaresen PI. Early intervention improves cognitive outcomes for preterm infants: randomized controlled trial. Pediatrics 2010 Nov;126(5):e1088-e1094.

(270) Kynoe NM, Ravn IH, Torgersen AM, Fagerland MW, Smeby NA, Lindemann R. Effect of the Mother-Infant Transaction Program on parental stress measured at 12 and 36 months after a preterm birth. 2011.

Ref Type: Unpublished Work

(271) Smith L. Vermont-programmet av Virginia Rauh. Oversatt og tilpasset av Lars Smith. 1998.

Ref Type: Unpublished Work 
I 



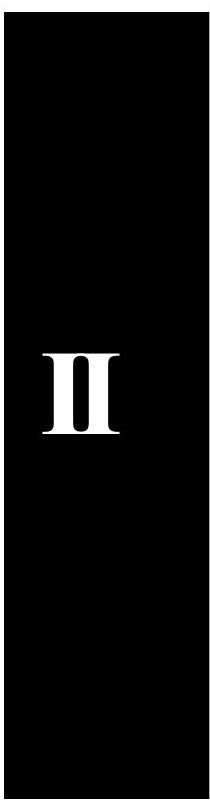





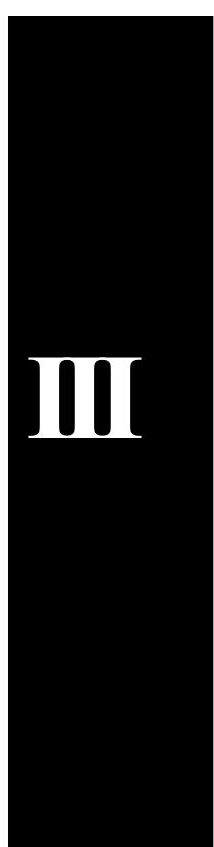



APPENDIX 



\section{Appendix A}

\section{The Mother-Infant Transaction Program}

Summary of the MITP is based on the publication by Rauh et al. (1). The MITP is translated and adjusted to Norwegian conditions, and some minor adjustments have been made (2).

\section{Day 1. Introduction: Getting acquainted with the baby.}

The first session was used to become acquainted with the parents and the infant. The nurse demonstrates a method for evaluating behavior in newborns, the Brazelton Neonatal Behavioral Assessment Scale (NBAS), and demonstrates the infant's uniqueness and potential for self-regulation and interaction. Parents are encouraged to observe and ask questions. After the demonstration, the nurse explored the parents' perception of the infant's unique appearance, family resemblances, and attractiveness. She discussed the parents' reaction to the infant's hospitalization and physical condition, and to the amount of contact she and her baby had had. Parents are encouraged to express their potential anxiety. The main purpose of this first contact was to emphasize the infant's uniqueness and developmental potential, to allay fears, and to encourage the parents to enjoy their infant. This is the basis for later and more complex forms of interaction.

\section{Day 2. Homeostasis: how the baby feels.}

On the second day, the nurse introduced the parents to the behavioral indices of the homeostatic reflex systems. Together, they noted the signs of infant distress, disorganization, and distinguished them from the signs of composure and stability. The nurse emphasizes more focus on the infant's body code than the parents' reactions. Sources of environmental stress were discussed, such as cold, loud noise, bright light, or sudden movement. Cyanosis, mottling of the skin, irregular breathing, apnea, hiccupping, vomiting, startles, grimaces, and twitches were presented as indices of homeostatic breakdown. The parents analyzed the environmental stresses to which her infant was most sensitive, and learned how to support the infant's homeostatic controls by providing warmth, moderate lighting, soothing sounds and gentle rhythmic movements.

\section{Day 3. The motor system: How the baby moves.}

The nurse introduces the parents to the concept of motor system, and how posture, muscle tonus and movement can be important signs of disorganization. The parents learn to 
distinguish immature movements from well-modulated and organized movements, and how they can help the infant to inhibit startles, twitches and tremors.

The nurse teach the parents about different different levels of behavioral organization, and gradually the parents were guided in how to respond to infant cues in a way that reduced stress and promoted organization by changing the environment or by modifying parents' responses in accordance with their increased sensitivity to infant cues.

\section{Day 4. State regulation: enhancing the baby's organization.}

The nurse teach the parents how different levels of consciousness (sleep, drowsiness, alertness and fussing) may indicate whether the infant is socially accessible or whether social stimulation would be disruptive. The nurse describes how preterm infants tend to exhibit poorly defined, labile, diffuse, or fleeting states, and demonstrates how these levels could be recognized according to their autonomic and motor characteristics. The nurse demonstrates how the infants respond differently at each level, and how the parents can recognize and take advantage of the quiet, alert state. Finally the nurse demonstrates how the infant can regulate itself for example by sucking their own hands, or benefit from external help from the parents. The parents were also encouraged to experiment with gazing, vocalization, holding the hands on feet, shifting the infant's position, rocking, cuddling, holding, and wrapping the infant to help it organize itself when distressed.

\section{Day 5. Social interaction: Engaging the baby and sustaining an interaction.}

The parents learn how to engage the infant and sustain social interaction. The nurse demonstrates how the infant could be roused by alertness, how long it could stay awake, and whether its awareness could be prolonged by external stimulation. The parents were shown how the infant can attend to animate or inanimate stimuli, how they can sustain the infant's alertness by stimulating the infant with a red ball, or by imitating the infant's facial expression. The parents learned how to help the baby focus attention and follow parents with eyes and head, and learned to recognize if manipulation produced stress and overstimulation, hyperalertness, exhaustion, or inaccessibility.

\section{Day 6. Recognizing and responding to cues: Facilitating daily care.}

Now that the parents have become more familiar with the infant's capasity, they were ready to provide daily care in a more effective manner. They learned to coordinate daily activities with periods of wakefulness. The nurse suggested that periods of daily care can be 
opportunities to enjoy the infant, understand the infant's signals and respond in a way that increased behavioral organization and reduced stress.

\section{Day 7. Preparing for home.}

The parents should now be prepared to take the infant home. The previous six lessons were reviewed. The nurse encouraged the parents to take advantage of the new knowledge, and to trust their own initiative about how to alert, engage, and support the baby. Thus was laid the foundation of mutually satisfying play.

\section{Home visit 1 (three days): Consolidation.}

The nurse reviewed the mutual attunement in the mother-infant dyad/father-infant dyad and the adjustment to the domestic situation. The nurse ascertained whether the parents' sensitivity, responsiveness and enjoyment of their baby have deteriorated. If so, the parents were encouraged to discuss the problems and to identify the changes that had occurred in the infant's behavior. The nurse helped the parents to define their own style of responding in order to explore how well it matched the infant's style of response. They discussed those activities that were most and least enjoyable for the infant, and the nurse identified the parents' strengths, reinforced them and supported their confidence and own initiative.

\section{Home visit 2 (two weeks after discharge): Mutual enjoyment through play.}

By now, infants and parents were better adjusted; the infant's cycles were more regular and predictable, and the rhythms of caretaking had been established. The parents and infant would have more time for social interaction, and the nurse reinforces mutual enjoyment through play. Nurse and parents note which activities the parents and the infant found most rewarding, and the nurse suggests a variety of techniques to help the parents expand their repertoire even further.

\section{Home visit 3 (one month): Temperamental patterns.}

The parents were introduced to different temperamental patterns. The parents were helped to discern the infant's emerging response style and to appreciate the effect of the infant's temperament on their interaction. The parents learned how they could enhance the "fit" between the infant and themselves by taking into consideration the baby's likes and dislikes. 
To ascertain the infant's temperamental pattern, the parents were asked to analyze the infant's immediate behavioral cues and enduring style of response, and the nurse helped the parents to explore a variety of means to assist the baby regulate itself.

\section{Home visit 4 (three months): Review and termination.}

In the final home visit, the nurse reviews with the parents the automatic homeostatic and motor reflex systems. Current skin color, respiratory regulation, vocalization, facial expression, posture, tone and movement were evaluated. The nurse assesses the infant's visual, auditory, and tactile development, and asks the parents to recall recent progress. The results of the intervention were reviewed.

\section{Reference List}

(1) Rauh VA, Nurcombe B, Achenbach T, Howell C. The Mother-Infant Transaction Program. The content and implications of an intervention for the mothers of lowbirthweight infants. Clin Perinatol 1990 Mar;17(1):31-45.

(2) Smith L. Vermont-programmet av Virginia Rauh. Oversatt og tilpasset av Lars Smith. 1998.

Ref Type: Unpublished Work 